
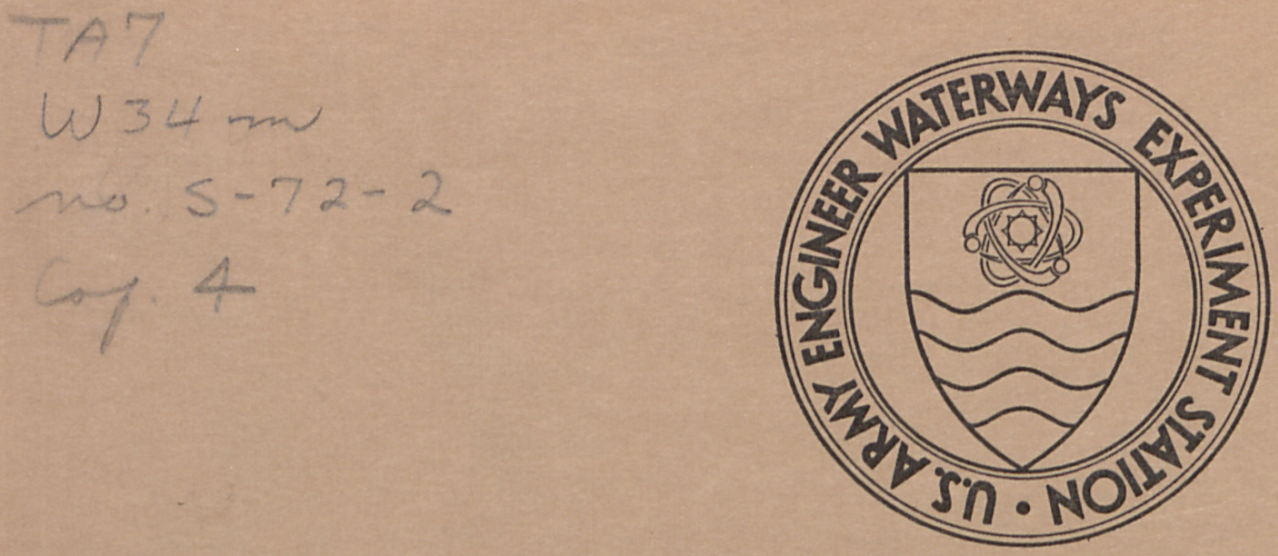

MISCELLANEOUS PAPER S-72-2

\title{
APPLICATION OF FINITE ELEMENT METHOD IN DETERMINING STABILITY OF CRATER SLOPES
}

by

\author{
J. B. Palmerton, D. C. Banks
}
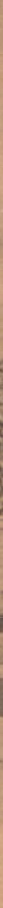

Sponsored by U. S. Army Engineer Nuclear Cratering Group

Conducted by U. S. Army Engineer Waterways Experiment Station, Vicksburg, Mississippi 


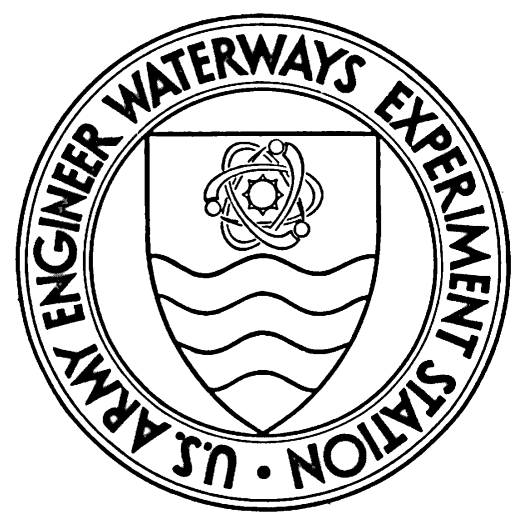

MISCELLANEOUS PAPER S-72-2

\title{
APPLICATION OF FINITE ELEMENT METHOD IN DETERMINING STABILITY OF CRATER SLOPES \\ by
}

\author{
J. B. Palmerton, D. C. Banks
}

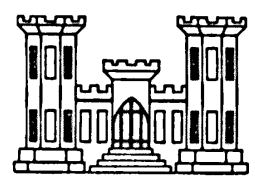

January 1972

Sponsored by U. S. Army Engineer Nuclear Cratering Group

Conducted by U. S. Army Engineer Waterways Experiment Station, Vicksburg, Mississippi 


\section{FOREWORD}

The investigations reported herein were performed under the analytical studies portion of the "Engineering Properties of Nuclear Craters, Theoretical Studies Program" for the U. S. Army Engineer Nuclear Cratering Group (NCG).*

This report was prepared by Messrs. J. B. Palmerton and D. C. Banks under the supervision of Messrs. J. P. Sale and W. C. Sherman, Soils Division. The report was reviewed by $\mathrm{Mr}$. S. J. Johnson, Special Assistant, Soils Division. Special recognition is given to Prof. J. M. Duncan of the University of California, Berkeley, who served as consultant on this project. His suggestions concerning the use of a hyperbolic stress-strain curve and relationships between initial modulus and confining pressure formed the basis for much of the work in this study.

Directors of the U. S. Army Engineer Waterways Experiment Station during these investigations and the preparation of this report were COL John R. Oswalt, Jr., CE, COL Levi A. Brown, CE, and COL Ernest D. Peixotto, CE. Messrs. J. B. Tiffany and F. R. Brown were Technical Directors. LTC B. C: Hughes, CE, COI W. E. Vandenberg, CE, and LTC R. I. LaFrenz, CE, were Directors of the NCG during performance of this work.

* The Nuclear Cratering Group is now designated the Explosive Excavation Research Office and is under the jurisdiction of the U. S. Army Engineer Waterways Experiment Station. 
FOREWORD . . . . . . . . . . . . . . . . . . . . . . . . . . iii

CONVERSION FACTORS, BRITISH TO METRIC UNITS OF MEASUREMENT . • . • . vii

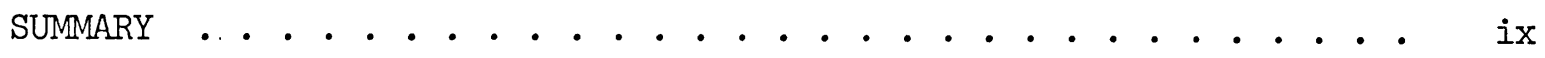

PART I: INTRODUCTION . . . . . . . . . . . . . . . . . . . I 1

Purpose and Scope of Study . . . . . . . . . . . . . 1

Background . . . . . . . . . . . . . . . . . . . 1

PART II: FINITE ELEMENT METHOD . . . . . . . . . . . . . . . . . 3

Description ....................... . 3

Mathematical Development . . . . . . . . . . . . 5

Application . . . . . . . . . . . . . . . . . . 10

PART III: FINITE ELEMENT COMPUTER PROGRAMS . . . . . . . . . . . . 11

Linear Elastic Computer Program . . . . . . . . . . . . 11

A Nonlinear Finite Element Program . . . . . . . . . . . 12

PART IV: APPLICATIONS TO SIMPLE SLOPES . . . . . . . . . . . . . 26

Description of Problems . . . . . . . . . . . . . 26

Results . . . . . . . . . . . . . . . . . . 29

Significance of Analyses . . . . . . . . . . . . . . . 43

Interpretation of Results for Factors of Safety . . . . . . . 43

PART V: NONLINEAR FINITE ELEMENT ANALYSIS OF OTTER BROOK DAM • • • 53

Description of Problems . . . . . . . . . . . . 53

Results . . . . . . . . . . . . . . . . . . . 56

Differences in Finite Element Codes . . . . . . . . . . . 59

Factors of Safety . . . . . . . . . . . . . . . 61

PART VI: NONLINEAR FINITE ELEMENT ANALYSIS OF A CRATER SLOPE • • • 63

Description of Problem . . . . . . . . . . . . . 63

Results ........................... 66

Factor of Safety .................... . . . 66

PART VII: CONCLUSIONS AND RECOMMENDATIONS . . . . . . . . . . . . 70

LITERATURE CITED . • • • . . . . . . . . . . . . . . . 71 


\section{CONTENTS}

APPENDIX A: WES NONLINEAR FINITE ELEMENT COMPUTER PROGRAM • • • • •

Finite Element Computer Program for Slopes . . . . . . . . . Al

Purpose . . . . . . . . . . . . . . . . . . Al

Input Data . . . . . . . . . . . . . . . . . . Al

Input Deck Setup . . . . . . . . . . . . . . . . A5

Output from the Program . . . . . . . . . . . . . . A6

APPENDIX B: COMPUTER PROGRAM TO COMPUTE FACTORS OF SAFETY

FROM FINITE ELEMENT STRESSES . . • . • . • • • • • BI

Computer Program for the Stability Analysis of

Embankments or Slopes .. . . . . . . . . . . BI

Purpose .. . . . . . . . . . . . . . . . . B Bl

Sequence of Operation . . . . . . . . . . . . . . BI

Input Data Procedure . . . . . . . . . . . . . . B2 
CONVERSION FACTORS, BRITISH TO METRIC UNITS OF MEASUREMENT

\begin{tabular}{|c|c|c|}
\hline Multiply & By & To Obtain \\
\hline feet & 0.3048 & meters \\
\hline pounds per square foot & 4.88243 & kilograms per square meter \\
\hline tons per square foot & $9.764 \times 10^{3}$ & kilograms per square meter \\
\hline pounds per cubic foot & 16.02 & kilograms per cubic meter \\
\hline kilotons & $9.07 \times 10^{5}$ & kilograms \\
\hline
\end{tabular}


SUMMARY

The investigations reported herein comprise studies to evaluate applicability of the finite element method to stability analysis of explosively excavated slopes.

A finite element program based on nonlinear material properties was developed during this study. The program incorporates a capability to simulate incremental construction of slopes of arbitrary geometry either by excavation or by building up. The stress-strain relationships of materials forming the slope and its foundations are approximated by hyperbolic curves. The hyperbolic curves are asymptotic to the yield strength of the materials as defined by Mohr-Coulomb strength parameters, c (cohesion) and $\varnothing$ (friction angle). Initial states of stress may be incorporated into the analyses.

Several examples of simple slopes under various initial states of stress were analyzed. Additional examples were a symmetrical, homogeneous embankment on a rigid foundation and hypothetical row crater excavation slope. Stresses and displacements for the different examples are presented along with a method for determining the factor of safety of a slope from nonlinear stress analysis. 


\section{PART I: INTRODUCTION}

\section{Purpose and Scope of Study}

1. The basic objective of the study of engineering properties of nuclear craters is to identify, describe, and assign usable engineering parameters to the geologic and physical properties that control the behavior of a nuclear crater. One of the most important of the factors that determine a crater's behavior is the deformation and the attendant stress distribution within the zones adjacent to such craters. Previous studies have reviewed empiriçal data relating to slope stability; ${ }^{1-4}$ conventional $^{-1}$ approaches using limit-equilibrium methods have also been presented. ${ }^{5}$ The purpose of this study was to investigate the use of the finite element technique as a method of determining the behavior of a crater excavation with particular emphasis on the stability of slopes.

2. This report describes a finite element computer program developed at the U. S. Army Engineer Waterways Experiment Station (WES) for use in analyzing the stability of slopes. The computer code contains provisions for nonlinear stress-strain curves that may be analytically approximated by hyperbolas. In addition, the code permits inclusion of residual stresses and incremental removal or addition of material to construct the final slope geometry. Application of the code to slopes of simple geometry is illustrated with a discussion of factor of safety predictions from the nonlinear finite element technique. The results of applying the finite element code to a symmetrical homogeneous embankment on a rigid foundation and to a hypothetical row crater excavation slope are presented.

\section{Background}

3. During the 1950's, the concept and use of the finite element method emerged as engineers were faced with the need for analyses of more complex structures. With the advent of large, high-speed computers, solutions could be obtained for the large number of simultaneous equations 
required when simulating a continuum by a discretized structure, and the method was applied to a wide variety of problems. The finite element concept as applied to continuum mechanics was introduced by Turner et al. 6 The first practical application of the finite element method in the analyses of dams was made by Prof. R. W. Clough, University of California, for the Iittle Rock District, U. S. Army Corps of Engineers, in a study of Norfolk Dam. 7 From the standpoint of application to problems in soil and rock mechanics, several important papers are available.

4. WES activity in the use of the finite element method for soil and rock mechanics studies began in January 1966 when the Nuclear Cratering Group (NCG) requested information and provided funds to determine possible applications of the method to analysis of crater slopes. The work was considerably expedited in June 1966 when WES personnel attended a series of informal lectures on the finite element method at the University of California. As a result, and through the generosity of personnel at the University of California, several computer programs have been made available for use at WES. Cooperative work between Mr. J. L. Kirkland of the WES Nuclear Weapons Effects Division and the authors of this report, as well as other engineers of the WES Soils Division, led to expanded use of the technique at WES. Preliminary analysis of problems with these early computer programs indicated that an application to stability of slopes might be possible. A report outlining some of the early investigations at WES suggested that modifications to then existing computer programs were necessary to better model a rock or soil mass. ${ }^{12}$ A second report gave the results of continued study of the technique at WES and early stages of modification of existing codes during FY 1968. 13

5. Close and continued liaison with personnel at the University of California has greatly aided the WES efforts. The program entitled "A Digital Computer Program for the Finite Element Analysis of Solids with Nonlinear Material Properties" by Prof. E. I. Wilson served as a basic computer program at WES, as well as for many other investigators around the country, and as a valuable guide for the development of the code discussed in subsequent parts of this report. Prof. J. M. Duncan has served as a consultant to WES on this project and his guidance has been most helpful. 


\section{Description}

6. Engineering structures may be visualized as an assemblage of discrete elements, such as beams or rods, connected at a discrete number of points. Many methods have been devised to study the behavior of these structures. A continuum may be thought of as being divided into a number of elements connected at their nodes. The finite element method is then applied as follows:

a. A displacement function is chosen that uniquely defines the displacements of all points within each element in terms of nodal point displacements.

b. Since the displacement field within each element is determined, the strain state may also be uniquely defined in terms of nodal displacements.

c. The stress state within an element may be determined from a knowledge of the state of strain used in connection with the constitutive properties of the material.

d. Finally the stresses within each element are resolved into equivalent nodal point forces by accounting for the shape and size of the individual elements.

From these steps, equations are generated whereby the forces at the nodal points are related to the nodal point displacements. The resulting equations are in the form

$$
\{\mathrm{Q}\}=[\mathrm{K}] \cdot \mathrm{d}\}
$$

where $\{Q\}$ is a force matrix, $\{d\}$ is a matrix of the nodal point displace- . ments, and $[\mathrm{K}]$ is the stiffness matrix. The stiffness-matrix depends on the geometry of the elements and the deformation properties of the material.

7. The character of the assumed displacement field within an element is of major importance. The choice of a proper displacement function dictates the basic shape of the elements used to subdivide the continuum and the character of the strain field within each element. If a linear 
displacement function is chosen, i.e.,

$$
\begin{aligned}
& u=A_{1}+A_{2} x+A_{3} y \\
& v=A_{4}+A_{5} x+A_{6} y
\end{aligned}
$$

where

$$
\begin{aligned}
u, v & =\text { components of displacement in the } x \text { and } y \text { directions } \\
A_{1} \ldots A_{6} & =\text { displacement coefficients } \\
\mathrm{x}, \mathrm{y} & =\text { coordinates }
\end{aligned}
$$

then the correct choice of element shape is triangular and the corresponding strain field will be constant for each element. If, on the other hand, a displacement function is chosen with quadratic terms, i.e.,

$$
\begin{aligned}
& u=A_{1}+A_{2} x+A_{3} y+A_{4} x y \\
& v=A_{5}+A_{6} x+A_{7} y+A_{8} x y
\end{aligned}
$$

(where $u, v, A_{1} \ldots A_{8}, x$, and $y$ are defined as above), the correct choice of element shape is a quadrilateral and the strain field will vary linearly across the element. The strain field follows from the definition of strain:

$$
\epsilon_{x}=\frac{\partial u}{\partial x}, \epsilon_{y}=\frac{\partial v}{\partial y}, \gamma_{x y}=\frac{\partial u}{\partial y}+\frac{\partial v}{\partial x}
$$

where

$$
\begin{aligned}
\epsilon_{\mathrm{x}} & =\text { strain in the } \mathrm{x} \text { direction } \\
\epsilon_{\mathrm{y}} & =\text { strain in the } \mathrm{y} \text { direction } \\
\gamma_{\mathrm{xy}} & =\text { shearing strain }
\end{aligned}
$$

Problems in which constant strain within an element is not expected can still be solved using triangular elements (i.e., constrant strain formulation) by reducing the size of the elements so that approximations are not large. 
8. An example of a finite element representation of a mass in which a region has been subdivided into triangular elements is shown in fig. 1. Each element is connected to its neighbor only at the node points. Fig. 2

Fig. 1. Finite element representation of a mass
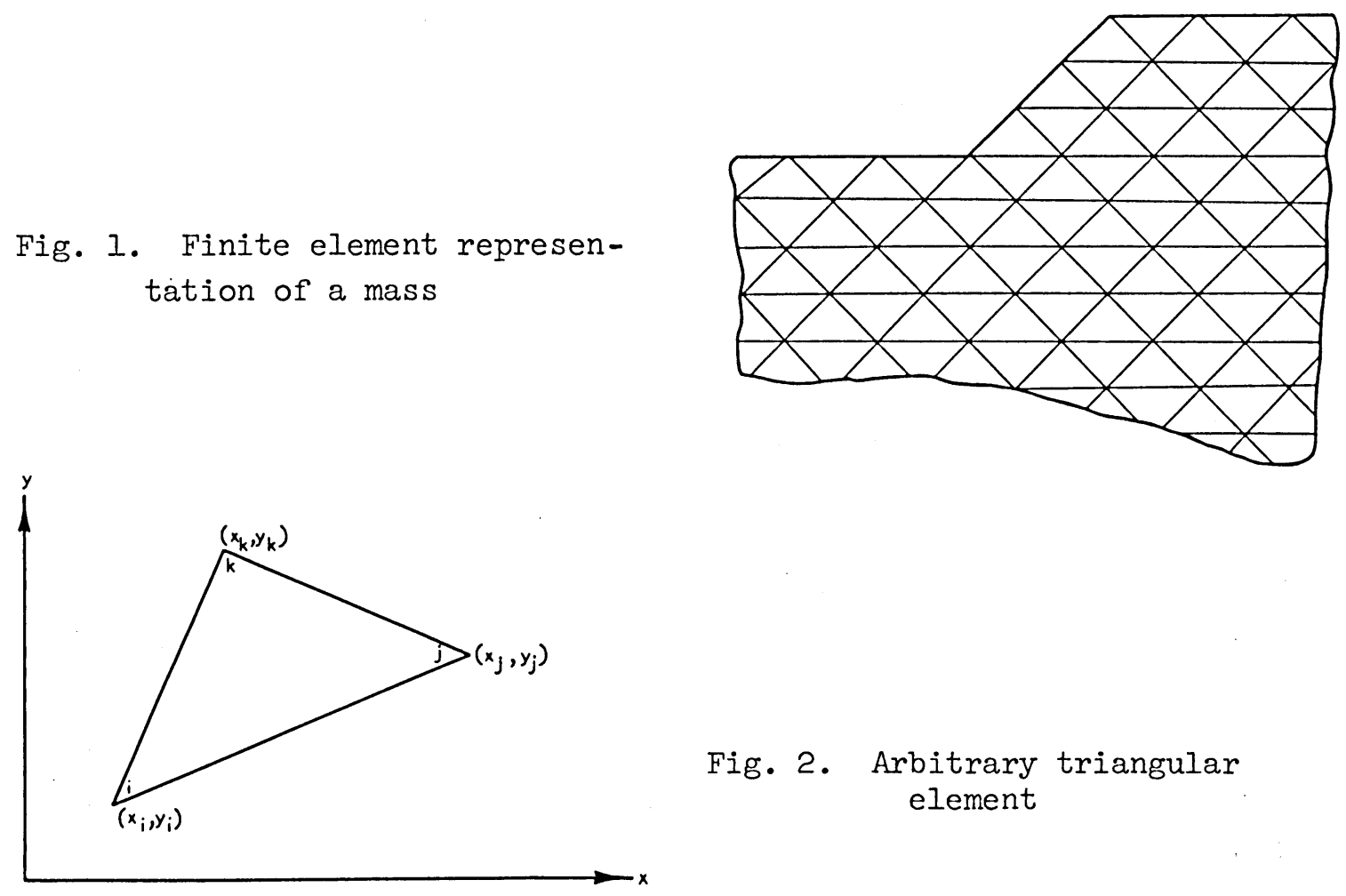

Fig. 2. Arbitrary triangular element

shows an arbitrary triangular element with the vertexes labeled. The coordinates $\left(x_{i}, y_{i}\right),\left(x_{j}, y_{j}\right)$, and $\left(x_{k}, y_{k}\right)$ determine the position of nodal points $i, j$, and $k$, respectively. In the following development, a linear displacement field (constant strain triangles) is the only one that will be considered; thermal effects and initial stresses are neglected. The following mathematical development is based on a physical explanation of the relationship between displacement, strain, stress, and force. An alternative procedure involves the minimization of the energy of the system by the use of calculus of variation. ${ }^{14,15}$

9. The displacements of each node of the triangle shown in fig. 2 may be written as follows: 


$$
\begin{aligned}
& u_{i}=A_{1}+A_{2} x_{i}+A_{3} y_{i} \\
& u_{j}=A_{1}+A_{2} x_{j}+A_{3} y_{j} \\
& u_{k}=A_{1}+A_{2} x_{k}+A_{3} y_{k} \\
& v_{i}=A_{4}+A_{5} x_{i}+A_{6} y_{i} \\
& v_{j}=A_{4}+A_{5} x_{j}+A_{6} y_{j} \\
& v_{k}=A_{4}+A_{5} x_{k}+A_{6} y_{k}
\end{aligned}
$$

The above six equations may be solved for $A_{1}, \ldots, A_{6}$ in terms of $u_{i}$, $u_{j}, u_{k}$ and $v_{i}, v_{j}, v_{k}$. In the absence of initial displacements, $A_{1}$ and $A_{4}$ are zero, and the remaining coefficients are given by the following matrix:

$$
\left[\begin{array}{l}
A_{2} \\
A_{3} \\
A_{5} \\
A_{6}
\end{array}\right]=\left(\frac{1}{a_{j k} b_{k}-a_{k} b_{j}}\right)\left[\begin{array}{cccccc}
\left(b_{j}-b_{k}\right) & 0 & b_{k} & 0 & -b_{j} & 0 \\
\left(a_{k}-a_{j}\right) & 0 & -a_{k} & 0 & a_{j} & 0 \\
0 & \left(b_{j}-b_{k}\right) & 0 & b_{k} & 0 & -b_{j} \\
0 & \left(a_{k}-a_{j}\right) & 0 & -a_{k} & 0 & a_{j}
\end{array}\right]\left[\begin{array}{c}
u_{i} \\
v_{i} \\
u_{j} \\
v_{j} \\
u_{k} \\
v_{k}
\end{array}\right]
$$

where

$$
\begin{array}{ll}
b_{j}=y_{j}-y_{i} & a_{j}=x_{j}-x_{i} \\
b_{k}=y_{k}-y_{i} & a_{k}=x_{k}-x_{i}
\end{array}
$$

10. The strains within any element are by definition

$$
\begin{aligned}
\epsilon_{x} & =\frac{\partial u}{\partial x}=A_{2} \\
\epsilon_{y} & =\frac{\partial v}{\partial y}=A_{6} \\
\gamma_{x y} & =\frac{\partial u}{\partial y}+\frac{\partial v}{\partial x}=A_{3}+A_{5}
\end{aligned}
$$

or, in matrix form 


$$
\left[\begin{array}{c}
\epsilon_{x} \\
\epsilon_{y} \\
\gamma_{x y}
\end{array}\right]=\left(\frac{1}{a_{j} b_{k}-a_{k} b_{j}}\right)\left[\begin{array}{cccccc}
\left(b_{j}-b_{k}\right) & 0 & b_{k} & 0 & -b_{j} & 0 \\
0 & \left(a_{k}-a_{j}\right) & 0 & -a_{k} & 0 & a_{j} \\
\left(a_{k}-a_{j}\right) & \left(b_{k}-b_{j}\right) & -a_{k} & b_{k} & a_{j}-b_{j}
\end{array}\right]\left[\begin{array}{c}
u_{i} \\
v_{i} \\
u_{j} \\
v_{j} \\
u_{k} \\
v_{k}
\end{array}\right]
$$

or, in direct notation

$$
\{\epsilon\}=[A]\{r\}
$$

11. The stress-strain relation may be written directly from Hooke's law, which, for plane strain and a linear elastic material, takes the form

$$
\left[\begin{array}{c}
\sigma_{\mathrm{x}} \\
\sigma_{\mathrm{y}} \\
\tau_{\mathrm{xy}}
\end{array}\right]=\left[\frac{\mathrm{E}}{(1-v)(1-2 v)}\right]\left[\begin{array}{ccc}
1-v & v & 0 \\
v & 1-v & 0 \\
0 & 0 & \frac{1-2 v}{2}
\end{array}\right]\left[\begin{array}{c}
\epsilon_{\mathrm{x}} \\
\epsilon_{\mathrm{y}} \\
\gamma \\
\mathrm{xy}
\end{array}\right]
$$

where

$$
\begin{aligned}
& E=\text { Young's modulus } \\
& v=\text { Poisson's ratio }
\end{aligned}
$$

In direct notation the general stress-strain relation can be written

$$
\{\sigma\}=[D]\{\epsilon\}
$$

12. The stresses acting across the boundary of an element may be broken up into forces acting at the nodes of the elements by methods of statics (see fig. 3). If $\mathrm{F}_{\mathrm{x}}^{i}$ is the force at nodal point $i$ in the $\mathrm{x}$ direction and $\mathrm{F}_{\mathrm{y}}^{j}$ is the force in the $\mathrm{y}$ direction at nodal point $j$, etc., the following force matrix may be developed 


$$
\begin{aligned}
& F_{x}^{i}=\frac{\sigma_{x}}{2}\left(b_{j}-b_{k}\right) \\
& F_{x}^{j}=\frac{\sigma_{x}}{2}\left(b_{k}\right) \\
& F_{x}^{k}=\frac{\sigma_{x}}{2}\left(-b_{j}\right)
\end{aligned}
$$

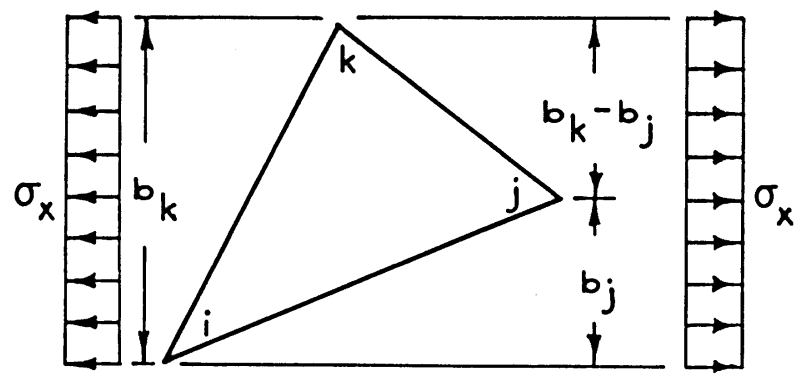

$$
\begin{aligned}
& F_{y}^{i}=\frac{\sigma_{y}}{2}\left(a_{k}-a_{j}\right) \\
& F_{y}^{j}=\frac{\sigma_{y}}{2}\left(-a_{k}\right) \\
& F_{y}^{k}=\frac{\sigma_{y}}{2}\left(a_{j}\right)
\end{aligned}
$$

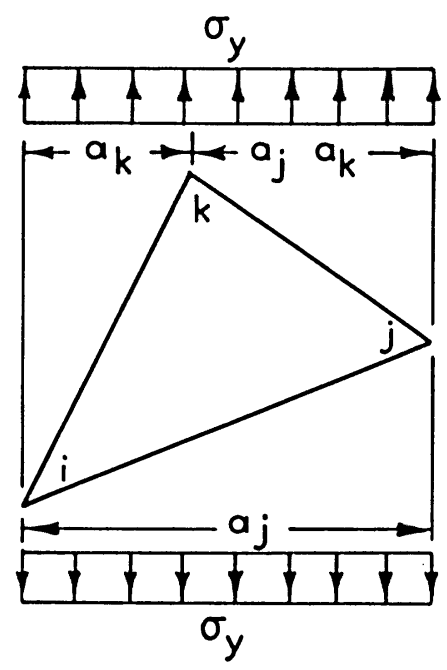

$F_{x}^{i}=\frac{\tau_{x y}}{2}\left(a_{k}-a_{j}\right)$

$F_{y}^{i}=\frac{\tau_{x y}}{2}\left(b_{j}-b_{k}\right)$

$F_{x}^{j}=\frac{\tau_{x y}}{2}\left(-a_{k}\right)$

$F_{y}^{j}=\frac{\tau_{x y}}{2}\left(b_{k}\right)$

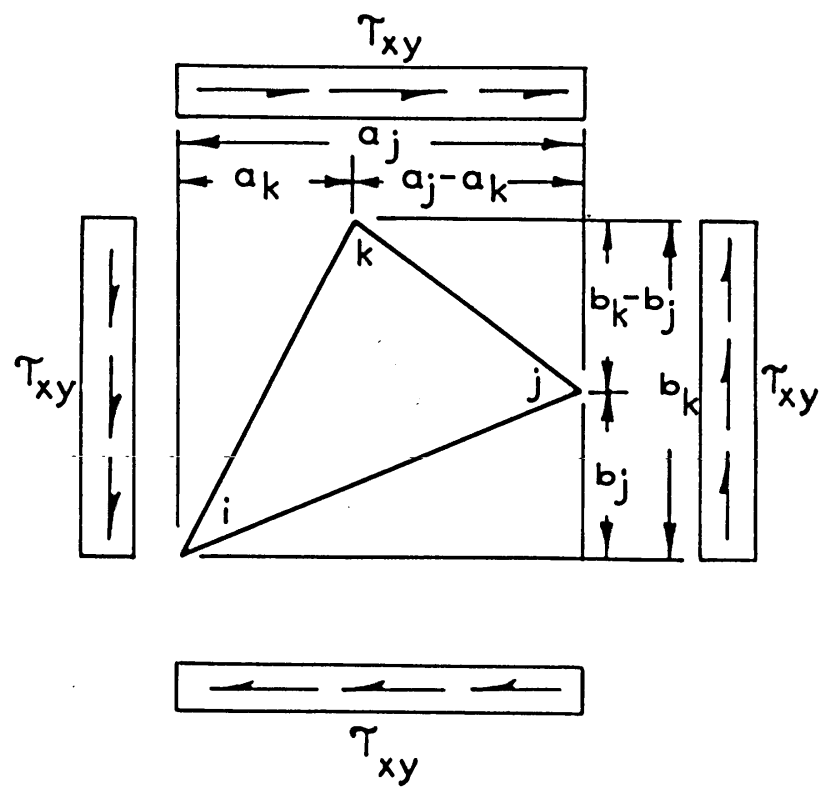

$F_{x}^{k}=\frac{\tau_{x y}}{2}\left(a_{j}\right)$

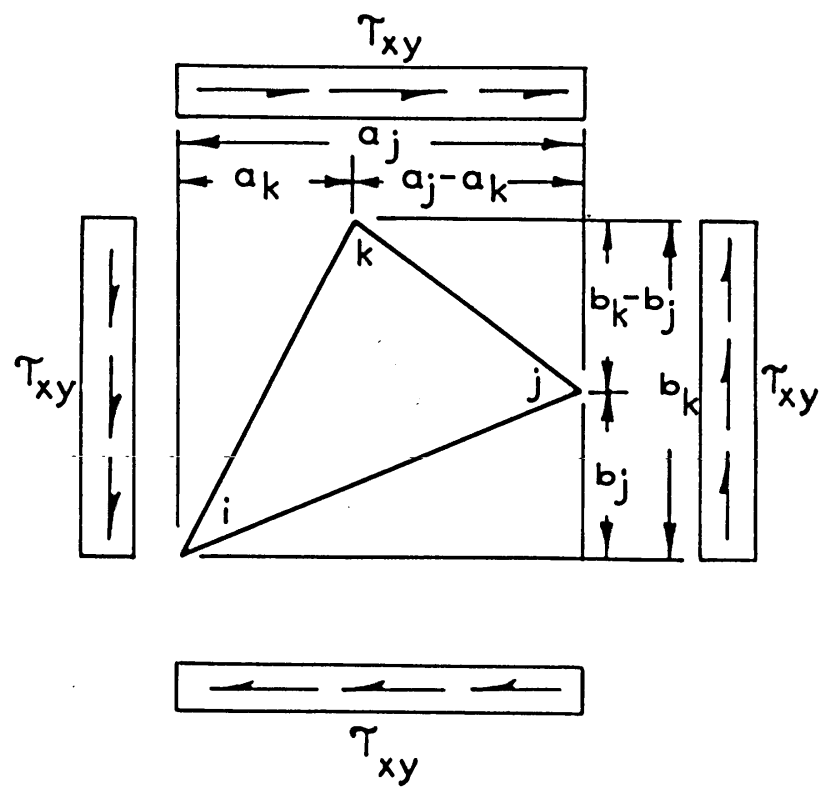

$F_{y}^{k}=\frac{\tau_{x y}}{2}\left(-b_{j}\right)$

Fig. 3. Stress resultants 


$$
\left[\begin{array}{c}
F_{x}^{i} \\
F_{y}^{i} \\
F_{x}^{j} \\
F_{y}^{j} \\
F_{x}^{k} \\
F_{y}^{k}
\end{array}\right]=(I / 2)\left[\begin{array}{ccc}
b_{j}-b_{k} & 0 & a_{k}-a_{j} \\
0 & a_{k}-a_{j} b_{j}-b_{k} \\
b_{k} & 0 & -a_{k} \\
0 & -a_{k} & b_{k} \\
-b_{j} & 0 & a_{j} \\
0 & a_{j} & -b_{j}
\end{array}\right]\left[\begin{array}{c}
\sigma_{x} \\
\sigma_{y} \\
\tau_{x y}
\end{array}\right]
$$

or, using direct notation,

But since

$$
\{F\}=[B]\{\sigma\}
$$

and

$$
\{\epsilon\}=[A]\{r\} \quad \text { (equation } 7 \mathrm{~b} \text { ) }
$$

then

$$
\{\sigma\}=[D]\{\epsilon\}=[D][A]\{r\}
$$

or

$$
\{F\}=[B]\{\sigma\}=[B][D][A]\{r\}
$$

where

$$
\{F\}=[k]\{r\}
$$

$$
[\mathrm{k}]=[\mathrm{B}][\mathrm{D}][\mathrm{A}]
$$

13. The matrix $[\mathrm{k}]$ is termed the stiffness matrix. For triangular elements, the matrix is composed of six rows and six columns and is symmetric with respect to the diagonal. The coefficients of the matrix are determined from the size of the element and the constitutive relations that describe the deformation of the material. Since each element is connected to its neighbors at the nodal points, certain equations will share common displacement terms. An equation of the type $\{F\}=[k]\{r\}$ is written for 
each element of the system. Since the equations are linear, they may be added to result in the equilibrium equations for the entire problem. The result is a system of linear simultaneous equations of the form:

$$
\{\mathrm{Q}\}=[\mathrm{K}]\{\mathrm{d}\}
$$

where

$[K]=$ summation of the individual stiffness matrices

Depending on the boundary conditions, either the force $\{Q\}$ or the displacement $\{d\}$ is known at every nodal point. Thus, from equation 12, a solution can be obtained for displacements at all nodal points. The strains within each element may then be calculated from equation $7 \mathrm{~b}$, and the stresses in turn may be determined within each element from equations $8 b$ or $9 \mathrm{c}$. Since even simple problems can easily involve the solution of several hundred simultaneous linear equations, it is apparent that a large high-speed digital computer is necessary to successfully utilize the finite element method.

\section{Application}

14. Although the preceding paragraphs on the finite element method described the formulation for a problem of linear elasticity, finite element methods have been used in widely diverse areas. Many other areas of engineering and mathematics involve boundary value problems that may be stated mathematically as extremum problems. The finite element method is readily adapted to many practical problems, such as seepage, consolidation, heat conduction, and stress analysis. The technique has also been extended to three-dimensional problems, although the time required by presently available computers for solving practical three-dimensional problems is quite large. Such applications of the method are illustrated in references 14 and 15 . 


\section{Linear Elastic Computer Program}

15. A University of California computer program entitled "Plane Stress Structures" was primarily used for earlier investigations at WEs. ${ }^{12}$ This program was formulated for materials obeying a linear elastic stressstrain relationship under plane stress conditions. (Plane strain conditions may be satisfied by a simple modification of matrix $D$ in equation $8 \mathrm{~b}$ involving Young's modulus $\mathrm{E}$ and Poisson's ratio $v_{.}$) The computer program will accept up to 800 elements and 900 nodal points. Either loads or displacements can be prescribed on the boundaries. The output consists of nodal point displacements and element stresses resulting from applied loads and gravity forces. The most common way to analyze a slope or an embankment with this program is to compute the stresses resulting from gravity forces using a technique commonly known as "gravity turn-on."

16. Since the program is formulated for linearly elastic materials, only problems in which the strength is considerably higher than calculated stresses are suitable for analyses; i.e., stresses must stay within the elastic range. Such is generally not the case for many soil and rock mechanics problems, particularly if stability is important. Secondly, observations of soil and rock behavior indicate that the response to changes in loads depends to a large extent upon the initial state of stress in the material. Thirdly, computed displacements are total displacements resulting from all applied and body forces. The engineer engaged in solution of soil and rock mechanics problems is generally interested only in displacements resulting from some applied load or change in existing loading and not displacements due to initial stresses.

17. Earlier investigations performed at WES with the elastic finite element programs indicated the need for an improved technique that would predict more accurately the behavior of an actual slope. The following modifications were considered necessary:

a. Incorporation of nonlinear stress-strain properties of the materials. 
b. Incorporation of strength parameters into the analyses.

c. Provisions for including the effect of residual stresses in the mass.

d. Techniques by which material may be added or removed incrementally.

The development of a computer program that incorporates these capabilities is described subsequently. The computer program with documentation regarding its use is presented in Appendix A to this report.

\section{A Nonlinear Finite Element Program}

Hyperbolic stress-strain curves

18. It has been shown in references 16-18 that stress-strain curves for many soils may be expressed in the form of a hyperbola, or

$$
\left(\sigma_{1}-\sigma_{3}\right)=\frac{\epsilon_{a}}{\frac{1}{E_{i}}+\frac{\epsilon_{a}}{\left(\sigma_{1}-\sigma_{3}\right)_{u}}}
$$

where

$$
\begin{aligned}
\epsilon_{a} & =\text { axial strain } \\
E_{i} & =\text { initial tangent modulus of the stress-strain curve } \\
\left(\sigma_{1}-\sigma_{3}\right)_{u} & =\text { ultimate stress difference }
\end{aligned}
$$

A hyperbolic stress-strain curve is shown in fig. 4a. Since $E_{i}$ and $\left(\sigma_{1}-\sigma_{3}\right)_{u}$ define the hyperbolic stress-strain curve, it is convenient to transform equation 13 into a linear form

$$
\frac{\epsilon_{a}}{\sigma_{1}-\sigma_{3}}=\frac{1}{E_{i}}+\frac{\epsilon_{a}}{\left(\sigma_{1}-\sigma_{3}\right)_{u}}
$$

with each term defined above. In the linear form of equation 14, the intercept and the slope of the transformed stress-strain curve are the reciprocal of the initial tangent modulus and the ultimate stress difference, respectively, as shown in fig. $4 \mathrm{~b}$. 
19. Computational procedures can be further benefited if $E_{i}$ and $\left(\sigma_{1}-\sigma_{3}\right)_{u}$ can be expressed in terms of stresses and material constants. A consultant to this study suggested that the initial tangent modulus $E_{i}$ be expressed as a function of the confining pressure $\sigma_{3}$ from triaxial test results. Specifically,

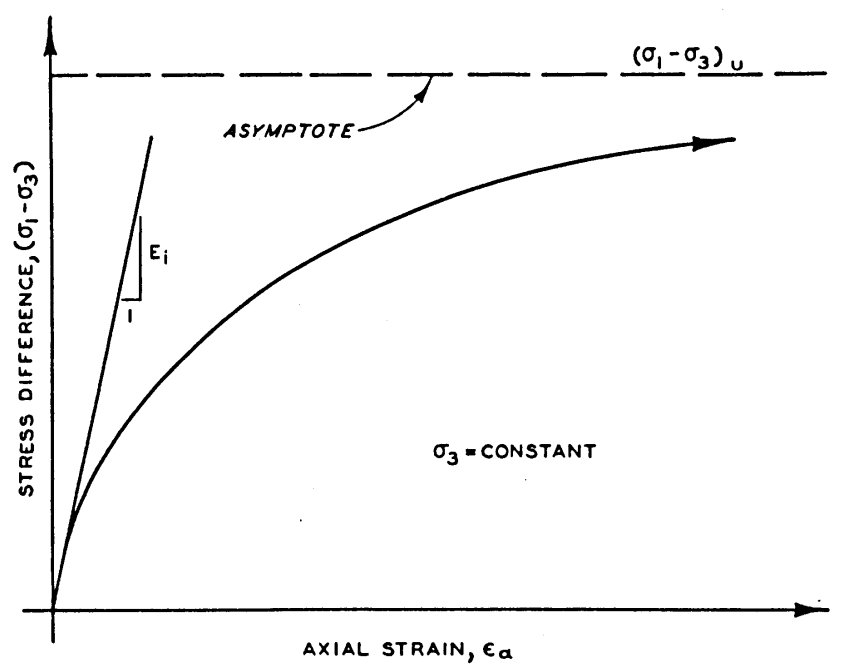

$$
E_{i}=K \sigma_{3}^{n}
$$

where $\mathrm{K}$ and $\mathrm{n}$ are empirical constants to be determined from laboratory tests. The form of equation 15 was suggested in reference 19 and has been recently shown to be a useful concept for finite element analyses. $^{20}$ Fig. 5 a shows a plot of initial tangent modulus $E_{i}$ versus confining pressure

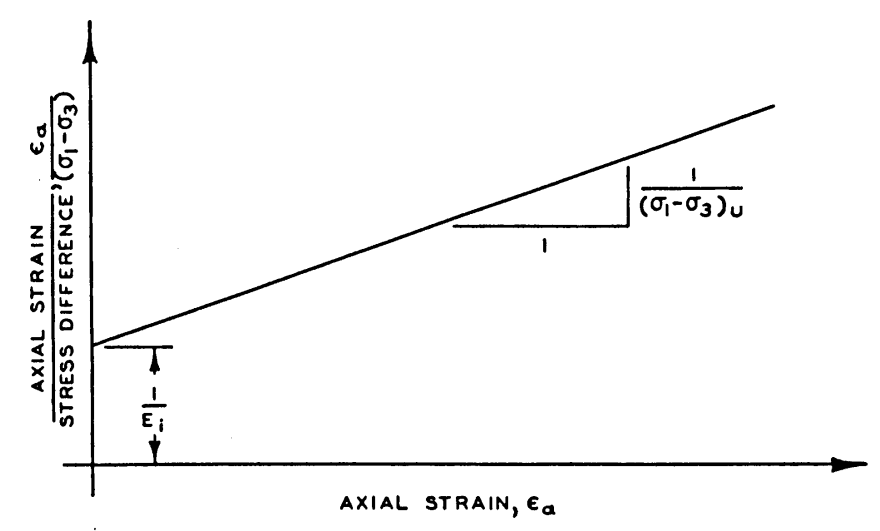
b. TRANSFORMED HYPERBOLIC STRESS-STRAIN CURVE

Fig. 4. Hyperbolic stress-strain relationships

$\sigma_{3}$ (logarithmic scales), from which $K$ is the intercept at $\sigma_{3}=1$ pressure unit and $\mathrm{n}$ is the slope of the line.

20. Kondner's hyperbola (equation 13) is asymptotic to the ultimate stress difference $\left(\sigma_{1}-\sigma_{3}\right)_{u}$. Since the maximum stress difference or stress difference at failure $\left(\sigma_{1}-\sigma_{3}\right)_{f}$ always occurs at some finite value of strain, it is apparent that the hyperbolic relationship must be terminated at some point along its locus, fig. 5b. To accommodate this restriction the hyperbolic stress-strain curve is made to yield

$$
\left(\sigma_{1}-\sigma_{3}\right)=\left(\sigma_{1}-\sigma_{3}\right)_{f} \text { at } \epsilon=\epsilon_{f}
$$




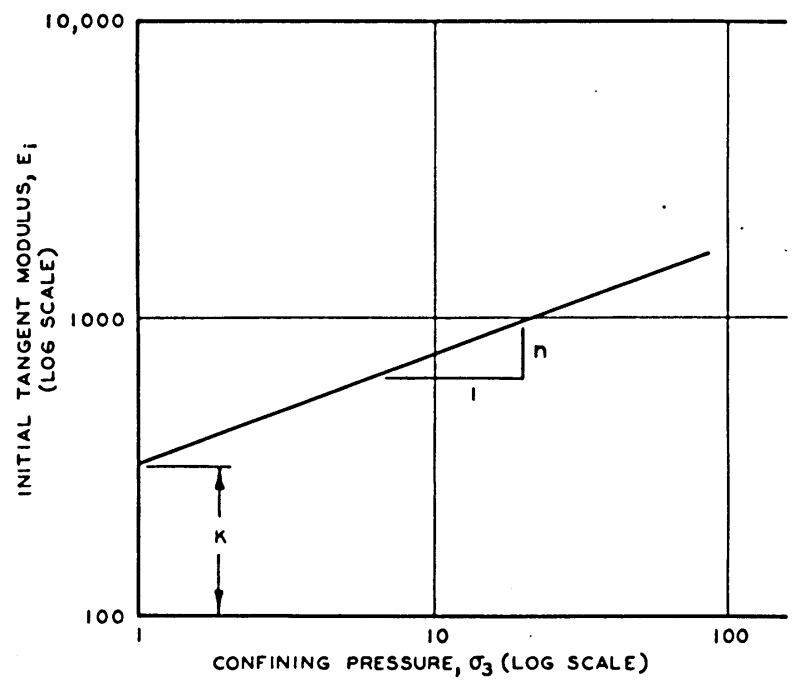

a. INITIAL TANGENT MODULUS RELATIONSHIPS

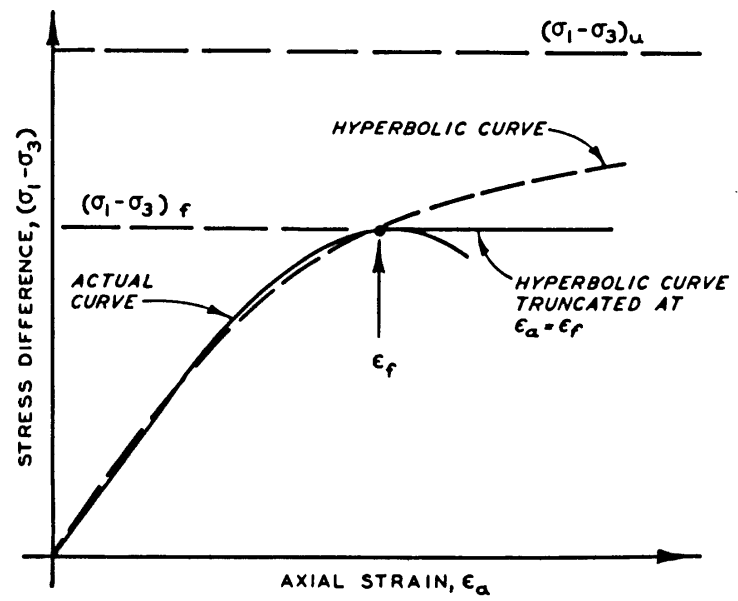

b. TRUNCATED HYPERBOLIC STRESS-STRAIN CURVE

Fig. 5. Bounds to hyperbolic stress-strain curves

where

$$
\begin{aligned}
\left(\sigma_{1}-\sigma_{3}\right)_{f} & =\text { stress difference at failure } \\
\epsilon_{f} & =\text { axial strain at failure }
\end{aligned}
$$

When these conditions are substituted into equation 13

then

$$
\begin{aligned}
& \left(\sigma_{1}-\sigma_{3}\right)_{f}=\frac{\epsilon_{f}}{\frac{1}{E_{i}}+\frac{\epsilon_{f}}{\left(\sigma_{1}-\sigma_{3}\right)_{u}}} \\
& \left(\sigma_{1}-\sigma_{3}\right)_{u}=\frac{E_{i} \epsilon_{f}\left(\sigma_{1}-\sigma_{3}\right)_{f}}{E_{i} \epsilon_{f}-\left(\sigma_{1}-\sigma_{3}\right)_{f}}
\end{aligned}
$$

and the hyperbolic equation becomes

$$
\left.\left(\sigma_{1}-\sigma_{3}\right)=\frac{E_{i} \epsilon_{a}}{\frac{1+E_{i} \epsilon_{a}}{\left(\sigma_{1}-\sigma_{3}\right)_{f}}-\frac{\epsilon_{a}}{\epsilon_{f}}} \quad \text { (for } 0 \leq \epsilon \leq \epsilon_{f}\right)
$$

21. An appropriate expression for the stress difference at failure $\left(\sigma_{1}-\sigma_{3}\right)_{f}$ can be obtained by assuming that the material fails in accordance with the Mohr-Coulomb failure criteria.

$$
\tau=c+\sigma_{n} \tan \varnothing
$$


where

$\tau$ and $\sigma_{n}=$ shear and normal stress, respectively, on the failure surface

$c=$ cohesion of the material

$\phi=$ friction angle of the material

Thus an expression for the stress difference at failure can be written as

$$
\left(\sigma_{1}-\sigma_{3}\right)_{f}=2 c \cos \phi+\left(\sigma_{1}+\sigma_{3}\right) \sin \phi
$$

22. When the expressions for the initial tangent modulus (equation 15) and the stress difference at failure (equation 2l) are substituted into the hyperbolic relationship (equation 19), the following expression is obtained.

$$
\left(\sigma_{1}-\sigma_{3}\right)=\frac{K \sigma_{3}^{n} \epsilon_{a}}{\frac{1+K \sigma_{3}^{n} \epsilon_{a}}{2 c \cos \phi+\left(\sigma_{1}+\sigma_{3}\right) \sin \phi}-\frac{\epsilon}{\epsilon_{f}}}
$$

The expression for the tangent modulus at any point on the stress-strain curve may be found by differentiating equation 19 with respect to the strain, i.e.

$$
E_{t}=\frac{d\left(\sigma_{1}-\sigma_{3}\right)}{d \epsilon_{a}}=\frac{E_{i}}{\left[1+\frac{E_{i} \epsilon_{a}}{\left(\sigma_{1}-\sigma_{3}\right)_{f}}-\frac{\epsilon_{a}}{\epsilon_{f}}\right]^{2}}
$$

The axial strain is written from equation 19 as

$$
\epsilon_{a}=\frac{\left(\sigma_{1}-\sigma_{3}\right)}{E_{i}-\frac{E_{i}\left(\sigma_{1}-\sigma_{3}\right)}{\left(\sigma_{1}-\sigma_{3}\right)_{f}}+\frac{\left(\sigma_{1}-\sigma_{3}\right)}{\epsilon_{f}}}
$$

Although too long to reproduce here, an expression for the tangent modulus at any point along the hyperbolic stress-strain curve may be obtained by substituting into equation 23 the expression for the axial strain (equation 24), the initial modulus (equation 15), and the stress difference at failure 
(equation 21). The expression involves the terms $\left(\sigma_{1}-\sigma_{3}\right)$ and $\sigma_{3}$, which are determined from the existing state of stress and $\mathrm{K}, \mathrm{n}, \mathrm{c}, \varnothing$, and $\epsilon_{f}$, which were defined previously and are determined from laboratory tests.

23. It is convenient for calculation purposes to define a mobilization factor, $M$, such that

$$
M=\frac{\left(\sigma_{1}-\sigma_{3}\right)}{\left(\sigma_{1}-\sigma_{3}\right)_{f}}
$$

is a measure of the stress difference (equal to twice the maximum shear stress) at a point in comparison to the maximum allowable stress difference at the point. When $\left(\sigma_{1}-\sigma_{3}\right)$ equals zero, the mobilization factor is also zero (by equation 25) and the axial strain is zero (by equation 24). For this condition, $E_{t}$ equals $E_{i}$ from equation 23 . Conversely when the mobilization factor equals unity, $\epsilon_{a}$ equals $\epsilon_{f}$ from equation 24, but the expression for tangent modulus (equation 23) becomes

$$
E_{t}=\frac{\left(\sigma_{1}-\sigma_{3}\right)_{f}^{2}}{E_{i} \epsilon_{f}^{2}}
$$

Thus the expression for the tangent modulus is not zero at the failure stress. The finite element program truncates the stress-strain curve at the desired strain and sets the tangent modulus at a small value (the code developed at WES uses $E_{t}=0.01$ pressure unit) at the failure strain. The expressions as derived above hold only for monotonically increasing values of stress differences. For decreasing values of stress differences, the tangent modulus $E_{t}$ is assumed to be equal to the initial modulus $E_{i}$. Residual stresses

24. Quite often soil and rock masses are stressed contrary to that indicated by conventional elastic theory. Measurements of in situ stresses in rock commonly indicate ratios of horizontal to vertical stress in excess of unity, possibly caused by past overburden pressures, tectonic activity, etc. Since static equilibrium must be maintained, the vertical stress for a horizontally layered system may be expressed as 


$$
\sigma_{y}=\Sigma \gamma_{i} t_{i}
$$

where

$$
t_{i}=\text { thickness of each layer containing a material of density } \gamma_{i}
$$
If only one density material is present, then

$$
\sigma_{y}=\gamma \Sigma t_{i}=\gamma \mathrm{y}
$$

where

$y=$ depth from the surface to the point in question

If the material is not horizontally layered or if the ground surface is not horizontal, the vertical stress distribution may be quite difficult to determine. In fact, the distribution of vertical stress for a complicated surface geometry is a type of problem particularly suited for finite element analysis.

25. The initial state of stress produced by a finite element solution is controlled by the value of Poisson's ratio and the boundary conditions. If, for example, a plane strain problem, bounded by a horizontal surface, vertical sides, and a horizontal base, is solved under the condition that the side boundaries cannot displace laterally, the vertical stresses will equal

$$
\sigma_{\mathrm{v}}=\sigma_{\mathrm{y}}=\gamma \mathrm{y}
$$

and the horizontal stresses will equal

$$
\sigma_{h}=\sigma_{x}=\left(\frac{v}{1-v}\right) \sigma_{v}
$$

While this state of stress is valid for linear elastic materials and may exist in some practical problems, it is advantageous to have techniques at hand to produce stress states which agree with the more typical case of nonlinear material behavior, as revealed by in situ stress measurements. In one technique, the finite element program is used directly to produce the desired stress state by applying pressure distributions (or forces) on 
the boundaries that differ from the elastic values by a desired amount; prescription of boundary displacements will produce similar results. Generally this procedure results in a trial-and-error solution of the problem with new boundary conditions (i.e., pressures or displacements) being applied until the desired result is obtained. A simpler method may be employed when the initial horizontal and vertical stresses may be considered as principal stresses. A finite element solution is made to obtain the vertical and horizontal stresses. The calculated horizontal stresses are then replaced by the desired horizontal stresses by multiplying the vertical stresses by a suitable factor $k$, which is equal to the principal stress ratio $\sigma_{3} / \sigma_{1}$. Therefore it follows that, if $\sigma_{\mathrm{y}}=\sigma_{1}$, then

$$
\sigma_{\mathrm{x}}=\cdot \mathrm{k} \sigma_{\mathrm{y}}
$$

If, on the other hand, $\sigma_{y}=\sigma_{3}$

then

$$
\sigma_{\mathrm{x}}=\frac{1}{\mathrm{k}} \sigma_{\mathrm{y}}
$$

By this definition, $k$ is always less than or equal to unity and can take on negative values for conditions where $\sigma_{\mathrm{x}}$ and $\sigma_{\mathrm{y}}$ are principal stresses. The computer program is formulated such that a different $k$ may be used for each material.

Strength considerations

26. Upon assignment of initial stresses by use of the principal stress ratio $\mathrm{k}$, the initial principal stress difference $\left(\sigma_{1}-\sigma_{3}\right)_{i}$ will become

$$
\left(\sigma_{1}-\sigma_{3}\right)_{i}=(\gamma \mathrm{y}-\mathrm{k} \gamma \mathrm{y})=\gamma \mathrm{y}(1-\mathrm{k})
$$

where

$$
\mathrm{k}=\sigma_{3} / \sigma_{1}
$$

Thus if $\mathrm{k}$ is not equal to one, the above equation predicts an increasing 
principal stress difference with depth. Previously the mobilization factor $M$ was defined as

$$
M=\frac{\left(\sigma_{1}-\sigma_{3}\right)}{\left(\sigma_{1}-\sigma_{3}\right)_{f}}
$$

For practical problems, the mobilization factor should remain less than unity for initial conditions. Therefore

$$
\left(\sigma_{1}-\sigma_{3}\right)_{i} \leq\left(\sigma_{1}-\sigma_{3}\right)_{f}
$$

Since $\left(\sigma_{1}-\sigma_{3}\right)_{f}$ for a Mohr-Coulomb material can be written (from equation 2l) as

$$
\begin{aligned}
\left(\sigma_{1}-\sigma_{3}\right)_{f} & =2 c \cos \phi+\left(\sigma_{1}+\sigma_{3}\right) \sin \phi \\
& =2 c \cos \phi+\gamma y(1+k) \sin \phi
\end{aligned}
$$

then

$$
\gamma \mathrm{y}(1-\mathrm{k}) \leq 2 \mathrm{c} \cos \varnothing+\gamma \mathrm{y}(1+\mathrm{k}) \sin \varnothing
$$

and for some depth $\mathrm{y}$,

$$
\mathrm{y}=\frac{2 \mathrm{cos} \phi}{\gamma[(1-\sin \phi)-\mathrm{k}(1+\sin \phi)]}
$$

the initial stress difference may (dependent upon the value of $k$ ) exceed the stress difference at failure. For example in a purely cohesive material (i.e., $\varnothing=0$ ), the critical depth below the surface is

$$
\mathrm{y}=\frac{2 \mathrm{c}}{\gamma(1-\mathrm{k})}
$$

and for a pureIy frictional material ( $i . e ., c=0$ ), the principal stress difference at failure $\left(\sigma_{1}-\sigma_{3}\right)_{f}$ will be exceeded at all depths if

$$
\mathrm{k} \leq \frac{1-\sin \varnothing}{1+\sin \varnothing}
$$

27. Since the assignment of tangent moduli is dependent upon the 
mobilization factor (see paragraph 23), the initial tangent modulus will be set to zero at the critical depth if provisions are not made for strength to increase with depth in a particular material zone. For this reason, a cohesion parameter $\bar{c}$ is introduced such that

$$
c=\bar{c} y
$$

where

$$
\bar{c}=\text { cohesion per unit of depth } y \text { from some reference height } h_{0}
$$
Then rewriting equation 21 gives

$$
\left(\sigma_{1}-\sigma_{3}\right)_{f}=2 \bar{c} y \cos \phi+\left(\sigma_{1}+\sigma_{3}\right) \sin \phi
$$

If initially

then

$$
\begin{aligned}
& \sigma_{1}=\gamma \mathrm{y} \\
& \sigma_{3}=\mathrm{k} \gamma \mathrm{y}
\end{aligned}
$$

$$
\left(\sigma_{1}-\sigma_{3}\right)_{f}=2 \bar{c} y \cos \varnothing+\gamma y(1+k) \sin \varnothing
$$

From equations 30 and 40 , the initial mobilization factor $M_{i}$ is given by:

$$
M_{i}=\frac{\gamma y(1-k)}{2 \overline{c y} \cos \phi+\gamma y(1+k) \sin \phi}
$$

Solving for $\bar{c}$ yields

$$
\bar{c}=\frac{\gamma}{M_{i}}\left[\frac{1-M_{i} \sin \phi-k\left(1+M_{i} \sin \phi\right)}{2 \cos \phi}\right]
$$

Thus, the value of $\bar{c}$ necessary to obtain a desired initial mobilization factor $M_{i}$ can be calculated from $k$ and $\varnothing$. A different $\bar{c}$ can be assigned each material by specifying a different reference height $h_{0}$ for each material. This reference height is generally the vertical ordinate of 
the top of a material layer. The computer program computes the distance from the reference height $h_{0}$ to the element center and calculates the true value of cohesion from

$$
c=\bar{c} y=\bar{c}\left(h_{0}-y_{e}\right)
$$

28. If the $\bar{c}$ provision is not used, then precautions must be taken to assign sufficiently high strengths to all materials below the critical depth so that the initial mobilization factor is not greater than unity at or below that depth.

29. If the cohesive component of the material strength does not increase with depth, meaningful results can in general be obtained only by choosing the range of $k$ such that the mobilization factor is always less than unity, i.e., is less than or equal to the strength at all points in the material. This condition is satisfied if

$$
2 c \cos \phi+\gamma y(1+k) \sin \phi \geq \gamma y(1-k)
$$

where all terms have been previously defined and $\gamma y$ is the maximum vertical stress occurring in the material. By definition $k$ must be less than or equal to unity and solving equation 44

$$
1 \geq k \geq \frac{1-\sin \phi}{1+\sin \phi}-\frac{2 c \cos \phi}{\gamma \mathrm{y}(1+\sin \phi)}
$$

Construction sequences

30. Removal or addition of material in a series of steps may be employed to simulate an actual construction sequence for a slope. The removal process may be used to simulate excavation of a slope or canal, whereas the addition of material simulates the construction of an embankment or a levee. The construction analysis is made after assignment or determination of initial stresses throughout the mass and the calculated displacements resulting from the initial stress state are returned to zero.

31. Addition of material. The addition of material is shown schematically in fig. 6. After assignment of initial stresses, the initial tangent moduli are determined and the proper unit weight is assigned to the 


\section{$\left(\sigma_{i j}\right)$}

INITIAL CONDITION

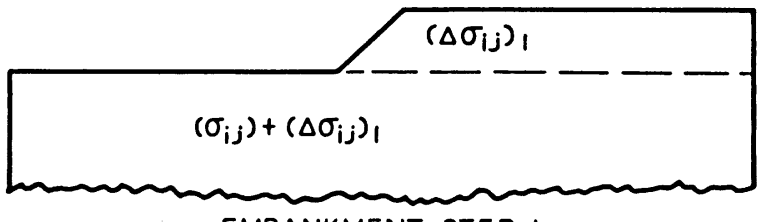

EMBANKMENT STEP ।

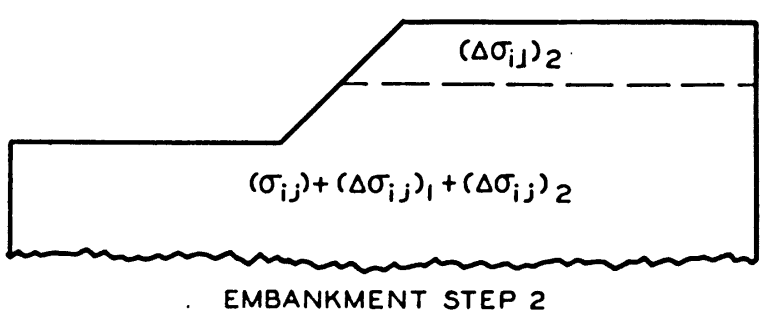

Fig. 6. Simulation of addition of material material being added. The force of gravity $g$ is then partially turned-on to a value of $\mathrm{g} / \mathrm{h}$, where $\mathrm{n}$ is any integer. The stresses and displacements caused by this load are then calculated and added to the initial stresses and displacements (the initial displacements are zero). The process is repeated $\mathrm{n}$ times, each time adding the changes in stresses and displacement to those of the preceding step, after which the next load is applied (i.e. $\left(\Delta \sigma_{i j}\right)_{2}$ in fig. 6), and the process is repeated. The stress state changes after each step requiring that new tangent moduli be computed and assigned to each element except the newly added elements. As the stress state is not yet known for the added elements, calculations of the tangent modulus cannot be made. The tangent modulus for elements defining the material being added is set to a small value $\left(E_{t}=100\right.$ pressure units). After each iteration, the displaced surface of the added region is returned to its original position; this process can be visualized as placing additional material to overcome the induced displacements and to achieve the desired final grade at the top of the added region. Before proceeding to the next construction step, the modulus within the newly added layer is calculated according to the now existing state of stress within that layer.

32. The capability for incrementing gravity was developed so that loads could be applied in small steps to approximate more nearly the stressstrain curve. The finite element grid could be prepared with smaller elements (i.e., to produce smaller loads in the region to be added), but difficulty is often encountered as certain numbering procedures must be followed when preparing finite element grids. The user of the computer 
program must specify the number of cycles or iterations per construction step and also an option of printing or not printing the output from each iteration.

33. Removal of material. The simulation of removal or excavation of material is more difficult than the addition of material since the boundary condition must be satisfied that all stresses be zero along the excavation surface. This condition is met by reversing the sign of stress acting along the excavation surface (see fig. 7) before removal and applying these stresses to the excavation surface so that, when summed with the previously existing. stress state, the resultant stresses are zero (i.e., $\left.\sigma_{y}=\sigma_{x}=\tau_{x y}=0\right)$. Since the excavation surface is defined by a series of nodal points, the average existing stresses at each nodal point are determined and the negative of the statically equivalent nodal point forces that would create this stress is applied. Stresses and displacements within the mass resulting from these forces are calculated by the finite element method and then summed to the previous state of INITIAL GEOMETRY

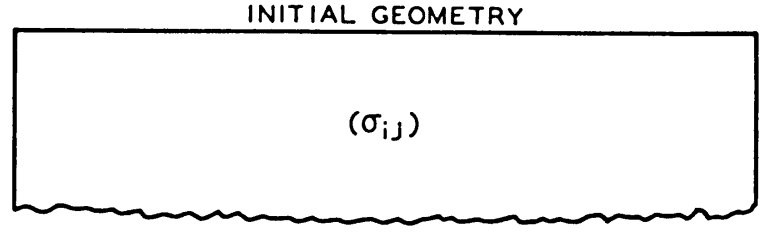

INITIAL CONDITION
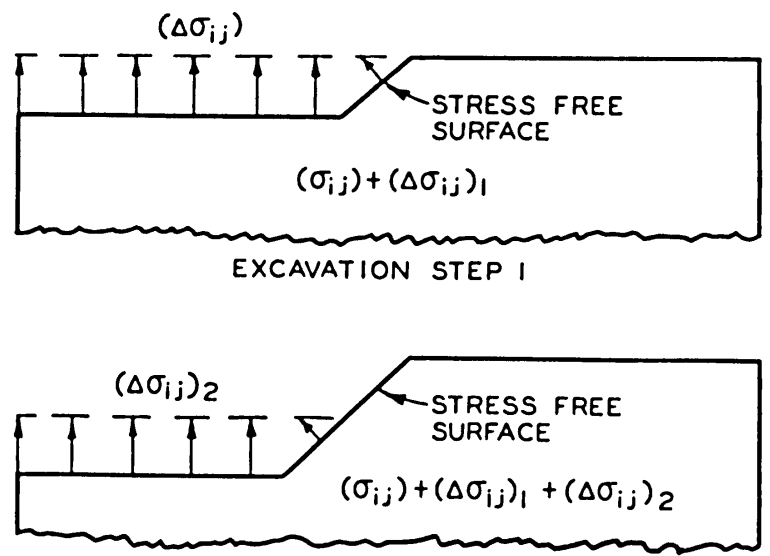

EXCAVATION STEP 2

Fig. 7. Simulation of excavation of material stress. The tangent moduli are recomputed after each step. Again, as in the case of adding material, each removal process is accomplished in $\mathrm{n}$ iterations with only $\mathrm{I} / \mathrm{n}$ th of the forces applied for each iteration.

Synopsis of the computer program

34. A simplified flow diagram is shown in fig. 8. As stated earlier, the initial, or residual, stresses may be assigned by use of the $k$ provision, or as a separate finite element problem. After assignment of the initial stresses, all displacements are set to zero. The boundary 


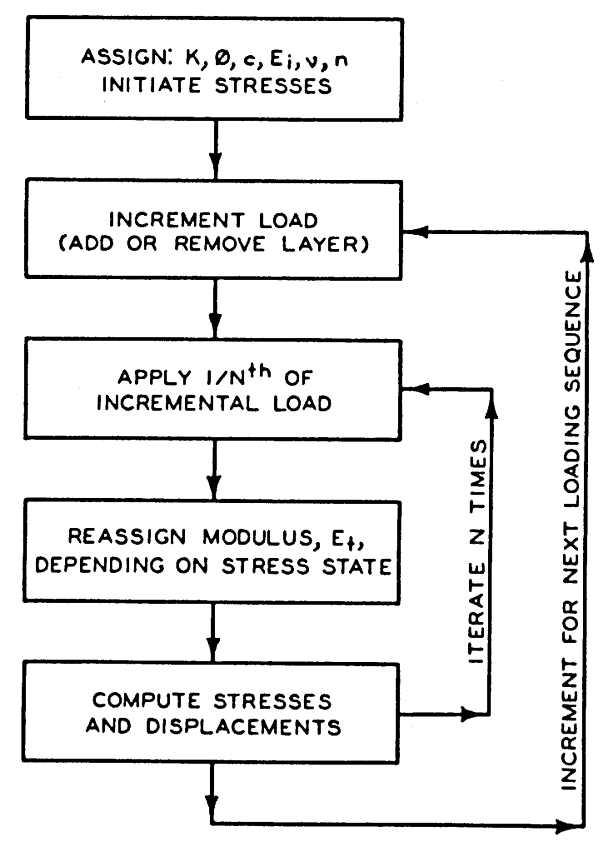

Fig. 8. Simplified flow diagram conditions on the right and left vertical boundaries are specified such that no horizontal movement can occur; the lower boundary is restrained from movement in any direction.

35. Conditions are now such that the first material layer may be added or removed. The tangent moduli are computed depending upon the state of stress in accordance with equation 23. Although the hyperbolic model used for expressing the relationship between stress and strain is nonlinear, the computer program approximates the curve in a piece-wise linear fashion. (After each iteration new tangent moduli are computed and these moduli behave linearly throughout that iteration.) All material weights are set to zero with the exception of any added layer elements. The stresses and displacements resulting from the added layer, or forces due to removal of a layer are determined in a series of iterations, each time applying one $n^{\text {th }}$ of the load or force, where $n$ is the number of iterations. The changes in stress and displacement are then added algebraically to the previous solution. That is,

$$
\begin{gathered}
\sigma_{x}=\left(\sigma_{x}\right)_{p}+\Delta \sigma_{x} \\
\sigma_{y}=\left(\sigma_{y}\right)_{p}+\Delta \sigma_{y} \\
\tau_{x y}=\left(\tau_{x y}\right)_{p}+\Delta \tau_{x y} \\
u_{x}=\left(u_{x}\right)_{p}+\Delta u_{x} \\
u_{y}=\left(u_{y}\right)_{p}+\Delta u_{y}
\end{gathered}
$$


where

$$
\begin{aligned}
& \sigma_{\mathrm{x}}=\text { new horizontal stress } \\
&\left(\sigma_{\mathrm{x}}\right)_{\mathrm{p}}=\text { previous horizontal stress } \\
& \Delta \sigma_{\mathrm{x}}=\text { change in horizontal stress due to the load increment, etc. } \\
& \text { 36. The next construction step is then considered. Up to } 150 \text { ele- }
\end{aligned}
$$
ments may be removed or added for each construction step. The number of iterations required for each construction step depends on the size of the elements involved (i.e., the total change in load to be considered). Changes in mobilization factor should vary by reasonable amounts between iterations, otherwise the approximation of tangents to the stress-strain curve could be poorly simulated and lead to an intolerable overshoot of stress. 


\section{PART IV: APPLICATIONS TO SIMPLE SLOPES}

\section{Description of Problems}

37. For purposes of illustrating the application of the nonlinear computer code, eight cases involving simple 45-deg slopes were studied. Four cases represent the construction of an embankment $20 \mathrm{ft} *$ high and the other four cases represent an excavated slope $20 \mathrm{ft}$ deep. The size of the problem and boundary conditions for the cut slope are indicated in fig. 9.

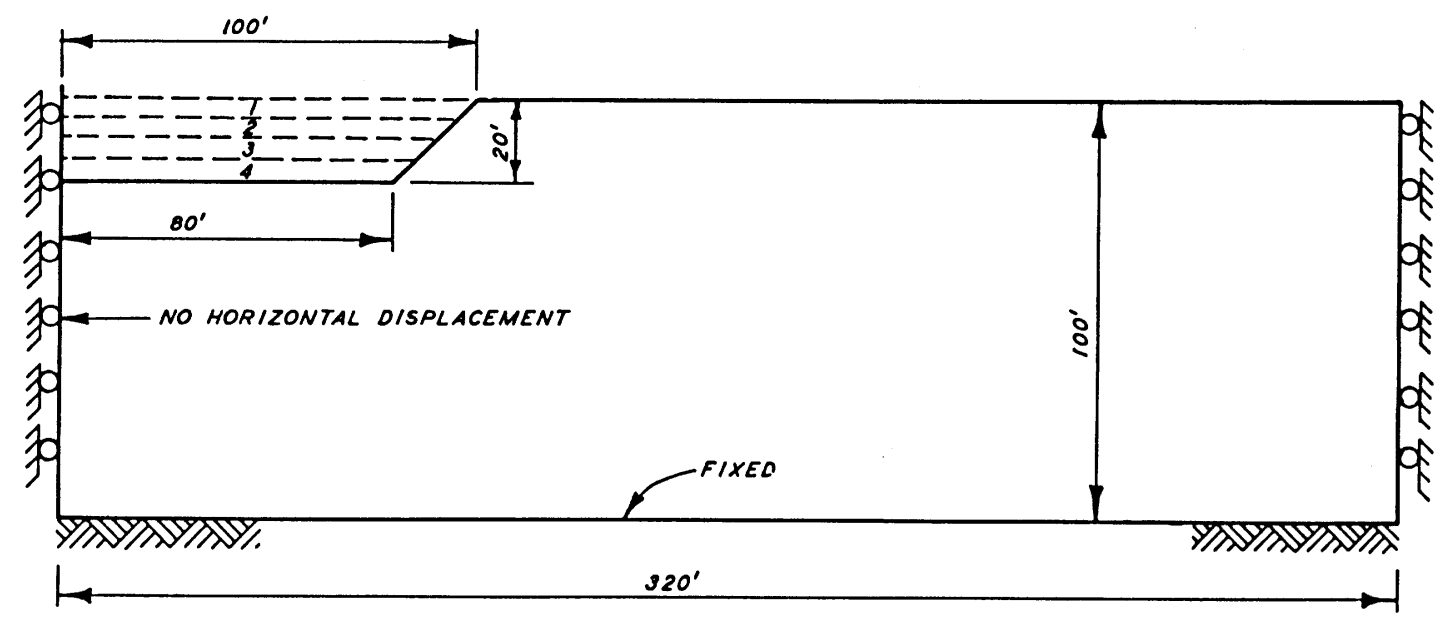

Fig. 9. Boundary conditions for simple 45-deg slopes

The lower boundary was assumed fixed. The right and left vertical boundaries were restrained in the horizontal directions. The original height of the grid (before excavation) was $100 \mathrm{ft}$ and the width was $320 \mathrm{ft}$. Similar boundary conditions and grid size were used for the embankment problem. The eight cases are indicated below.

\begin{tabular}{|c|c|c|c|c|}
\hline $\begin{array}{l}\text { Type Con- } \\
\text { struction } \\
\end{array}$ & Case & $\begin{array}{c}\text { Type } \\
\text { Analysis } \\
\end{array}$ & & $\begin{array}{c}k_{0} \\
\sigma_{h} / \sigma_{v}\end{array}$ \\
\hline Embankment & $\begin{array}{l}1 \\
2 \\
3 \\
4\end{array}$ & $\begin{array}{l}\text { Linear } \\
\text { Nonlinear } \\
\text { Nonlinear } \\
\text { Nonlinear } \\
\text { (Continued) }\end{array}$ & $\begin{array}{l}1.00 \\
1.00 \\
0.75 \\
0.80\end{array}$ & $\begin{array}{l}1.00 \\
1.00 \\
0.75 \\
1.25\end{array}$ \\
\hline
\end{tabular}

* A table of factors for converting British units of measurement to metric units is presented on page vii. 


\begin{tabular}{|c|c|c|c|c|}
\hline $\begin{array}{c}\text { Type } \\
\text { Construc- } \\
\text { tion } \\
\end{array}$ & Case & $\begin{array}{c}\text { Type } \\
\text { Analysis } \\
\end{array}$ & $\sigma_{3}^{k} / \sigma_{1}$ & $\begin{array}{c}\mathrm{k}_{\mathrm{o}} \\
\sigma_{\mathrm{h}} / \sigma_{\mathrm{v}}\end{array}$ \\
\hline Excavation & $\begin{array}{l}5 \\
6 \\
7 \\
8\end{array}$ & $\begin{array}{l}\text { Linear } \\
\text { Nonlinear } \\
\text { Nonlinear } \\
\text { Nonlinear }\end{array}$ & $\begin{array}{l}1.00 \\
1.00 \\
0.75 \\
0.80\end{array}$ & $\begin{array}{l}1.00 \\
1.00 \\
0.75 \\
1.25\end{array}$ \\
\hline
\end{tabular}

38. The linear elastic analyses (cases 1 and 5) were made for comparison with the nonlinear analyses and require no strength parameters for solution. All other cases were assumed to have strength parameters $c=200 \mathrm{psf}, \quad \varnothing=20 \mathrm{deg}$. For all analyses, the initial modulus was assumed to be $10^{5}$ psf (i.e., for nonlinear analysis $E_{i}=K \sigma_{3}^{n}$ with $K=10^{5}$ and $\left.n=0\right)$. The strain at failure $\epsilon_{f}$ was assumed equal to 10 percent. Poisson's ratio for all cases was assumed equal to 0.495 and the unit weight of all material was 100 psf. The variable examined in this series of solutions was the effect of the initial state of stress. For this purpose $k_{0}=\sigma_{h} / \sigma_{v}$ was assumed to be $1.25,1.00$, and 0.75 to produce $\mathrm{k}=\sigma_{3} / \sigma_{1}$ of $0.80,1.00$, and 0.75 , respectively.

39. For the nonlinear analyses, the embankments were constructed in four 5-ft lifts to produce an embankment $20 \mathrm{ft}$ high as shown in fig. 10.

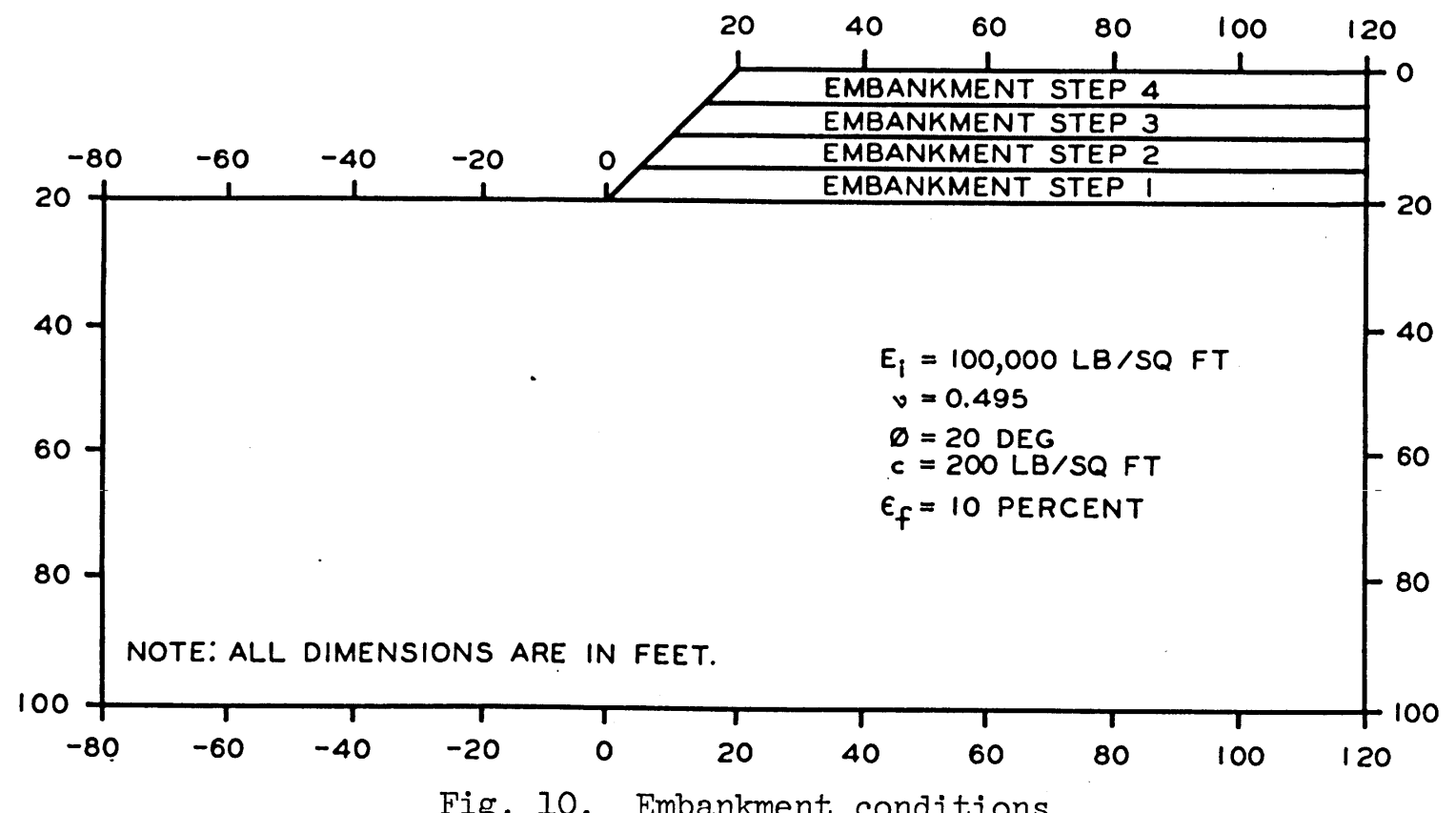

Fig. 10. Embankment conditions 
Each lift was accomplished by employing four iterations in which one-fourth of the load was applied for each iteration. Construction of the cut slope, fig. 11, was produced in a similar manner. The grid layout used in the vicinity of the slope is shown in fig. 12.

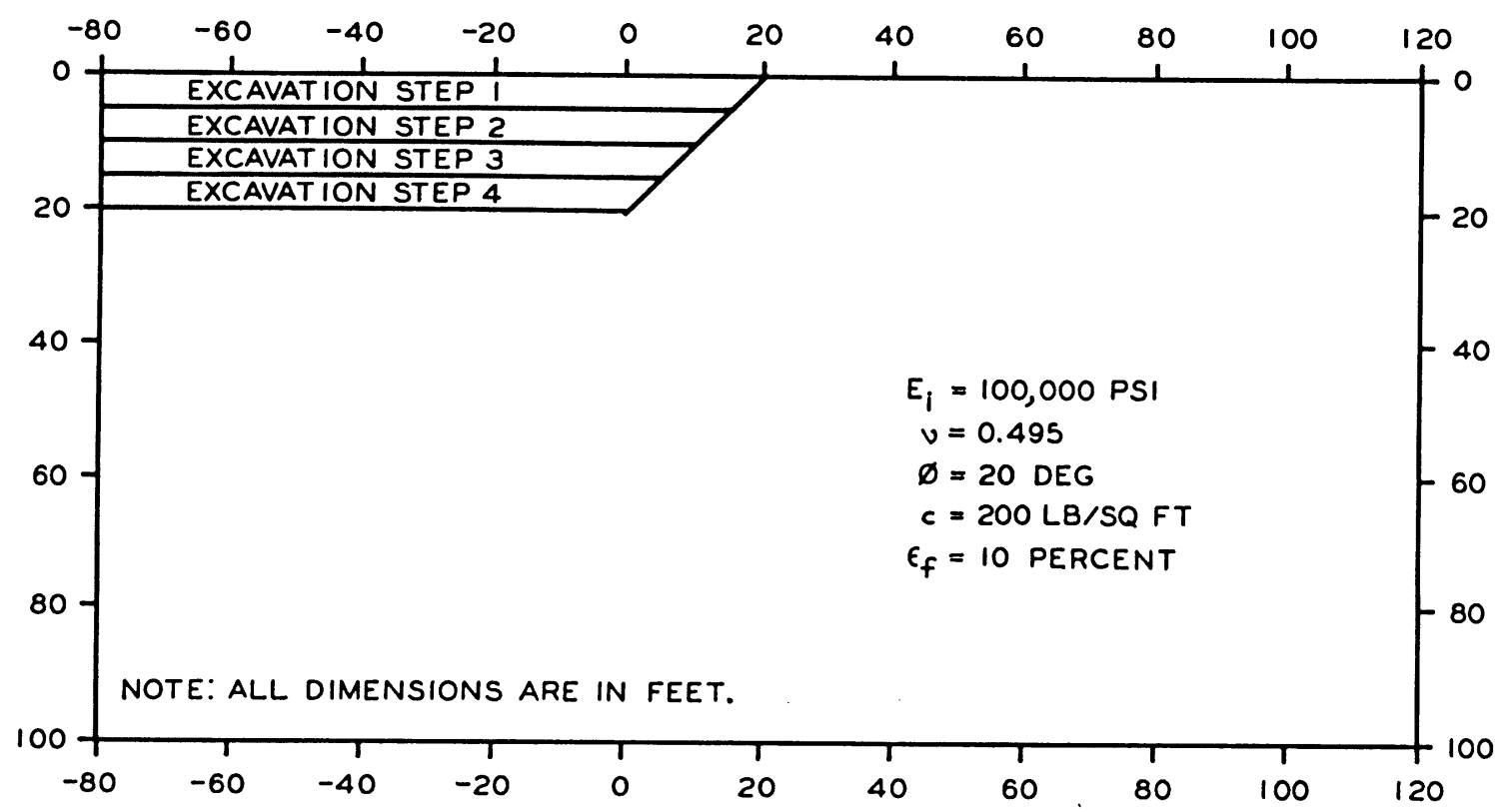

Fig. 11. Excavated slope conditions

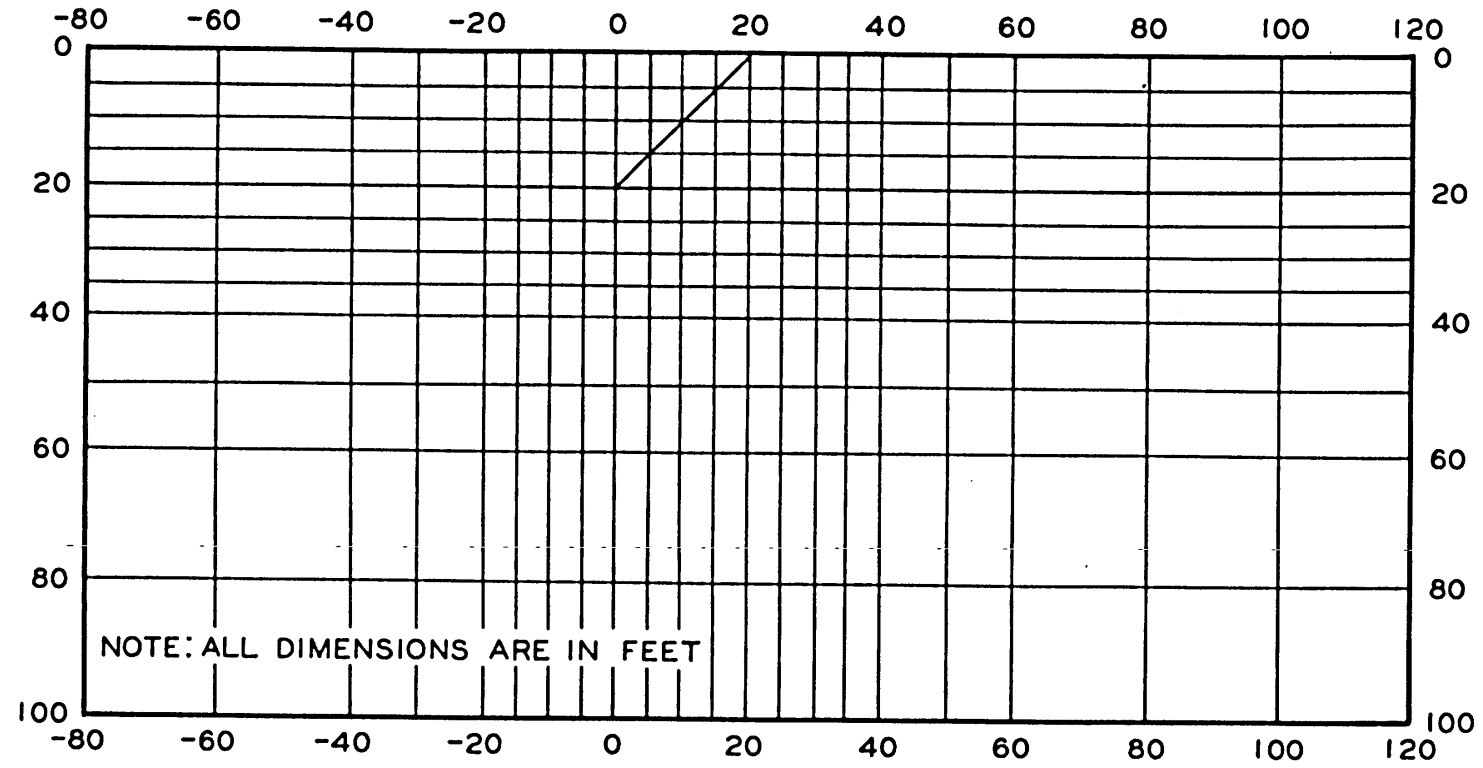

Fig. 12. Finite element grid employed for analyses 
40. At the end of each construction step, the displacement at all nodal points, and horizontal stresses $\sigma_{\mathrm{h}}$, vertical stresses $\sigma_{\mathrm{v}}$, shearing stresses $\tau_{x y}$, major principal stresses $\sigma_{1}$, minor principal stresses $\sigma_{3}$, direction of the major principal stresses with respect to $x$-axis, and the mobilization factors of the center of each element are printed to allow the graphical presentation of results. Selected results are presented and discussed below.

Displacement plots

41. The vector displacements of the surface beyond the toe of the slope, along the slope, and along the slope top, are shown for the embankment in fig. 13 and for the excavation in fig. 14. In the embankment

Fig. 13. Displacement along surface embankment
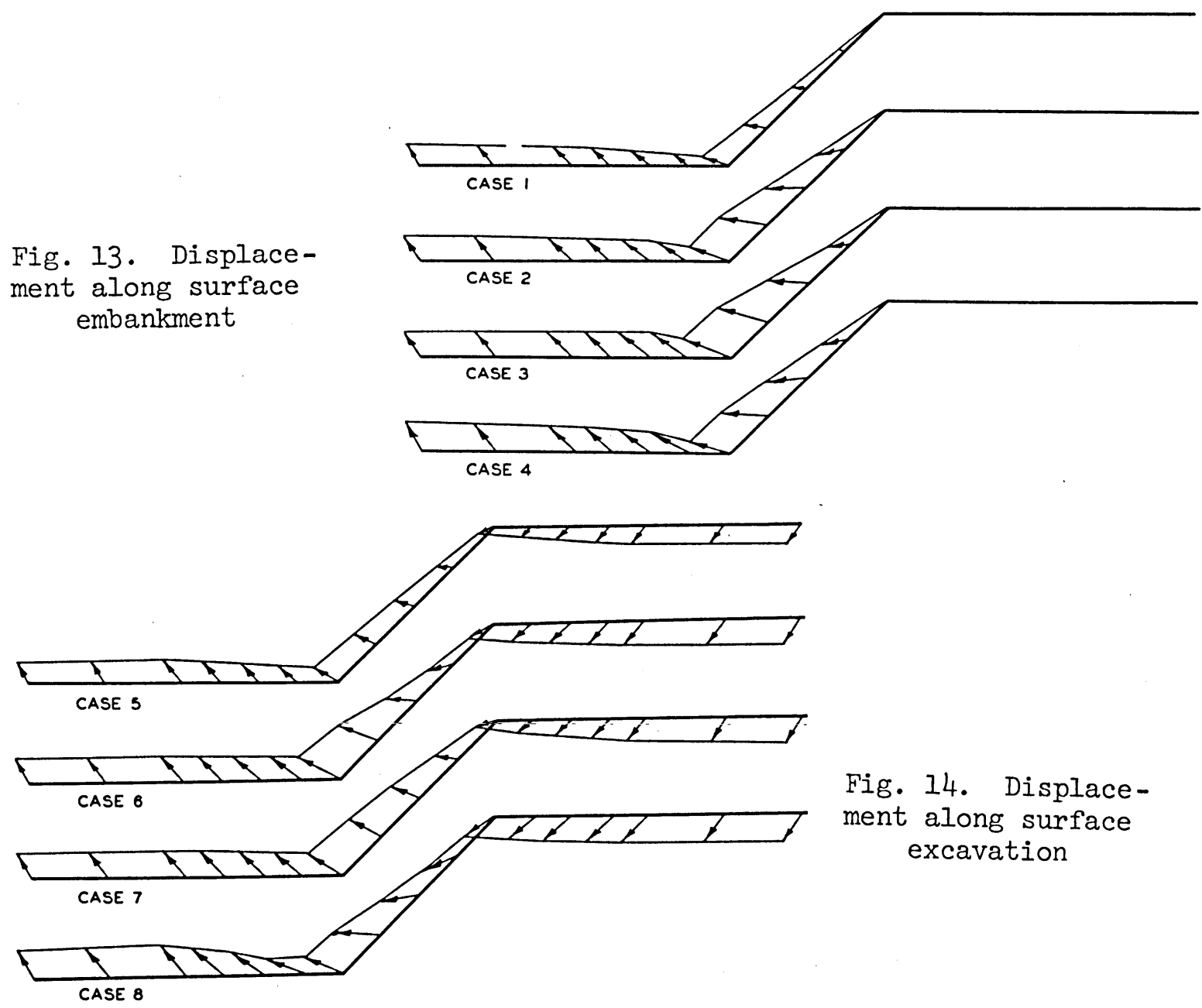
series the displacements at the top of any lift are not allowed to occur until the next lift is placed, see paragraph 31. For this reason, the displacements at the top of the embankment are zero. For the excavation series, the top of the slope can displace and, as shown in fig. 14, displacements are downward and inward toward the excavation. The displacements caused by the first lift or layer excavated are small in comparison with later displacements. The first change in loading is small and does not effectively overstress any large region. As the change in loading proceeds, larger areas are brought near failure conditions resulting in smaller tangent moduli and progressively larger displacements. In the cases illustrated, the displacements resulting from linear analyses are smaller than those from the nonlinear analyses.

\section{Stress plots}

42. The stresses obtained from the finite element solutions may be presented in a number of methods; for this report, contours of stresses are shown. Of particular interest are contours of horizontal stresses $\sigma_{\mathrm{x}}$, contours of vertical stresses $\sigma_{\mathrm{y}}$, contours of shear stresses $\tau_{\mathrm{xy}}$, and principal stress differences $\left(\sigma_{1}-\sigma_{3}\right)$, i.e. $\left(2 \tau_{x y}\right)_{\max }$.

43. Horizontal stresses. The horizontal stress contours shown in figs. 15 and 16 indicate very similar patterns for equal values of $k_{0}$. Comparison of cases 1, 2, 3, and 4 for the embankment series shows an increase in horizontal stress with depth in response to increasing the ratio of $k_{o}$ (i.e., $\sigma_{h} / \sigma_{v}$ ). Comparison of linear with nonlinear analysis for a $k_{0}$ value of unity for the embankment cases 1 and 2 indicates slightly higher values of $\sigma_{x}$ immediately beneath the base of the slope for the linear analysis. For the excavation, cases 5, 6, 7, and 8 (fig. 16), the same increase of horizontal stress with $k_{0}$ is apparent. Comparison of linear with nonlinear analysis for $k_{0}$ equal to unity (cases 5 and 6) again indicates slightly higher values of $\sigma_{x}$ beneath the base of the slope for the linear analysis. If corresponding cases are compared between the embankment and excavation series, it is seen that the excavation cases generally give higher values of $\sigma_{x}$ beneath the slope with the exception of the linear cases, which show very little difference in stress pattern. Any differences are probably associated with the low modulus value assigned to a 

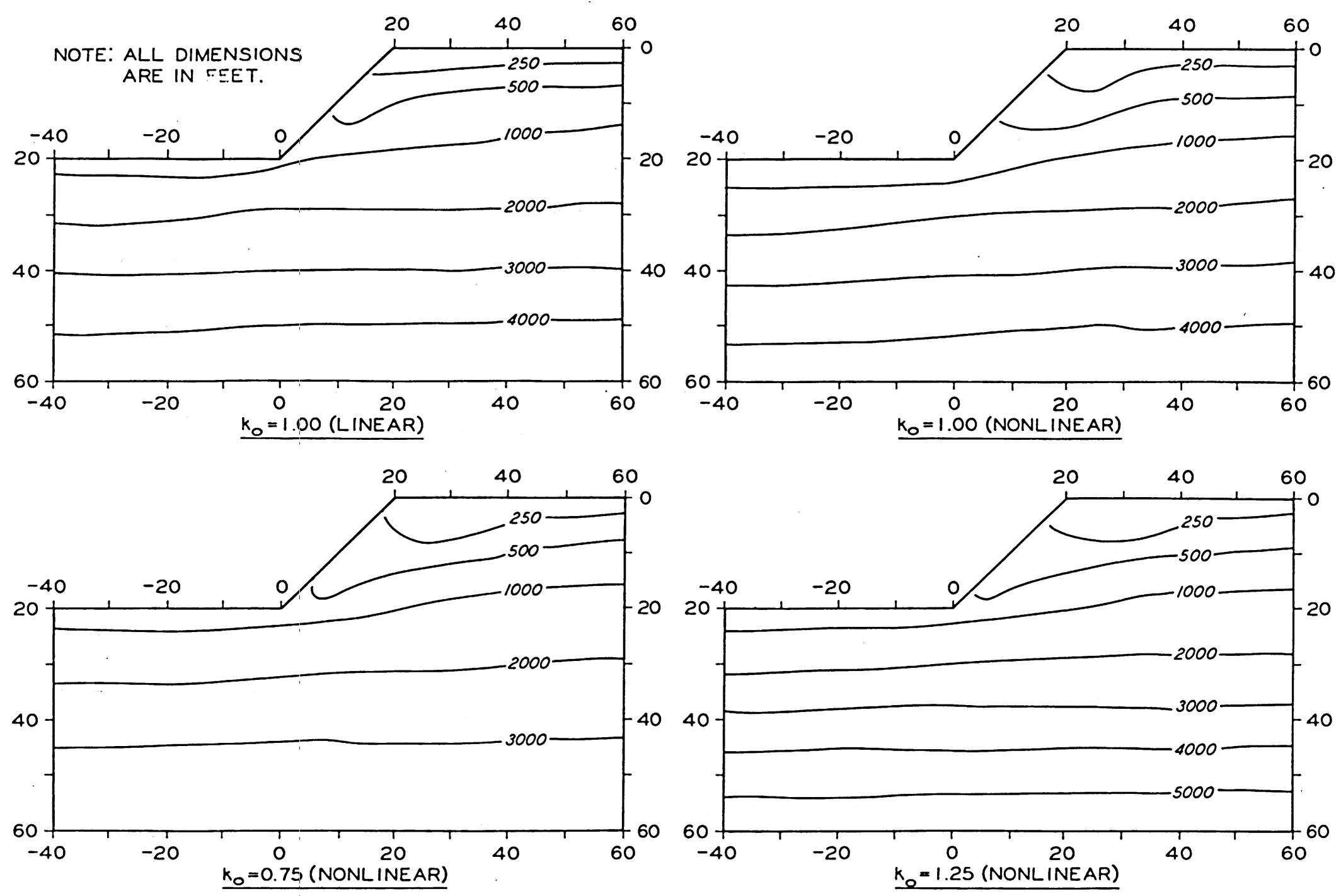

Fig. 15. Horizontal stresses, 1b/sq ft (embankment) 

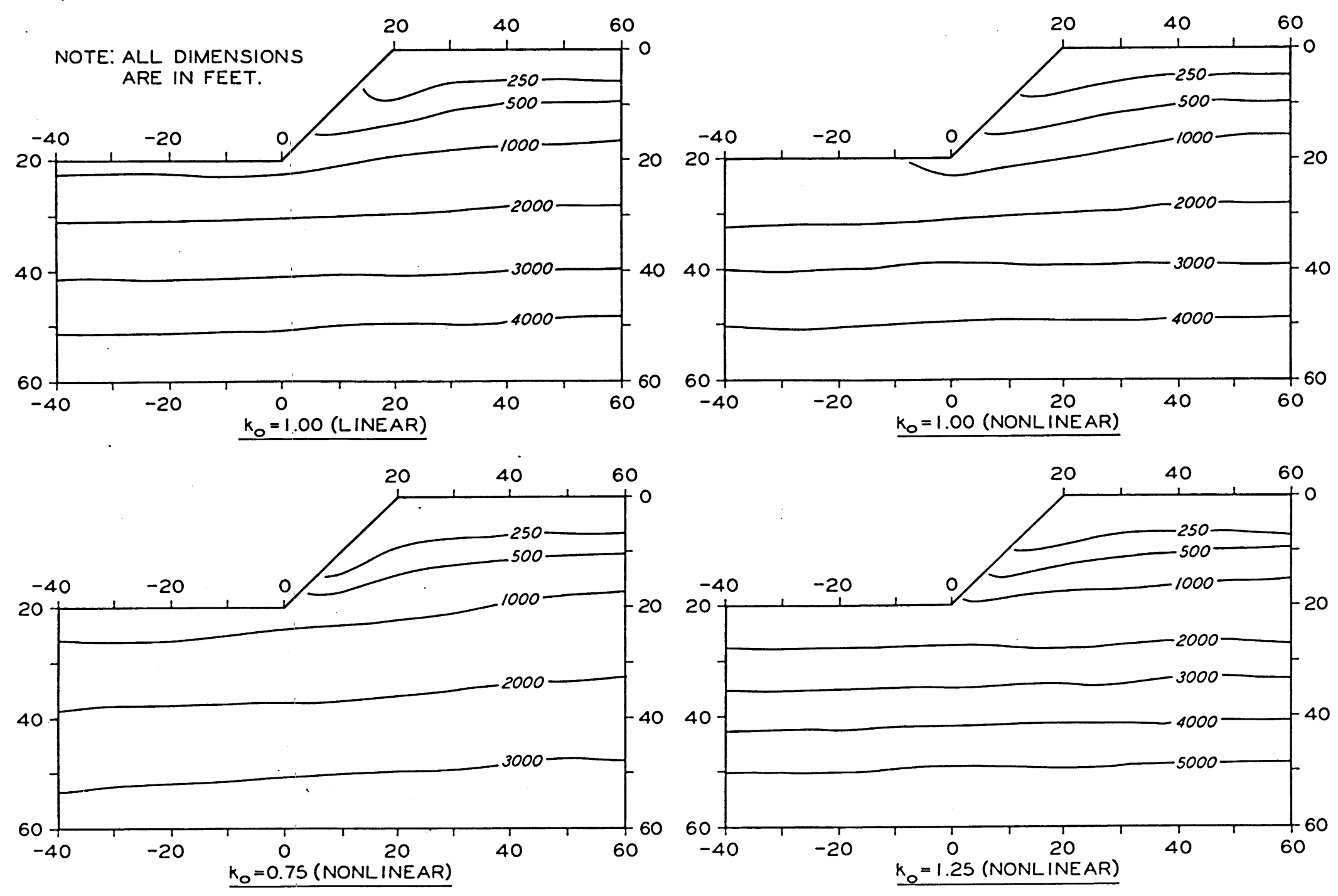

Fig. 16. Horizontal stresses, lb/sq ft (excavation) 
layer as it is placed in the embankment.

44. Vertical stresses. Contours of vertical stress for the embankment cases (fig. 17) and the excavation cases (fig. 18) indicate little difference between any of the examples. The vertical stresses are most sensitive to the value of $\gamma \mathrm{h}$, and since the unit weight was constant for all cases, little difference in results should be expected.

45. Shear stresses. Contours of shear stresses $\tau_{x y}$ for the embankment series (fig. 19) indicate a maximum value of 550 psf for the linear analysis; nonlinear analyses showed a smaller maximum value of $\tau_{x y} \cdot$ The location of the maximum value of $\tau_{x y}$ occurred close to the toe of the slope for the linear case, but was located approximately $15 \mathrm{ft}$ below the toe for the nonlinear cases. Contours of shear stress $\tau_{x y}$ for the excavation cases ( $f i g$. 20) indicate the maximum value occurred for the nonlinear analysis with $\mathrm{k}_{0}=1,\left(\tau_{\mathrm{xy}}=456 \mathrm{psf}\right)$. The linear analysis predicts the point of maximum value of $\tau_{x y}$ to be nearer to the toe of the slope than nonlinear analysis; nonlinear analyses indicate that the points of maximum shear stress are located at 15 to $20 \mathrm{ft}$ below the toe. Although the largest value of shearing stress occurred for a nonlinear case, the linear analysis gave considerably higher values in the vicinity of the toe of the slope.

46. Principal stress difference. Contours of principal stress differences (twice the maximum shear stresses) are shown in fig. 21 for the embankment series and in fig. 22 for the excavation series. For the linear analysis of the embankment (case 1), high principal stress differences are created immediately beneath the toe of the slope. The nonlinear analyses indicate a large reduction in the magnitude of the principal stress difference and further cause the maximum values to be located deeper within the base of the slope. The distribution of principal stress difference varies greatly depending upon the value of the initial state of stress. The maximum principal stress difference for the linear analysis of the excavation problem (case 5) occurs, as in the embankment problem, at the toe of the slope; however, the value of the maximum principal stress difference is reduced from 1200 to $1000 \mathrm{psf}$. As in the embankment cases, the nonlinear analysis caused a radical redistribution of principal stress difference, 

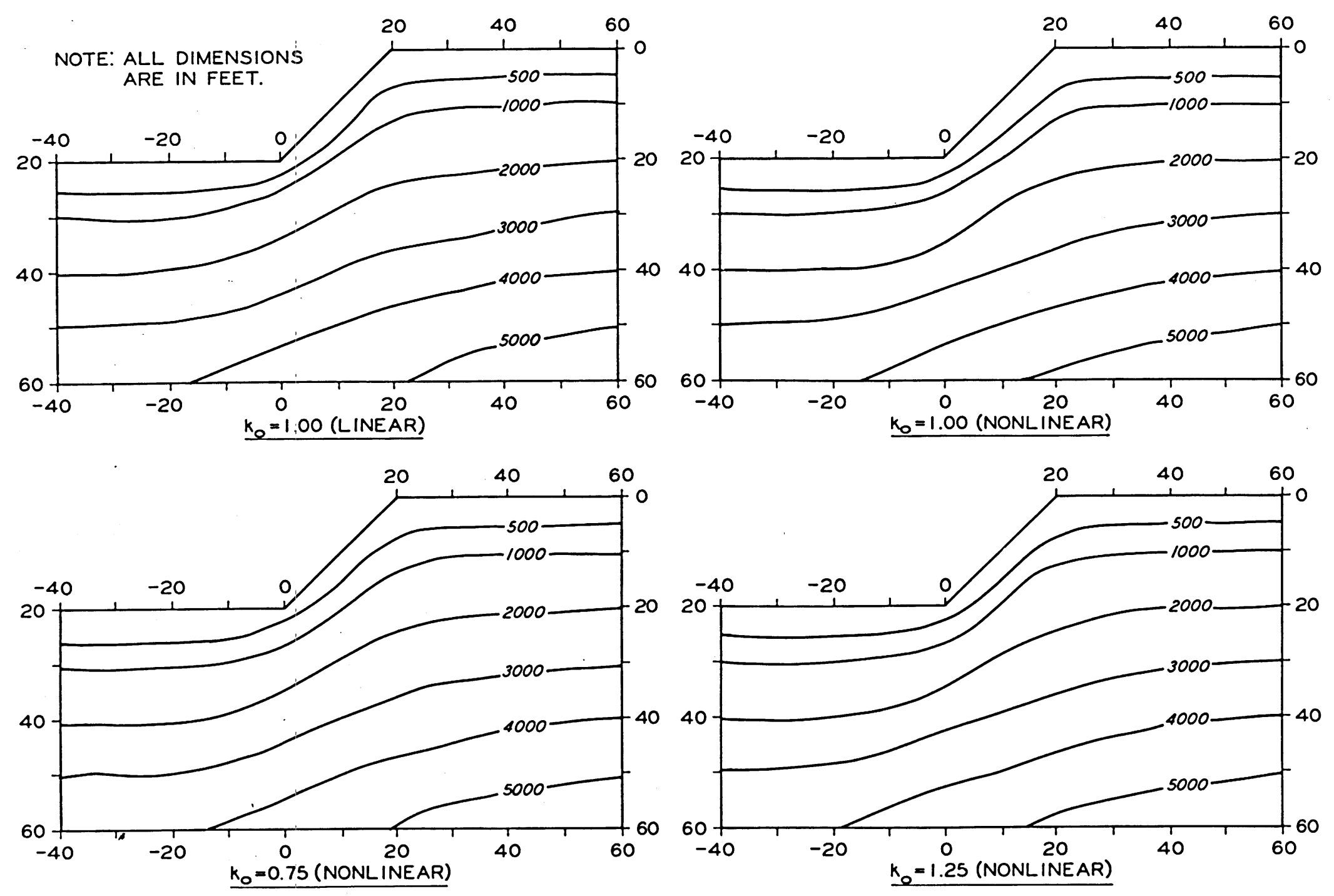

Fig. 17. Vertical stresses, Ib/sq ft (embankment) 

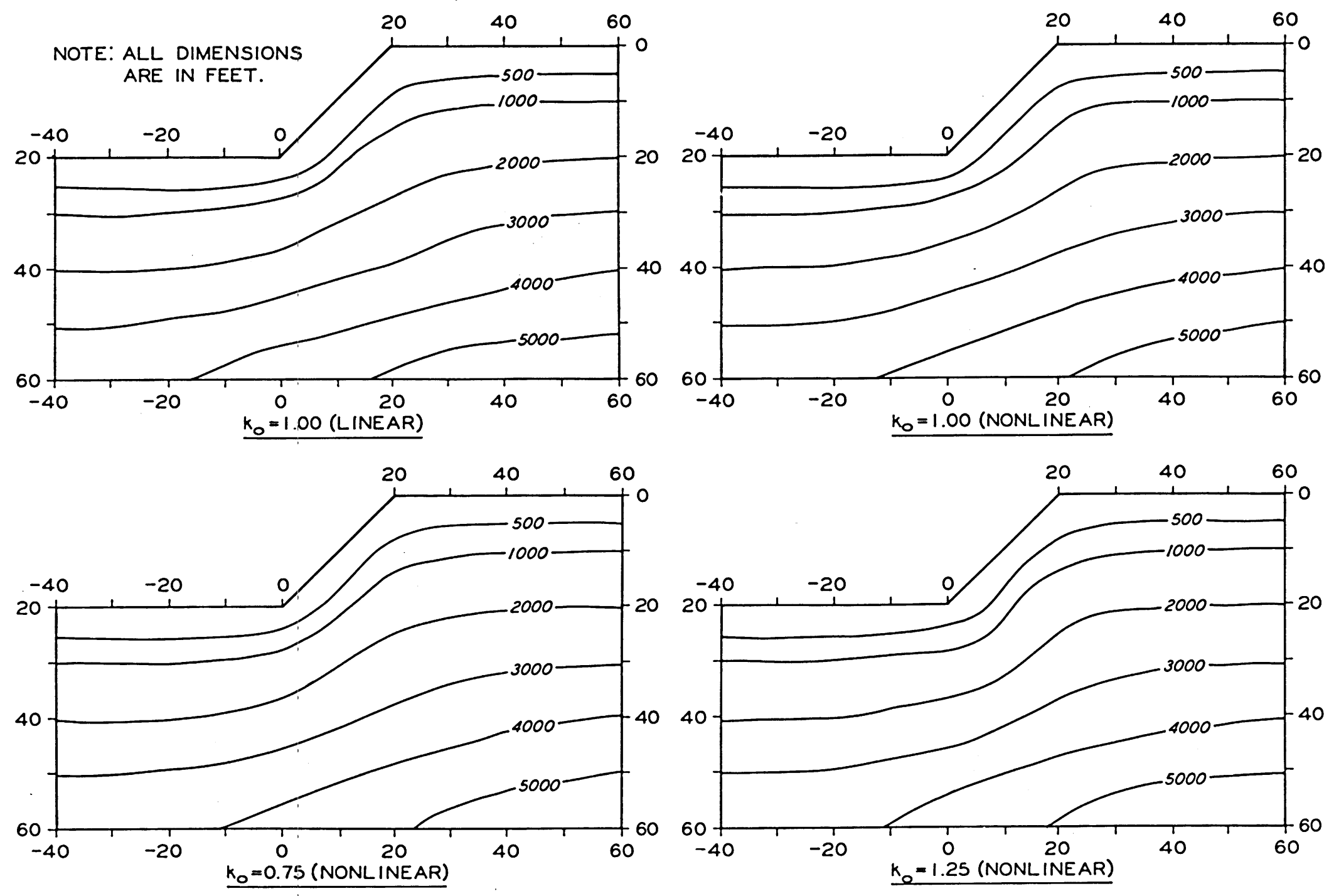

Fig. 18. Vertical stresses, Ib/sq ft (excavation) 

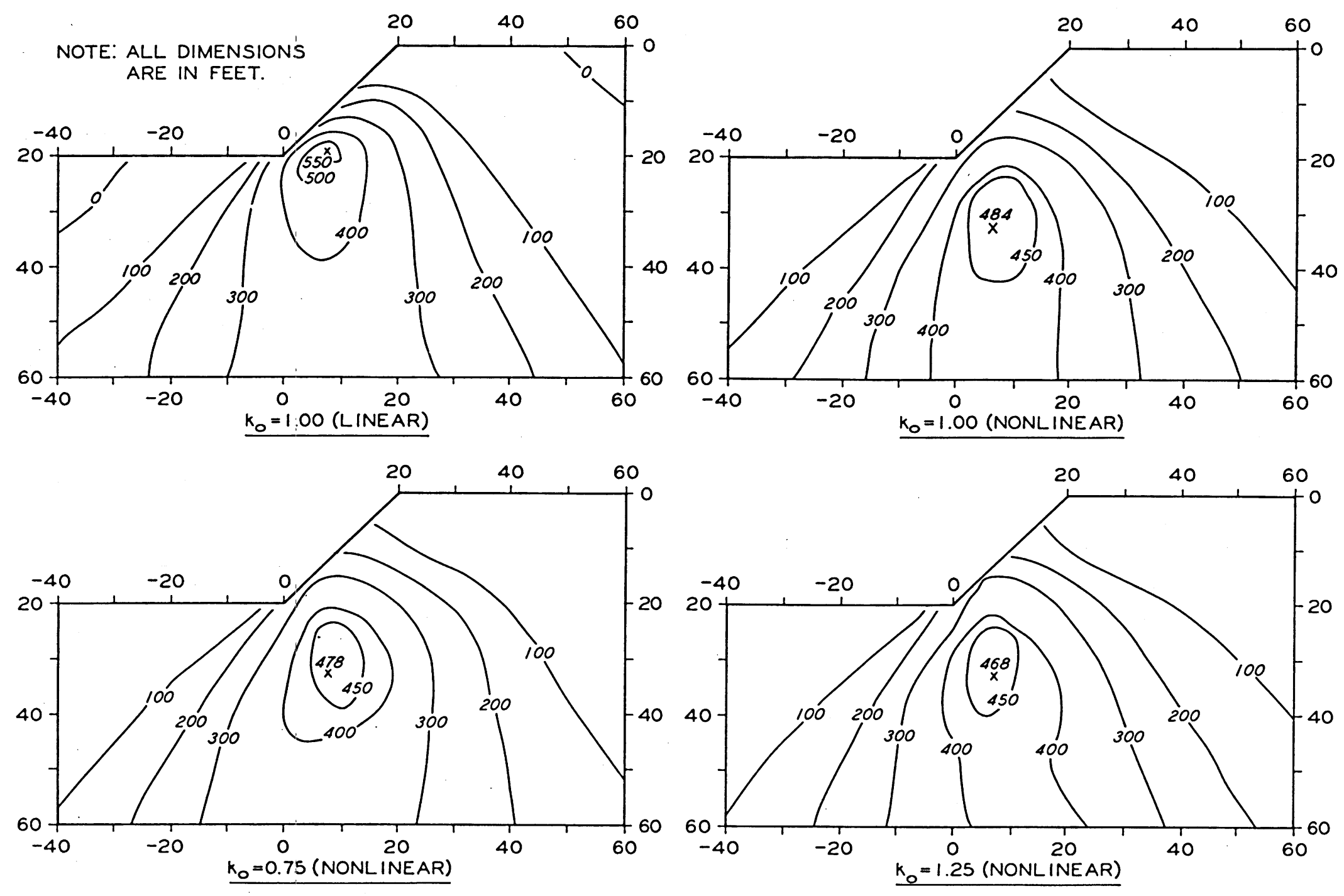

Fig. 19. Shearing stresses, lb/sq ft (embankment) 

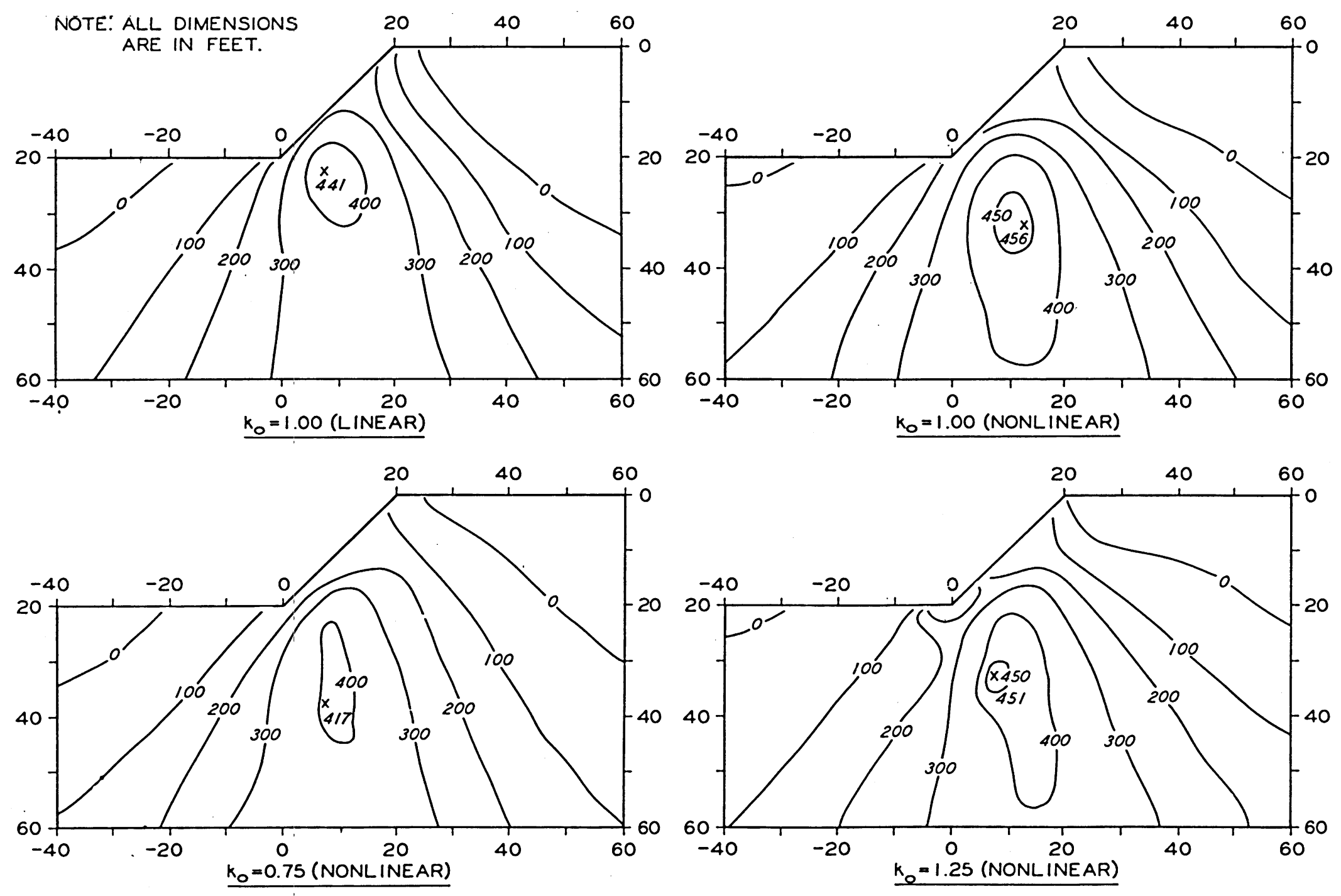

Fig. 20. Shearing stresses, $\mathrm{lb} / \mathrm{sq}$ ft (excavation) 

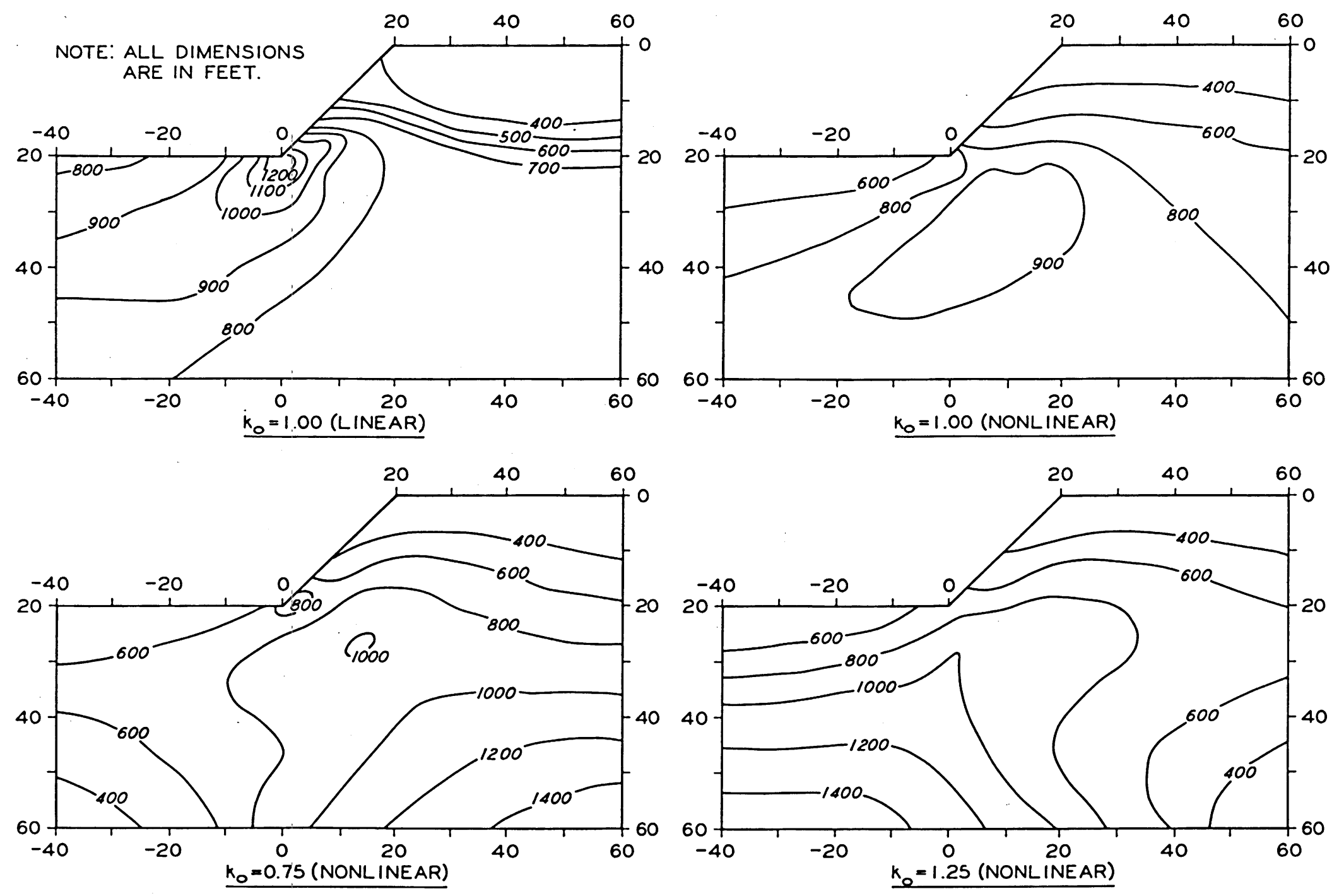

Fig. 21. Principal stress difference (embankment) 

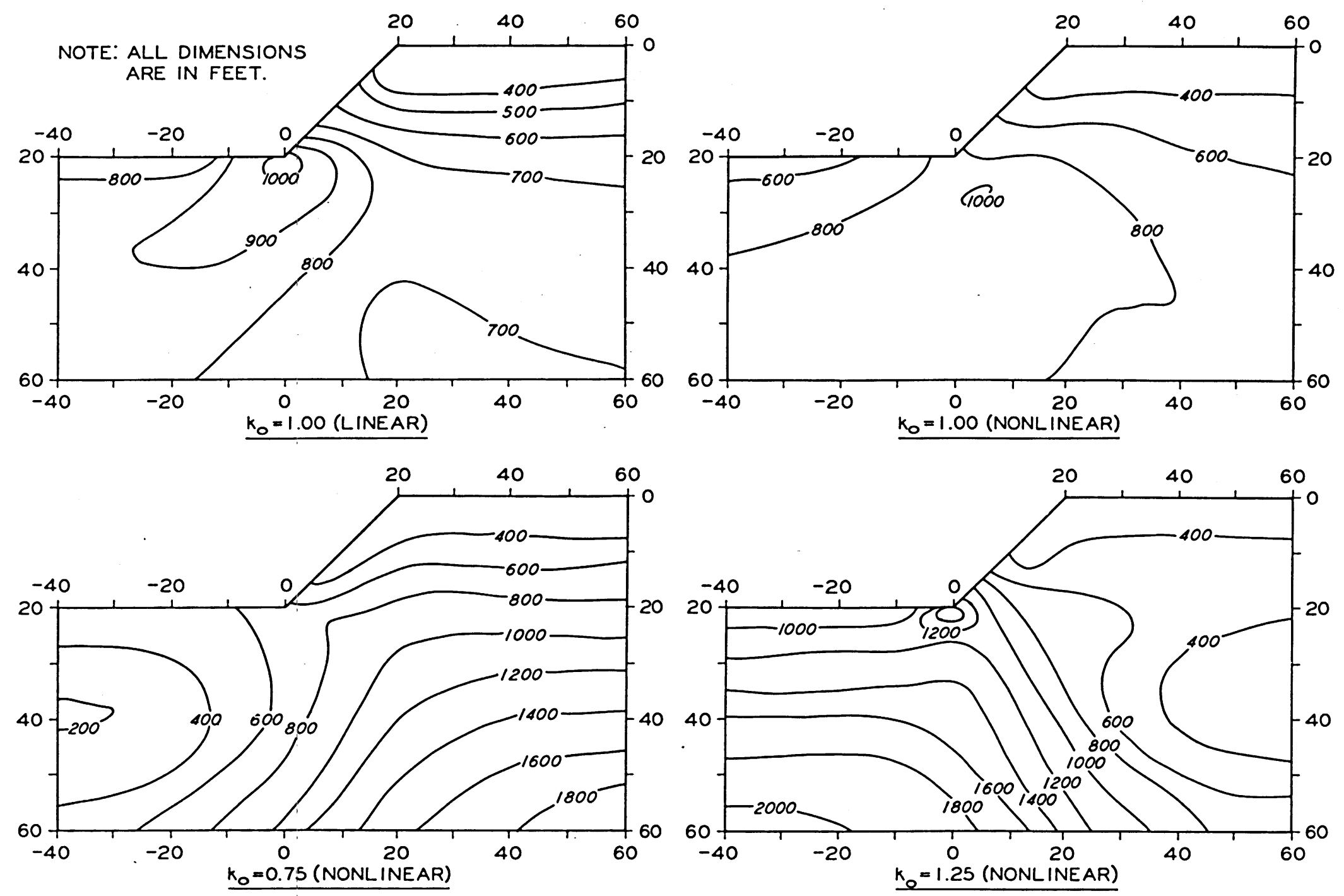

Fig. 22. Principal stress difference (excavation) 
but rather than reducing the values near the toe for all cases, the use of a high $\mathrm{k}_{\mathrm{o}}$ (i.e., $\sigma_{\mathrm{h}} / \sigma_{\mathrm{v}}=1.25$ ) caused a magnification of the stress difference at the toe.

Mobilization factors

47. Mobilization factors were determined from the stress differences using equation 17. Contours of the mobilization factor are shown for the embankment series in fig. 23 and for the excavation series in fig. 24 . Contours for linear analyses (cases 1 and 5) were determined by dividing the stress differences by the strength as determined by equation 25 using $c=200 \mathrm{psf}$ and $\phi=20 \mathrm{deg}$. The linear analyses show high mobilization factors in the vicinity of the toe of the slope since no reduction in modulus and redistribution of stresses is possible. The nonlinear analysis allows for a redistribution and limits the mobilization to 100 percent (except for small amount of overshoot when progressing along the stress-strain curve). The benefit from the nonlinear analyses is shown in fig. 23 where it is seen that at no point is the strength exceeded. Nonlinear analyses of the embankment cases show that larger volumes of the material are more highly stressed. For example, the 50 percent contour encompasses a much larger volume than was shown for the linear analysis. Fig. 23 also shows that the mobilization factors in the vicinity of the toe for nonlinear analyses are not influenced to a large extent by the value of $k_{0}$. 48. For the nonlinear analyses of the excavation series, fig. 24 , the mobilization factors were greatly reduced near the toe of the slope. Values were less than 100 percent except for the case of $k_{0}=1.25$ where some 10 percent overshoot in a zone immediately below the surface was experienced. For the case of excavation, the initial state of stress is shown to have a profound influence on the distribution of mobilization factors. For $k_{0}=0.75$ (i.e., $\sigma_{h}<\sigma_{v}$ ), at no point does the mobilization factor reach 100 percent or failure. At $k_{0}=1.00$ (i.e., $\sigma_{h}=\sigma_{v}$ ), a small zone at the toe of the slope failed, and for $k_{j}=1.25$ (i.e., $\left.\sigma_{\mathrm{h}}>\sigma_{\mathrm{v}}\right)$, the failed zone occupies a significant portion of the lower half of the slope and the surface beyond the toe of the slope. Orientation of major principal stresses

49. The orientations of the major principal stresses are shown in 

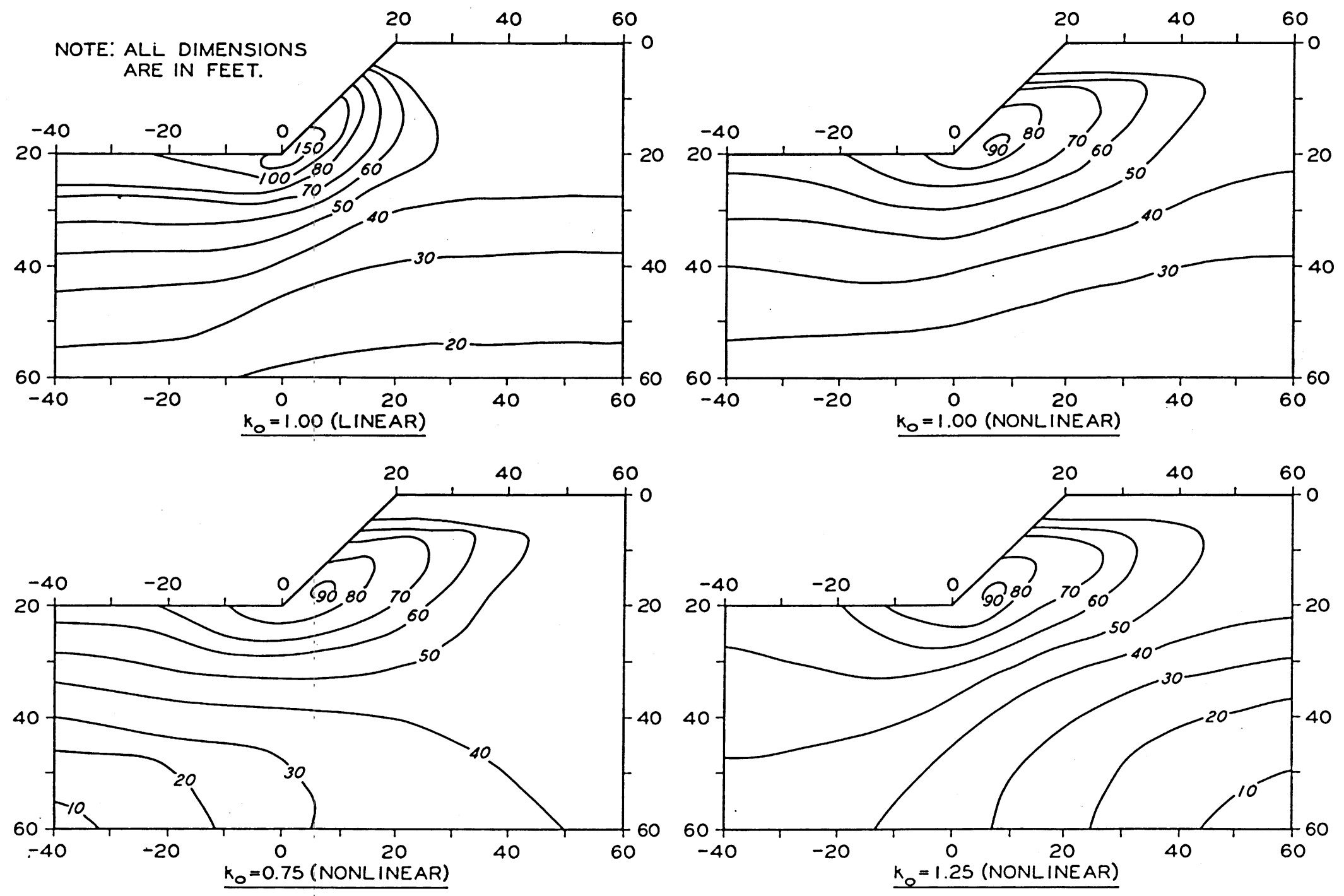

Fig. 23. Mobilization factor contours, percent (embankment) 

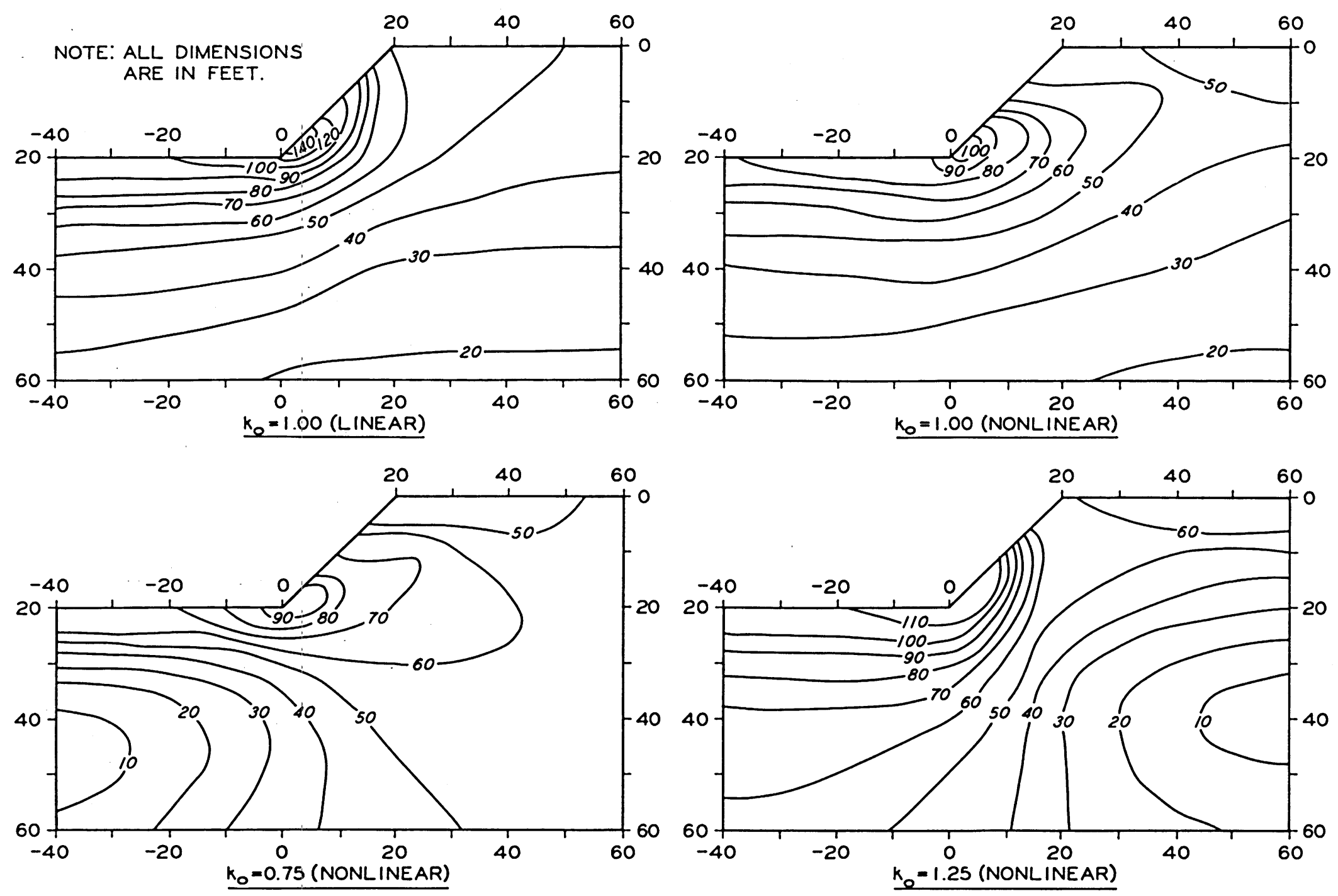

Fig. 24. Mobilization factor contours, percent (excavation) 
fig. 25 for the embankment series and in fig. 26 for the excavation series. If the excavation and embankment cases are compared for the same values of $\mathrm{k}_{\mathrm{o}}$, no appreciable difference in orientation is apparent. However, for cases in which $k_{0}=1.25$ (cases 4 and 8), initially the major principal stresses were horizontal (i.e., $\sigma_{1}=\sigma_{h}$ ); as a result, the direction of the major stresses tends to remain more horizontal than for the other cases.

\section{Significance of Analyses}

50. The preceding discussion and plots illustrate the application of the finite element method and the computer program developed at WES for analyses of simple slopes. The examples illustrate the different results obtained when a nonlinear analysis is performed, as opposed to a linear elastic analysis, and the influence of different initial states of stress for an embankment and an excavation of the same dimensions. The examples represent but a small sampling of possible variables that can be investigated by the method. For example, in a practical problem, layers or zones of material with dissimilar unit weights, strength, and nonlinear parameters, i.e., $K, n$, may exist in addition to different in situ states of stress and final geometry, all of which are amenable to finite element analysis.

\section{Interpretation of Results for Factors of Safety}

51. The stress distribution or mobilization factors are significant additionally since proper interpretation allows a determination of the factor of safety of the slope. The mobilization factor is, by definition, the ratio of the principal stress difference existing in the material to the maximum principal stress difference consistent with the strength of the material. By extension of the definition, i.e.,

$$
\text { Mobilization factor }=\frac{\left(\sigma_{1}-\sigma_{3}\right)}{\left(\sigma_{1}-\sigma_{3}\right)_{f}}=\frac{\left[\left(\sigma_{1}-\sigma_{3}\right) / 2\right]}{\left[\left(\sigma_{1}-\sigma_{3}\right) / 2\right]_{f}}
$$



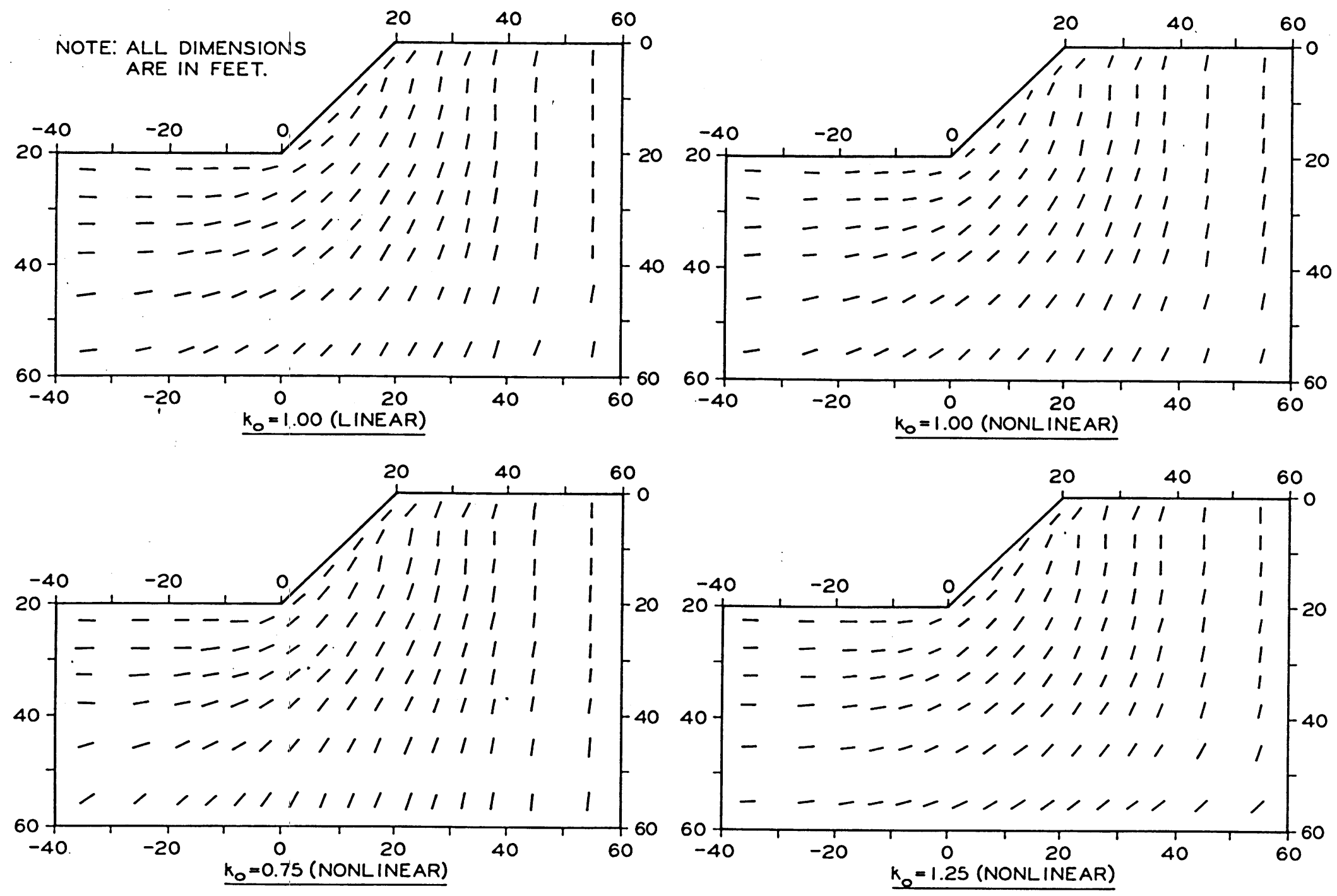

Fig. 25. Orientation of major principal stress (embankment) 

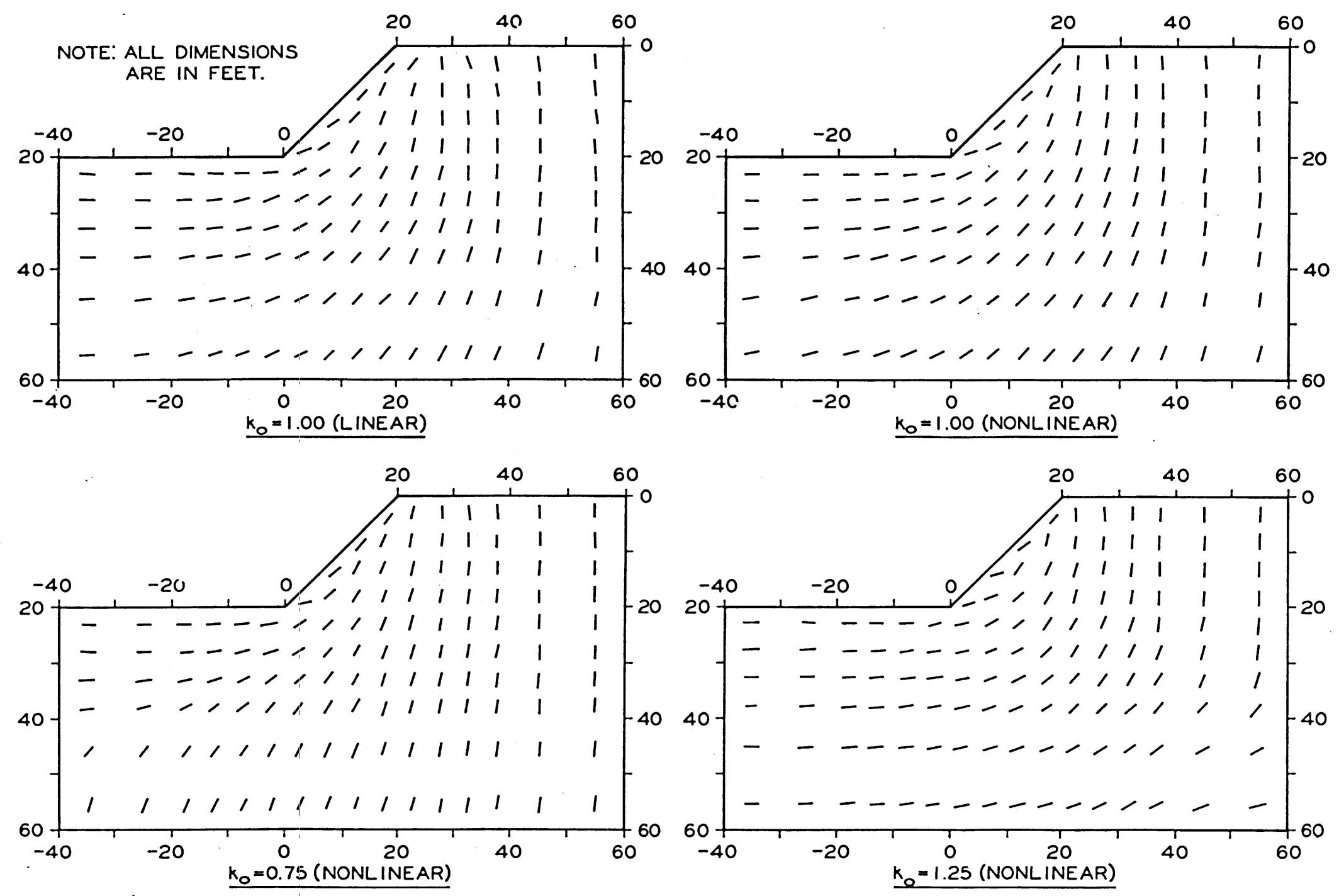

Fig. 26. Orientation of major principal stress (excavation) 
the mobilization factor is shown to equally define the ratio of the maximum shear stresses. Thus the mobilization factor can be thought of as a measure of the reciprocal factor of safety at a point:

$$
(f s)_{0}=\frac{I}{M}=\frac{\left(\sigma_{1}-\sigma_{3}\right)_{f}}{\left(\sigma_{1}-\sigma_{3}\right)}=\frac{2 c \cos \phi+\left(\sigma_{1}+\sigma_{3}\right) \sin \phi}{2 \tau_{\max }}
$$

This concept can be extended to an average factor of safety by

$$
F S_{s l}=\frac{\int_{a}^{b}(f s)_{0} d s}{\int_{a}^{b} d s}=\frac{\sum_{i=1}^{n}(f s)_{o i} \Delta s_{i}}{\sum_{i=1}^{n} \Delta s_{i}}
$$

where the point factor of safety for maximum shear stress is summed along a portion $\Delta S$ of the surface $\overparen{\mathrm{ab}}$. This definition of factor of safety has been termed the factor of safety with respect to the stress level or factor of safety with respect to local failure; ${ }^{20}$ an investigation of the implications of such a factor of safety is described in reference 20 .

52. In some applications, it may be expedient to view the results of finite element solutions in terms of the factor of safety with respect to the stress level, e.g., studies of critically stressed regions within a material in which progressive failure is possible. However, for purposes of studying overall stability or for comparison with conventionally defined factors of safety, the finite element solution should be viewed with respect to shear stress magnitudes. In conventional equilibrium procedures for assessing the stability of a slope, the minimum ratio of the available shear strength to the actual shear stress along some path is sought, i.e.,

$$
F S=\frac{\int_{a}^{b}\left(c+\sigma_{n} \tan \phi\right) d s}{\int_{a}^{b} \tau d s}=\frac{\sum_{i=1}^{n}\left(c+\sigma_{n} \tan \phi\right)_{i} \Delta s_{i}}{\sum_{i=1}^{n} \tau_{i} \Delta s_{i}}
$$


where

$\sigma_{\mathrm{n}}$ and $\tau=$ normal and shear stresses, respectively, along a portion $\Delta S$ of the surface $\overparen{a b}$

53. For materials possessing a frictional strength component, shear failure does not occur along the plane of maximum shearing stress ( $45 \mathrm{deg}$ from the plane of major principal stress) as tacitly assumed when determining the factor of safety with respect to stress level. Rather failure occurs along planes oriented at angles of $\pm 45-\phi / 2$ from the direction of the major principal stress as illustrated in fig. 27. If a given arc $\overparen{a b}$ through a slope is chosen such that at every point the inclination is oriented at $\phi / 2$ to the plane of maximum shear then the relationship between the factor of safety with respect to shear stresses and the factor of safety

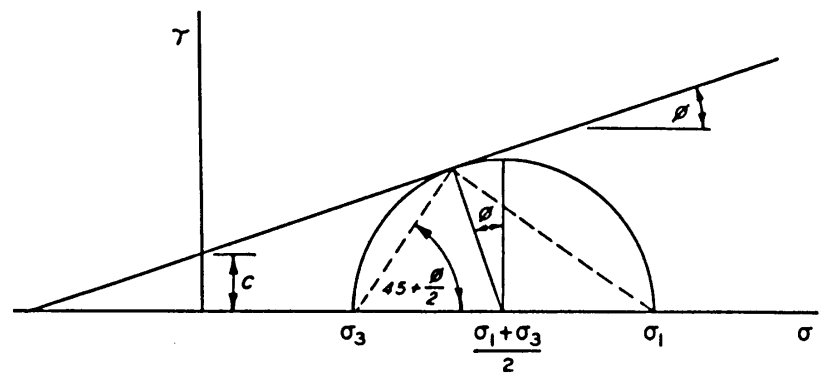
with respect to stress level is given by ${ }^{20}$

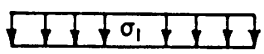

$F S_{S 1}=\frac{\left(F S^{2}+\tan ^{2} \phi\right)^{1 / 2}-\tan \phi}{\left(1+\tan ^{2} \phi\right)^{1 / 2}-\tan \phi}$

General guidance in positioning critical surfaces can be obtained by constructing lines $\pm 45-\varnothing / 2$ to the direction of the major principal stresses illustrated in figs. 25 and 26. However, since it is not always possible to draw an arc with such favorable inclina-

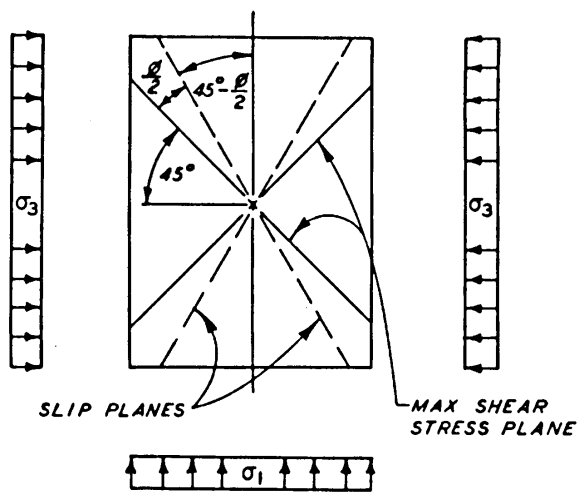

Fig. 27. Mohr-Coulomb diagram and orientation of slip planes tions at all points, the factor of safety with respect to shear stresses will generally fall above that predicted by equation 51 . In some cases, FS can be greater than $\mathrm{FS}_{\mathrm{Sl}}$. Although the smallest possible values of FS can be calculated from equation 51, the actual value of FS for a given surface $\widehat{\mathrm{ab}}$ should be determined by summing the normal and 
tangential stresses along the surface in accordance with equation 50. The process is repeated for various trial slip surfaces until a minimum factor of safety with respect to shear stresses is found for the slope.

Factors of safety from limit equilibrium analyses

54. The subject of the best or most applicable method of limit equilibrium analysis for determining slope stability or factors of safety for slopes was studied in depth by Wright. 21 For the investigation of homogeneous slopes, Wright concluded that Janbu's Generalized Procedure of Slices 22 and Spencer's procedure 23 gave similar results and were probably the most accurate procedures available. The log spiral procedure for conditions of zero pore water pressure gave results equally comparable to Janbu's and Spencer's procedures. For convenience in analyses of simple homogeneous slopes, Wright presented stability charts for the log spiral method from which the factor of safety could be determined directly. The chart is in a form similar to Janbu 24,25 in that a stability number $N_{c f}$ is determined uniquely from a dimensionless parameter $\lambda_{c} \varnothing$ and the slope inclination. The value of $\lambda_{c \phi}$ is determined for a given problem by calculating the value of $(\gamma \mathrm{H} \tan \phi) / c$ where $\gamma$ is the unit weight of the material, $H$ is the slope height, $c$ is the cohesion, and $\varnothing$ is the angle of internal friction. Once the value of $N_{c f}$ is determined from the chart, the factor of safety is calculated from

$$
\mathrm{FS}=\mathrm{N}_{\mathrm{cf}} \frac{\mathrm{c}}{\gamma \mathrm{H}}
$$

55. Evaluation of the factor of safety by the log spiral method for the simple homogeneous slope geometry used in the cases illustrated previously was made for the following conditions:

$\begin{array}{ll}\text { Final height of slopes } & 20 \mathrm{ft} \\ \text { Slope inclination } & 45 \mathrm{deg} \\ \text { Unit weight } & 100 \mathrm{pcf} \\ \text { Cohesion } & 200 \mathrm{psf} \\ \text { Angle of internal friction } & 20 \mathrm{deg}(\tan \varnothing=0.364)\end{array}$

A minimum factor of safety of 1.27 was calculated. The failure surface 
passes through the toe of the slope, but the radius or exit point of the failure arc cannot be determined from the charts presented.

56. The Modified Swedish Method as described in the U. S. Army Corps of Engineers Manual on Stability of Earth and Rock-fill Dams ${ }^{26}$ was used to obtain the minimum factor of safety for a slope of the geometry and properties previously presented. In this method, side forces on individual slices are assumed to act parallel to the average slope of the embankment. This assumption causes somewhat higher factors of safety to be calculated than from the log spiral method, particularly if the dimensionless parameter $\lambda_{c \varnothing}$ is less than approximately $5 .^{21}$ When applied to the present problem, a minimum factor of safety of 1.33 was determined. The critical surface was determined to have a radius of $36.2 \mathrm{ft}$ and to intersect the surface of the problem at the toe of the slope and $8.5 \mathrm{ft}$ behind the crest.

57. The above limit equilibrium analyses establish a range in factors of safety that could reasonably be expected from conventional means. In the conventional analyses by Janbu's, Spencer's, or the log spiral method, moment and force equilibrium are required to obtain a correct solution. These conditions of equilibrium are expressed as part of the equations to be satisfied but are obtained by trial-and-error assumption until a reasonable distribution of forces (stresses) is obtained. Once reasonable choices are made, the factor of safety is relatively insensitive to changes in the distribution of forces. 27 since the finite element method calculates a state of stress which is in equilibrium, factors of safety calculated from finite element results should be compared with the results of limit equilibrium methods to establish the relationships between the two approaches.

Factors of safety from finite element analyses

58. A computer program was developed to determine factors of safety using the stresses calculated from the finite element method. A trial surface of any shape is specified by a series of points along the surface, with additional information concerning the angle from the horizontal to the tangent of the trial surface at the points. The state of stress $\left(\sigma_{x}, \sigma_{y}, \tau_{x y}\right)$ as determined by the finite element programs is then 
specified at the coordinates of the element centers at which they act. The state of stress at the specified points along the trial surface is then interpolated according to equation of the type

$$
\sigma_{e}=A+B x_{e}+C_{e}+D x_{e} y_{e}
$$

where

$$
\begin{aligned}
\mathrm{x}_{\mathrm{e}} \text { and } \mathrm{y}_{\mathrm{e}}= & \text { coordinates at the center of element } \mathrm{e} \\
\mathrm{A}, \mathrm{B}, \mathrm{C} \text {, and } \mathrm{D}= & \text { constants determined by substituting the coordinates } \\
& \text { and stresses of the four element centers closest to } \\
& \text { a point on the failure surface }
\end{aligned}
$$

By the simultaneous solution of the four equations, values are determined for the constants A, B, C, and D, and thus the stress at the point on the failure surface can be calculated. The process is repeated until the state of stress $\left(\sigma_{x}, \sigma_{y}\right.$, and $\left.\tau_{x y}\right)$ is determined at each point along the trial surface. The shear and normal stresses acting along the surface at each point are calculated by suitably accounting for the tangent to the surface at the point. The average strength along the arc may then be found by summing the product of the unit strength at each point times the distance over which it acts, divided by the total length of arc $\mathrm{S}$, i.e.,

$$
\text { Average strength }=\frac{\sum_{i=1}^{n}\left(c+\sigma_{n} \tan \phi\right)_{i} \Delta s_{i}}{s}
$$

The average shearing stress along the arc is

$$
\text { Average shear stress }=\frac{\sum_{i=1}^{n} \tau_{i} \Delta s_{i}}{s}
$$

The factor of safety can then be determined by substituting into equation 50. The computer program developed to determine the factor of safety from stresses determined in the finite element program is contained in Appendix $B$.

59. Although the program can search for a minimum factor of safety, 
comparisons of the factors of safety were made for the critical arc given by the Modified Swedish Method, fig. 28. The factor of safety by the log

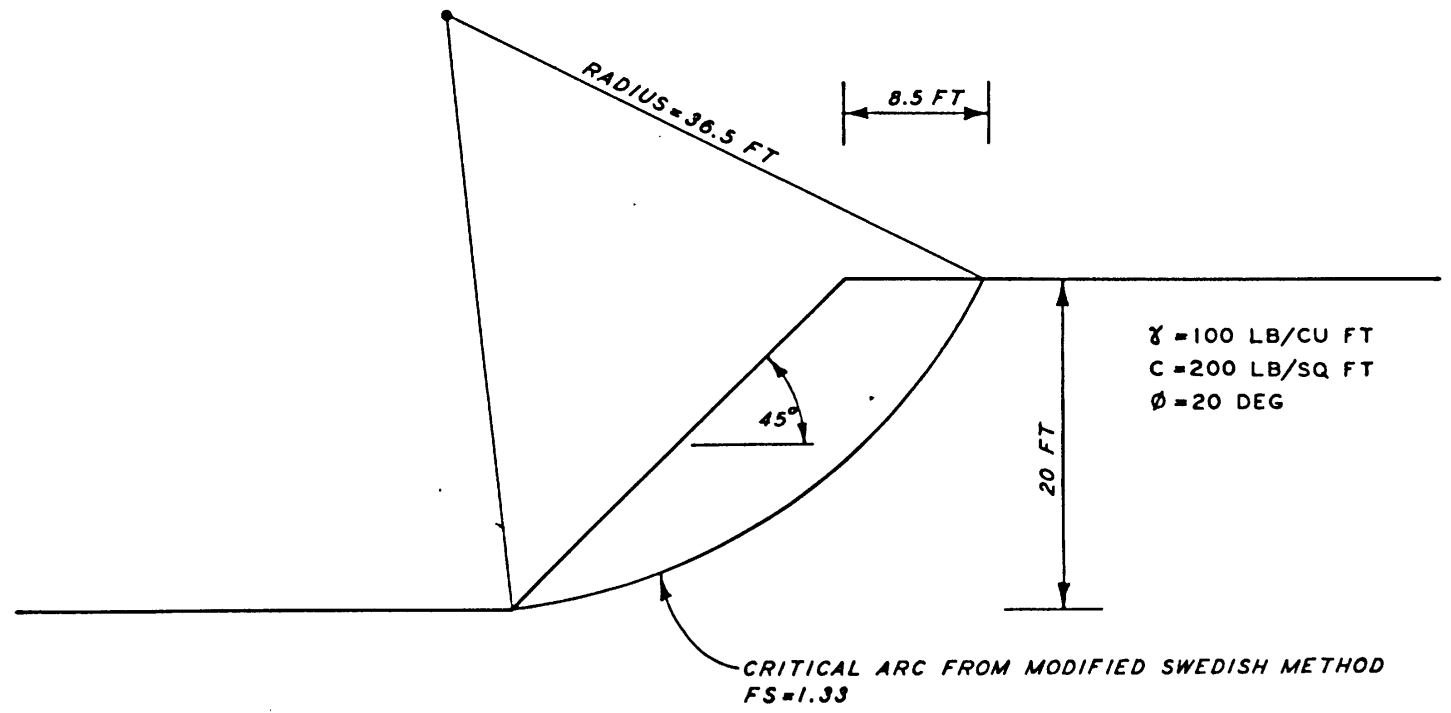

Fig. 28. Critical failure arc for simple slope

spiral method for the slope geometry and material properties illustrated in fig. 28 was 1.27; the Modified Swedish Method gave a factor of safety of 1.33 for the critical arc. The following tabulation shows the values of the factor of safety with respect to stress level (FS ${ }_{S I}$ ), the smallest factor of safety with respect to shear stresses consistent with FS $_{\text {SI }}$ (i.e., calculated from equation 51), and the factor of safety calculated from equation 50--all for the arc illustrated in fig. 28.

Type

Construc-

tion

Embankment

$\begin{array}{ll}1 & \text { Linear } \\ 2 & \text { Nonlinear } \\ 3 & \text { Nonlinear } \\ 4 & \text { Nonlinear }\end{array}$

Excavation $\mathrm{k}$ $\underline{\text { Case }} \begin{gathered}\text { Type } \\ \text { Analysis }\end{gathered}$
1.00

1.00

0.75

0.80

1.00
1.00
0.75
1.25

1.00

1.00

0.75

1.25

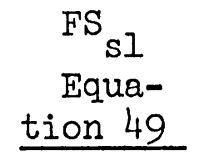

1.22

1.40

1.40

1.45

\begin{tabular}{c} 
FS \\
$\begin{array}{c}\text { Equa- } \\
\text { tion 51 }\end{array}$ tion 50 \\
\hline
\end{tabular}

1.06

1.20

1.20

1.24

1.30

1.37

1.41

1.13
1.38

1.34

1.34

1.36
1.97

2.00

1.77

2.04

8 Nonlinear

0.80

1.53

1.62

1.67

1.31

Note: Factors of safety determined by the log spiral method and the Modified Swedish Method equal 1.27 and 1.33, respectively. 
60. The factor of safety calculated from equation 50 is defined in the same manner as those obtained from limit analyses. As indicated in the preceding tabulation, the factor of safety for the embankment cases using equation 50 agrees closely with those obtained from the limit analyses. The solution for the embankment with linear material properties (case I), as expected, indicated the largest difference. When nonlinear properties were assumed, the factor of safety is approximately equal to the results from the Modified Swedish Method. For the excavation cases, the factor of safety from equation 50 is in poor agreement with the limit analyses. The results indicated in the tabulation are preliminary in that the influences of such variables as grid size or material properties and a search for the potential failure surface exhibiting a minimum factor of safety have not been adequately investigated. The results do indicate the strong effect of the initial state of stress; but, more importantly, they indicate the feasibility of determining the factor of safety of slopes from finite element analyses. 


\section{Description of Problems}

61. In Part IV, the finite element analysis of simple homogeneous slopes was presented. This section describes the application of the nonlinear finite element code to Otter Brook Dam, a rolled earth dam constructed in New Hampshire. 28 A cross section of the 131-ft-high dam is shown in fig. 29. The dam has a crest length of about $1300 \mathrm{ft}$ and is symmetrical

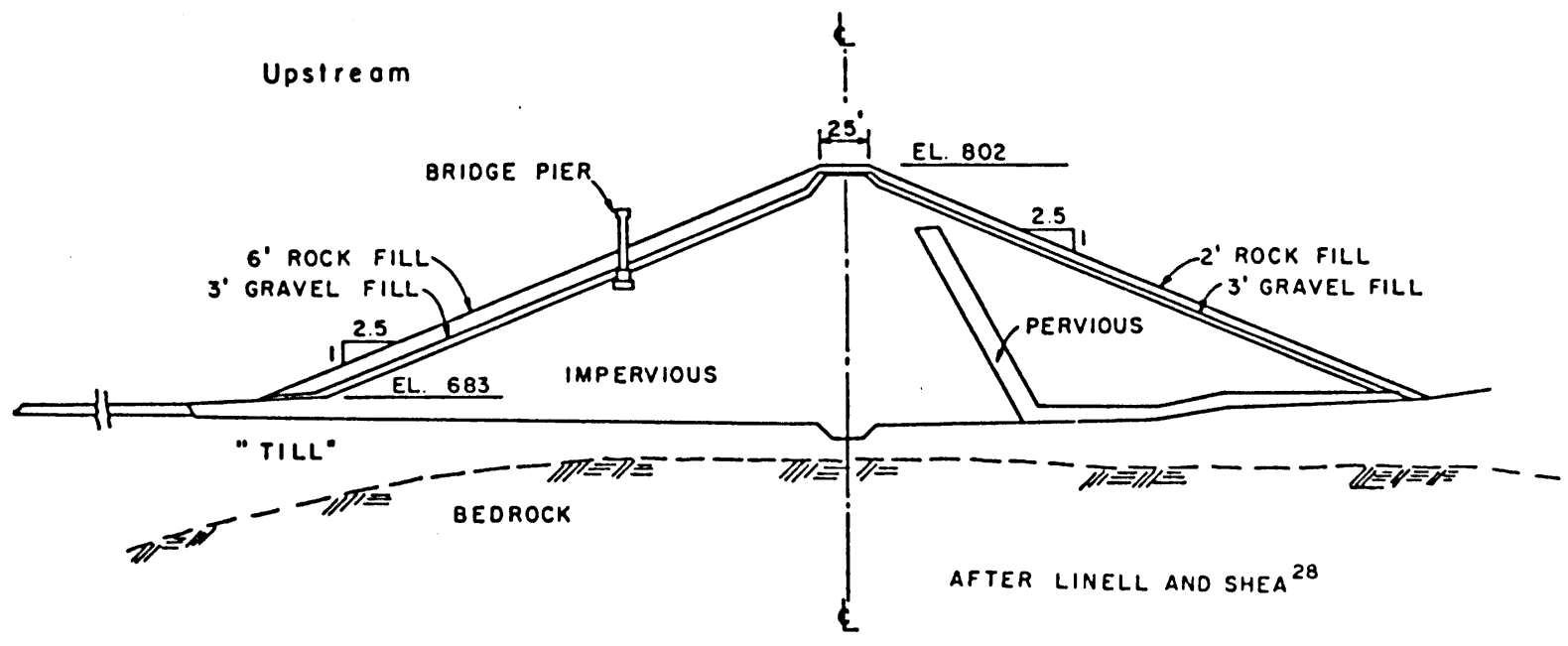

Fig. 29. Cross section of Otter Brook Dam (from reference 20)

about its axis with 2.5-on-1 side slopes. The main portion of the dam was constructed directly on bedrock and consists of well-graded clayey sand (glacial till) with 10 to 20 percent gravel and larger particles.

62. During construction of the dam, the bridge pier shown in fig. 29 tilted and displaced outward. Reference markers were established to monitor further movements. The markers indicated that movements were increasing and construction was halted after completion to approximately one-half the final height of the dam. The stability of the dam following this turn of events was found to be satisfactory and construction was resumed. At the completion of the dam, the upstream face of the dam had bulged outward by more than $3 \mathrm{ft}$. Thus Otter Brook Dam offers an excellent case study for the finite element method. The dam was previously studied with the finite element technique, 20 and the results afford data for comparison with results obtained at WES. 


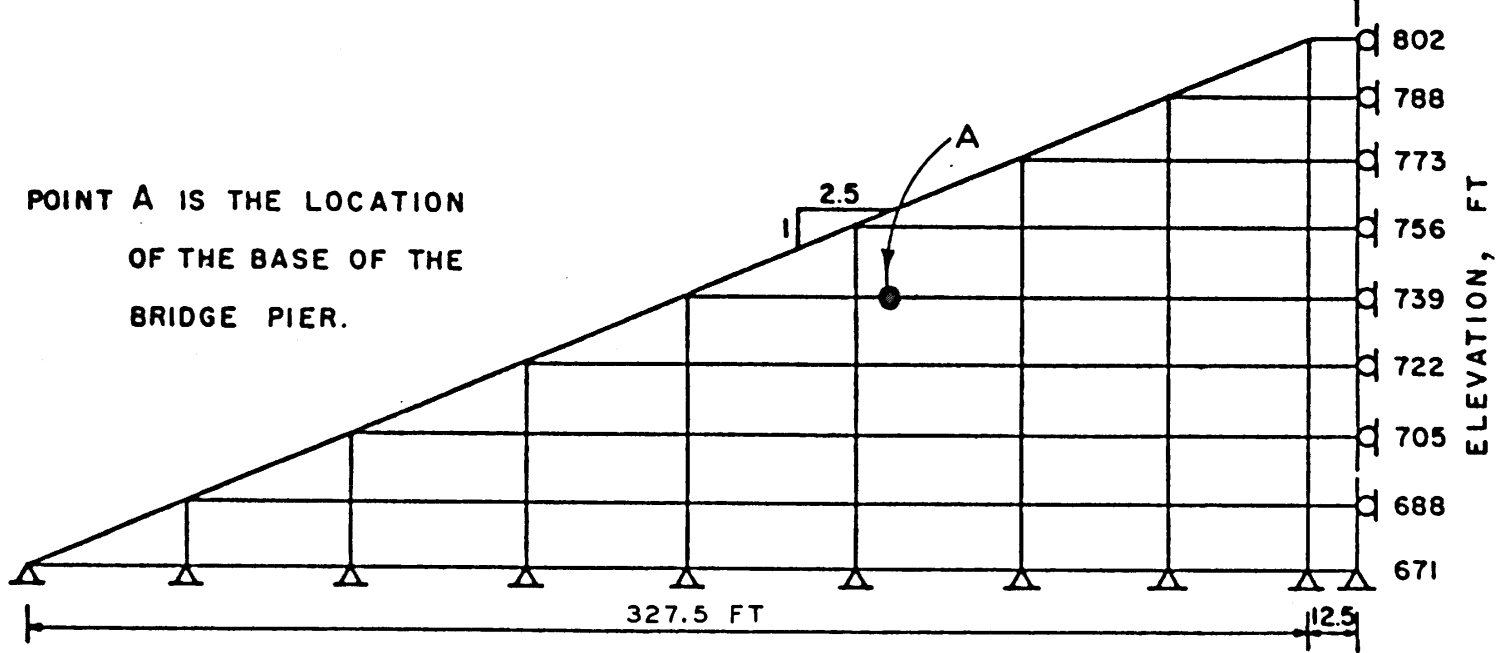

Fig. 30. Finite element grid for WES analysis

63. Fig. 30 shows the grid layout used in the WES analysis. The grid is defined by 54 nodal points and contains 44 elements. Since the dam is symmetrical, only the upstream half of the dam was used in the analysis. Point $\mathrm{A}$ on the grid indicates the location of the bridge pier that moved during construction. The construction of the dam was simulated in the WES analysis using eight layers with eight cycles of iteration for each layer (see paragraphs 31 and 32) to improve the accuracy of the calculations. The nodal points along the center line were not allowed to move in a horizontal direction; the contact between the dam and the rigid base was as sumed to be fixed in such a manner that no horizontal or vertical deformations were allowed.

64. The study described in reference 20 utilized nonlinear, stressdependent, stress-strain properties of the Otter Brook Dam material and inclưded a variâble Poisson's ratio as well as moduli. Additional analyses were made in which:

a. The placement of fill in successive layers was not simulated, but gravity forces were applied simultaneously throughout the entire embankment (gravity turn-on, see paragraph 15). The embankment material was assumed to be linear and homogeneous with respect to values of Poisson's ratio and modulus of elasticity. 
b. The placement of fill in successive layers was simulated, using incremental analysis procedures. The embankment material was again assumed to be linear and homogeneous.

c. The placement of fill in successive layers was simulated, using incremental analysis procedures. The modulus of elasticity was varied in accordance with the calculated values of stress, but the embankment material was assumed to be homogeneous with respect to Poisson's ratio.

The WES analysis involved the material properties and technique used in the analysis procedure $\underline{c}$ above. The material properties of Otter Brook Dam used in the WES analysis are shown in fig. 31 and the following tabulation.

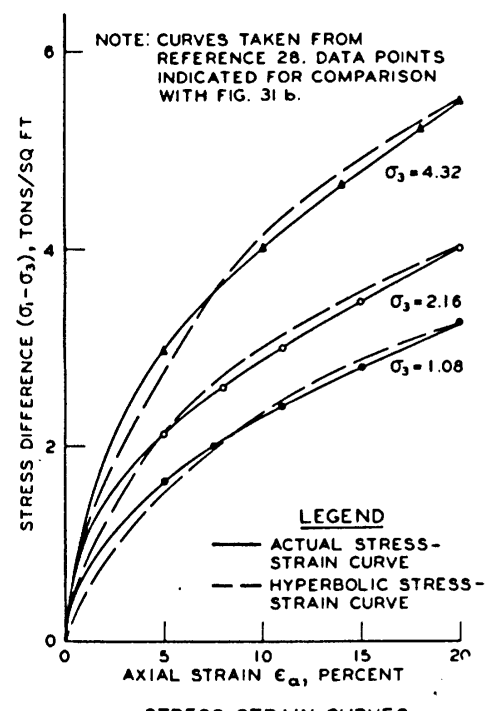

a. STRESS-STRAIN CURVES
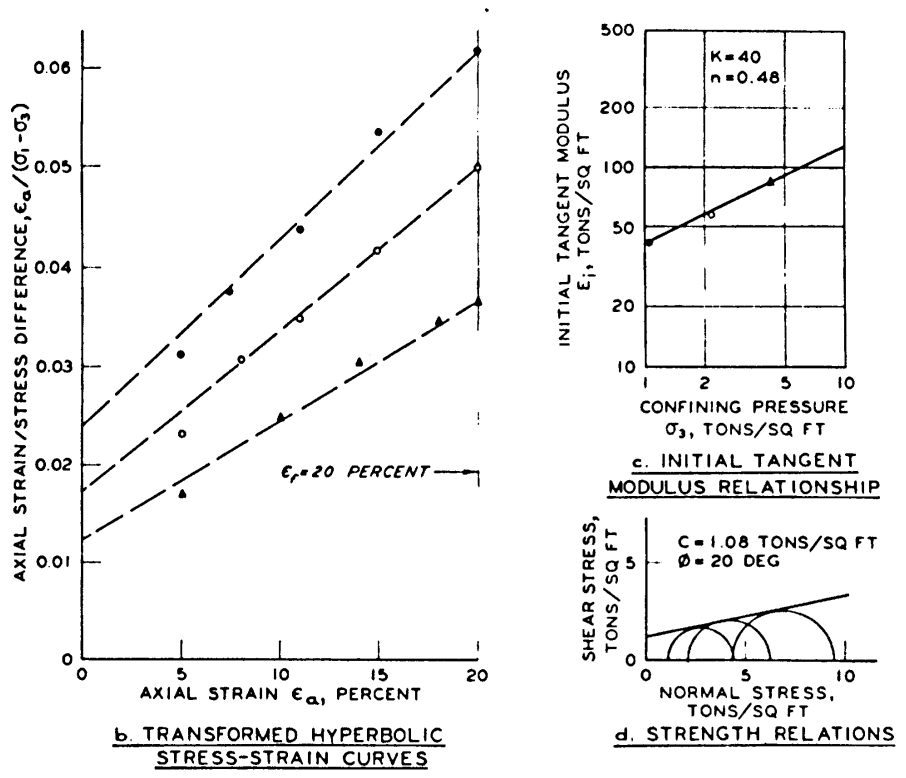

Fig. 31. Unconsolidated-undrained properties for Otter Brook Dam

Parameter

Unit weight, $\gamma$

Cohesion, $c$

Friction angle, $\varnothing$

Modulus number, $\mathrm{K}$

Modulus exponent, $\mathrm{n}$

Poisson's ratio, $v$

Limiting strain, $\epsilon_{f}$
Value

$140 \mathrm{pcf}$
1.08 tons $/ \mathrm{sq} \mathrm{ft}$
$14 \mathrm{deg}$
40 tons $/ \mathrm{sq} \mathrm{ft}$
0.48
0.475
$0.20 *$

* Failure ratio $R_{f}$ of 0.68 used in reference 20; see discussion in paragraph 69. 


\section{Results}

\section{Displacement plots}

65. Fig. 32 shows contours of the final horizontal and vertical displacements within the dam. Results from reference 20 are similar to those
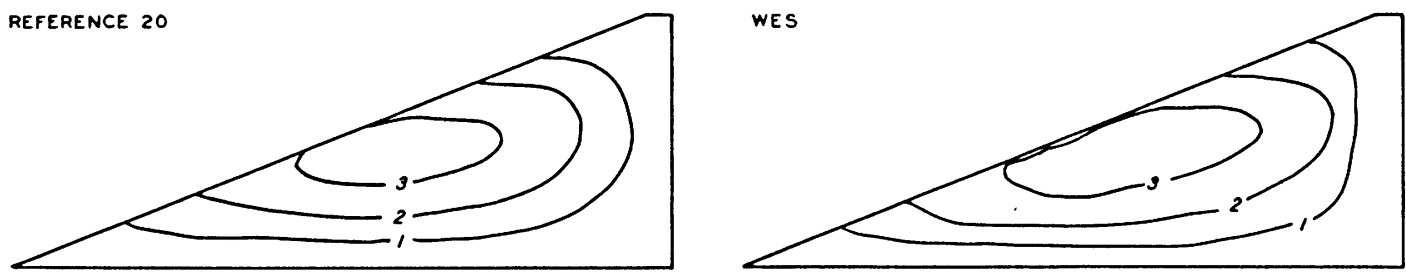

a.HORIZONTAL DISPLACEMENT †
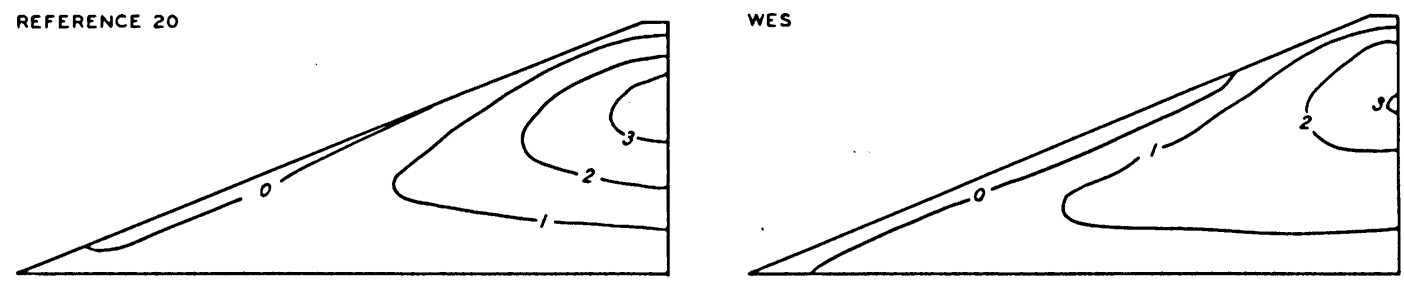

b. VERTICAL DISPLACEMENT +

Fig. 32. Displacement contours, Otter Brook Dam

of the WES analysis in both the horizontal and vertical directions. The bridge pier was noticed to be tilted after $7 \mathrm{ft}$ of material had béen placed above the base of the pier. Tilt records that were maintained subsequent to that stage were adjusted back to zero at the time the pier was placed on the embankment; the measured and adjusted displacements are shown in fig. 33. The calculated displacements of the base of the pier (Iocated at point A, fig. 30) are compared with the adjusted displacements in fig. 34. As indicated in the figure, displacements calculated by WES are close to those reported in reference 20 , and both compare well with the adjusted measured displacements. Fig. 35 shows the final horizontal movements of reference markers along the upstream face of the dam. Again good agreement is indicated by both finite element analyses.

66. While both finite element codes produce comparable displacements, 

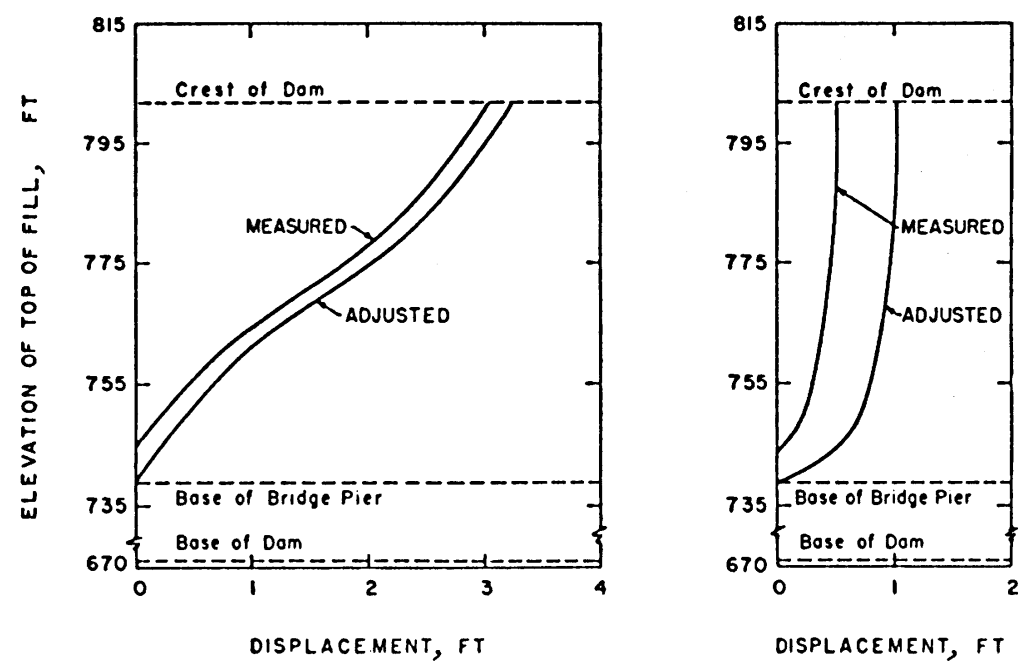

O. OUTWARD HORIZONTAL DISPLACEMENT

b. DOWNWARD VERTICAL OISPLACEMENT

Fig. 33. Measured and adjusted displacements of bridge pier in upstream face of Otter Brook Dam (from reference 20)

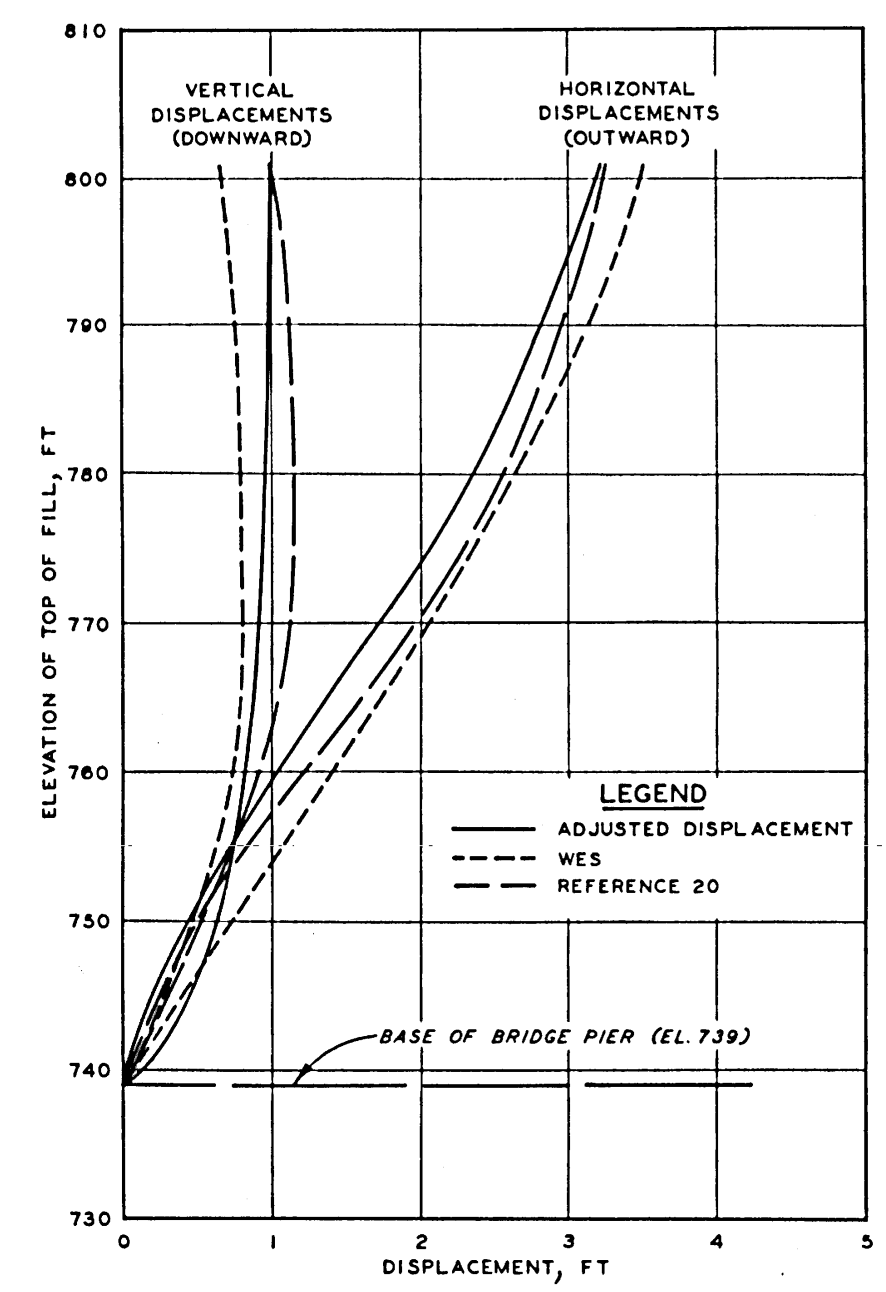

Fig. 34. Comparison of the computed displacements of base of bridge pier 


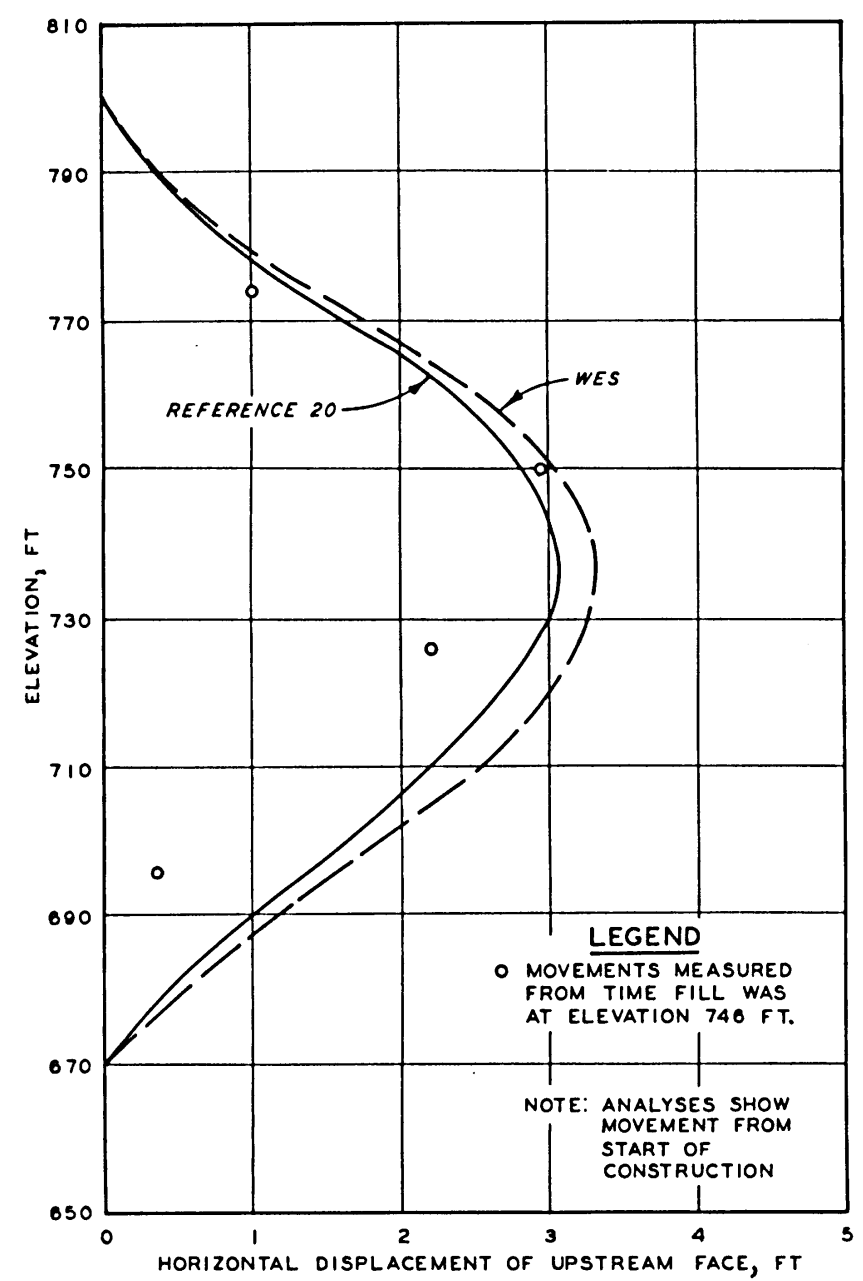

Fig. 35. Comparison of horizontal movements of upstream face the WES code generally produced slightly larger horizontal movements. The cause of the increased horizontal movements produced in the WES code is involved with the manner in which the stress-strain relationships are described. The differences between the description of the stress-strain relationships in the WES code and the code used in reference 20 are discussed in paragraph 69.

Stress plots

67. Fig. 36 shows contours of the major and minor principal stresses in the dam compared with similar results reported in reference 20 . The contours show great similarity and suggest that the differences in the codes which produce larger horizontal displacements in the WES code are not as crit-

ical in the determination of stress distributions. Analyses in reference 20, as described in paragraph 64, indicated that the stress distributions resulting from different methods were comparable. They suggested that in homogeneous embankments, the simple gravity turn-on procedure could be useful in calculating approximate stress distributions. This suggestion is of course not valid if displacements are to be considered or if stress distributions are such that portions of the problem become highly stressed. Mobilization factor plots

68. Fig. 37 shows contours of the mobilization factors determined by both WES and Kulhawy, Duncan, and Seed. 20 As should be expected from the 

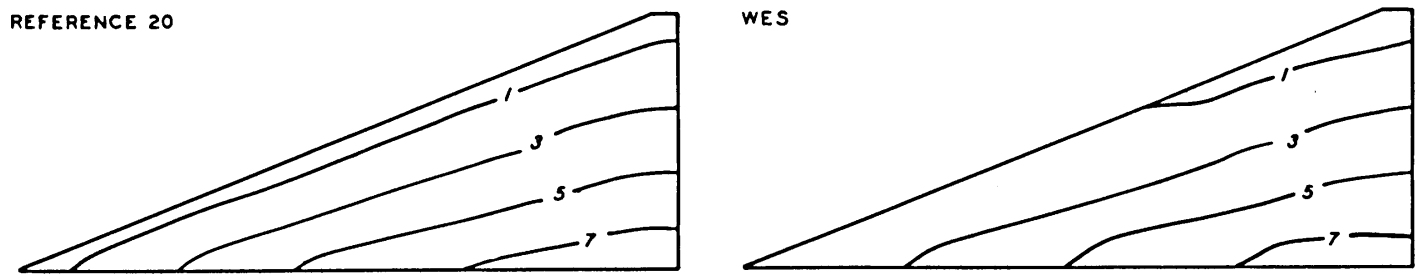

a. MAJOR PRINCIPAL STRESSES
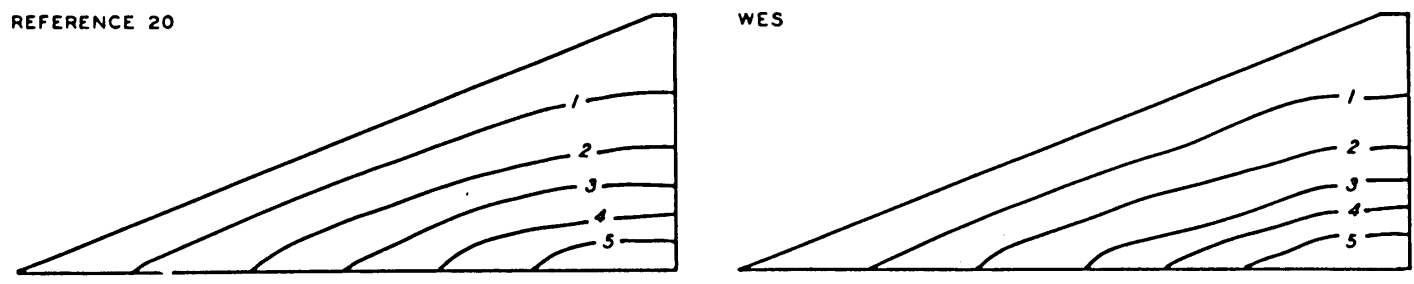

b. MINOR PRINCIPAL STRESSES

Fig. 36. Principal stress contours

similarity of stress distributions, the mobilization factors from both sources compare closely.

Differences in Finite Element Codes

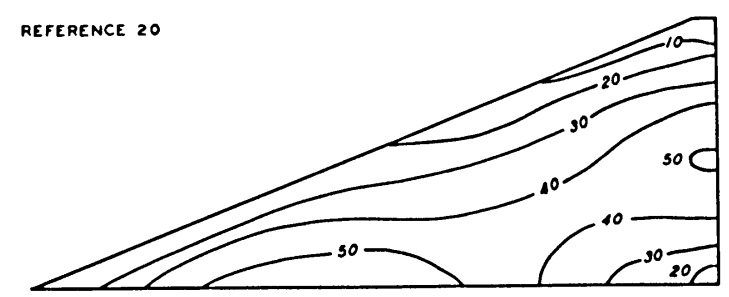

69. The differences in dis-

placements found from the two codes can be explained by the differences in the method of determining the hyperbola to approximate the actual stress-strain curve. The hyperbolic relationship expressed by Kondner $^{17}$ (see equation 13 and fig. 4) is shown in fig. $38 \mathrm{~b}$ for

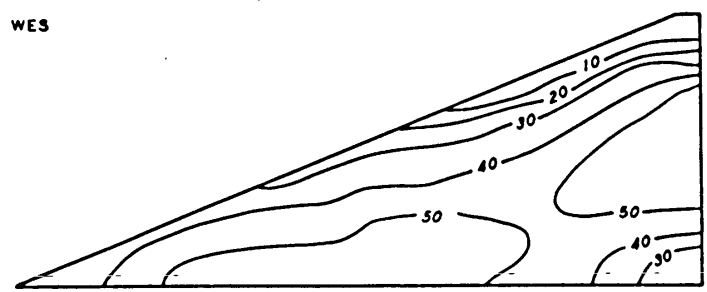

Fig. 37. Mobilization factor contours the Otter Brook material ( $\sigma=4.32$ tons/sq ft). The slope of the line is the reciprocal of the ultimate principal stress difference, i.e., $I /\left(\sigma_{1}-\sigma_{3}\right)_{u}$. The actual principal stress difference at failure 


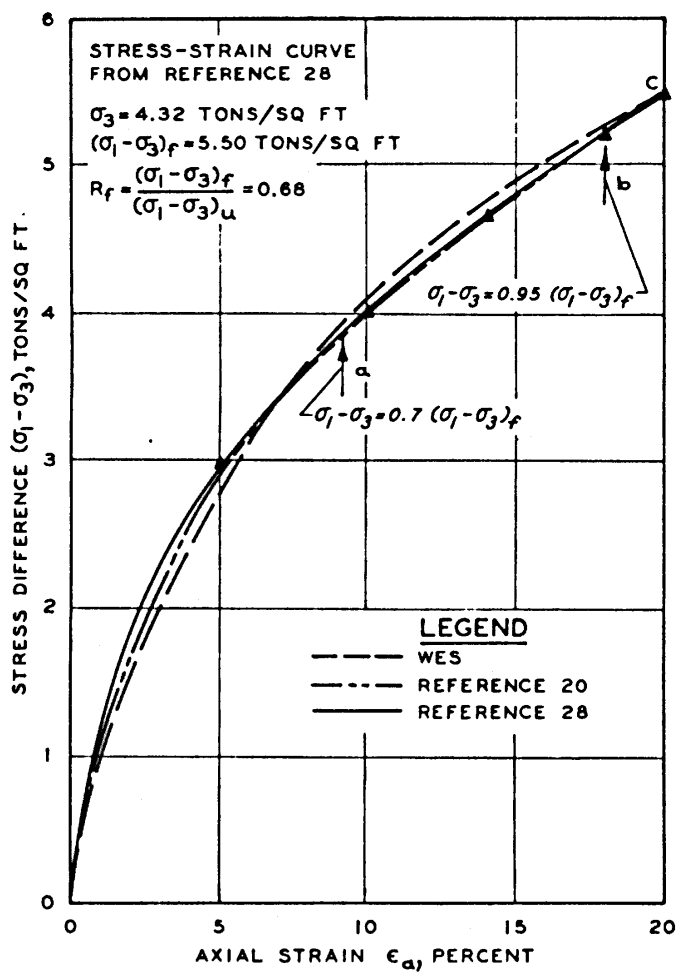

a. STRESS-STRAIN CURVES

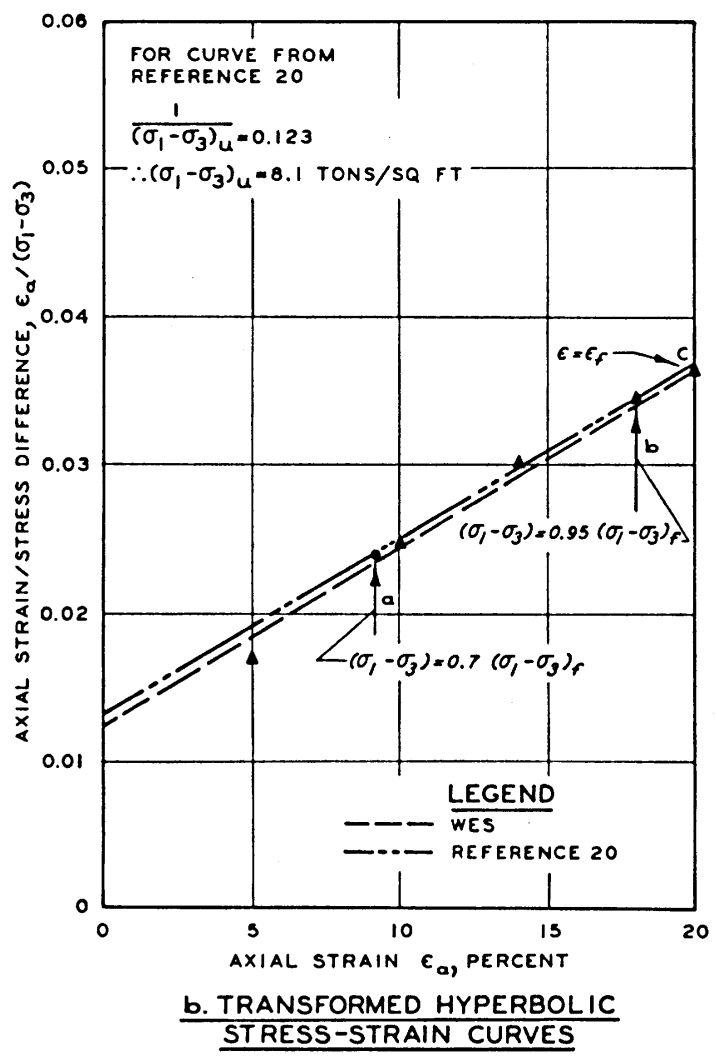

Fig. 38. Fitting of hyperbolic stress-strain curves

$\left(\sigma_{1}-\sigma_{3}\right)_{f}$ is less than $\left(\sigma_{1}-\sigma_{3}\right)_{u}$. The ratio of $\left(\sigma_{1}-\sigma_{3}\right)_{f} /\left(\sigma_{1}-\sigma_{3}\right)_{u}$ is termed the failure ratio $R_{f}$ by Kulhawy, Duncan, and Seed. ${ }^{20}$ For the Otter Brook material, they determined $R_{f}=0.68$. In the Kulhawy, Duncan, and seed procedure, the hyperbola is fitted to the actual stress-strain curve at points $a$ and $b$, which represent 70 and 95 percent of the stress difference at failure, respectively. Their hyperbola is truncated to correspond to the stress difference at failure.. In the method described in this report, the hyperbola is made to pass through the stress-strain curve at the failure strain, point c, fig. 38b. For the Otter Brook analysis, the failure strain, $\epsilon_{f}$, of 20 percent resulted in a flatter hyperbola than obtained by Kulhawy, Duncan, and Seed in the lower stress range. The flatter curve used by WES made the otter. Brook material slightly softer than was the actual case. For the stress-strain curves shown in fig. 38a, the tangent modulus to the Kulhawy, Duncan, and Seed 
hyperbola is on the order of 110 to 120 percent of the tangent modulus of the hyperbola used in the WES analyses in the stress range of interest. Since the displacements in a homogeneous material are inversely related to the modulus (for a constant Poisson's ratio), the calculated displacements by the WES code should be about 110 to 120 percent higher than those calculated by Kulhawy, Duncan, and seed. Figs. 34 and 35 substantiate this estimate.

\section{Factors of Safety}

70. Factors of safety with respect to shear stresses were computed by Kulhawy, Duncan, and Seed and from the results of the WES finite element analyses. The factors, along with factors of safety determined by the Ordinary Method of Slices, i.e., no side forces (Fellenius Method), 29 and Bishop's Modified Method, ${ }^{30}$ are presented in the following tabulation. The

\begin{tabular}{ll}
\multicolumn{1}{c}{ Method of Analysis } & FS \\
\hline Ordinary method of slices* & 1.85 \\
Modified Bishop* & 1.93 \\
Finite element** & 2.06 \\
Finite element (WES & 1.83 \\
$\quad$ analysis) &
\end{tabular}

\footnotetext{
* Reference 20.

* Interpolated from reference 20 for $\nu=0.475$.
}

factors of safety from the finite element analyses were determined from the arc shown in fig. 39. The arc is essentially the most critical for all re-

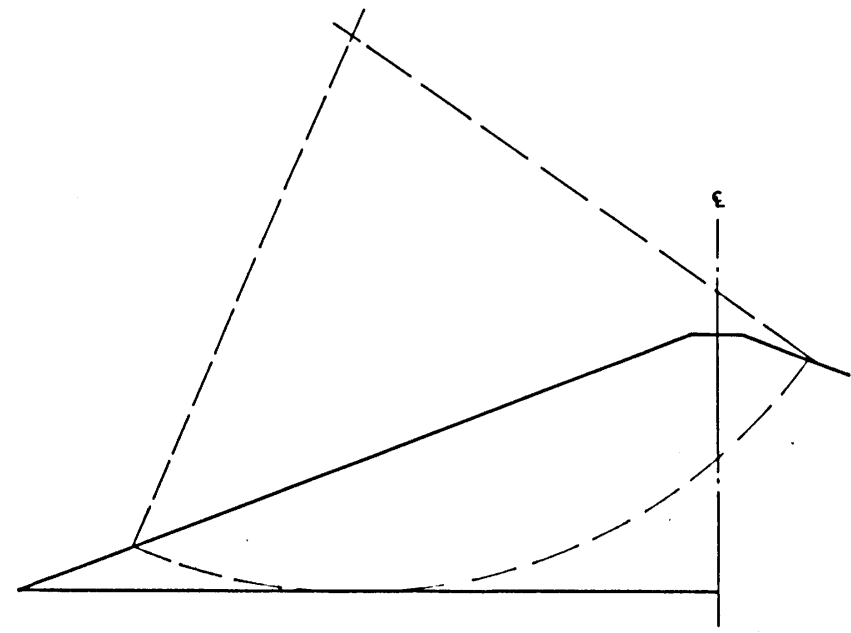

Fig. 39. Circular arc for determination of factors of safety sults presented in the preceding tabulation. As indicated in the tabulation, the factor of safety computed from the finite element solution is, for practical purposes, the same as for the equilibrium methods:

71. The shear and normal stresses acting on the failure arc are shown in fig. 40. The WES results indicate the same general distribution of stresses reported in reference 20 but are somewhat higher. This 

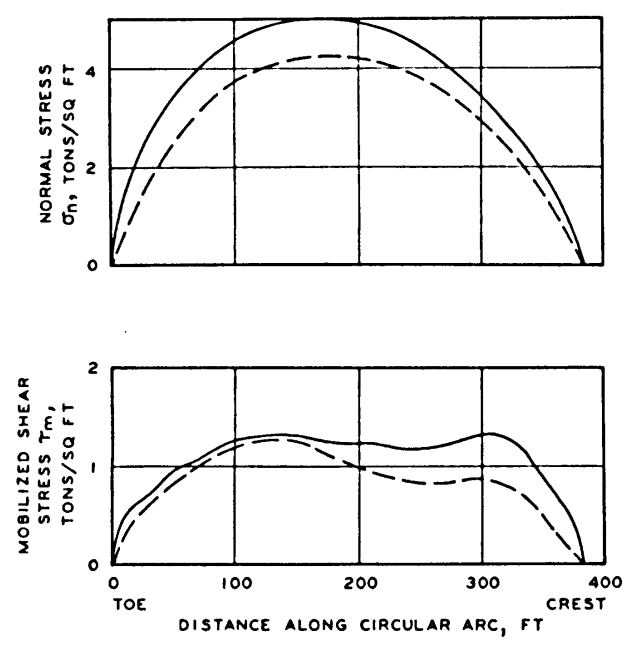

Fig. 40. Stress distributions along failure arc

$$
\text { LEGEND }
$$

- - REFERENCE 20

difference in results was probably caused by the different hyperbola used in the analysis, as previously discussed. It is interesting to note, however, that the differences had little effect on the computed factor of safety. 


\section{Description of Problem}

72. This part describes the application of the nonlinear finite element analysis to a single row crater with assumed properties. Observations and measurements of row crater geometries in a variety of materials have indicated that the resulting crater dimensions can be scaled in terms of the weight of the explosive per charge $W$, as indicated in fig. 41.31-33 Engineering investigations of craters have delineated several zones within the crater slopes which are distinguishable from the initial in situ materials. 34 In fig. 4l, these zones are identified as the fallback, ejecta, and rupture zone.

73. For purposes of this example, the weight of the explosive per charge was assumed to be $1 \mathrm{kt}$ so that scaling coefficients shown in fig. 41 are equal to the crater dimensions in feet. The grid employed for the analysis is shown in fig. 42. Several schemes can be adapted to simulate a static construction sequence that results in the final crater geometry. For this example, the apparent crater was assumed to be filled initially with fallback material that was subsequently removed in layers to result in the final crater profile. The values of parameters for the various zones employed in the analysis are shown below.

\begin{tabular}{|c|c|c|c|c|}
\hline Soil Parameter & Symbol & $\begin{array}{l}\text { Fallback and } \\
\text { Ejecta Zone }\end{array}$ & $\begin{array}{l}\text { Rupture } \\
\text { Zone }\end{array}$ & $\begin{array}{c}\text { Intact } \\
\text { Zone }\end{array}$ \\
\hline Unit weight, $1 \mathrm{~b} / \mathrm{ft}^{3}$ & $\gamma$ & 100.00 & 130.00 & 160.00 \\
\hline Cohesion, $1 \mathrm{~b} / \mathrm{ft}^{2}$ & c & 0 & 0 & 0 \\
\hline Friction angle, deg & $\varnothing$ & 37.0 & 40.0 & 45.0 \\
\hline Modulus number & $\mathrm{K}$ & 350.0 & 700.0 & 1200.0 \\
\hline Modulus exponent & $\mathrm{n}$ & 0.54 & 0.50 & 0.45 \\
\hline Limiting strain, percent & $\epsilon_{f}$ & 12.0 & 13.0 & 15.0 \\
\hline Poisson's rätio & $v$ & 0.33 & 0.40 & 0.45 \\
\hline
\end{tabular}

74. The final crater profile was simulated by the removal of material 


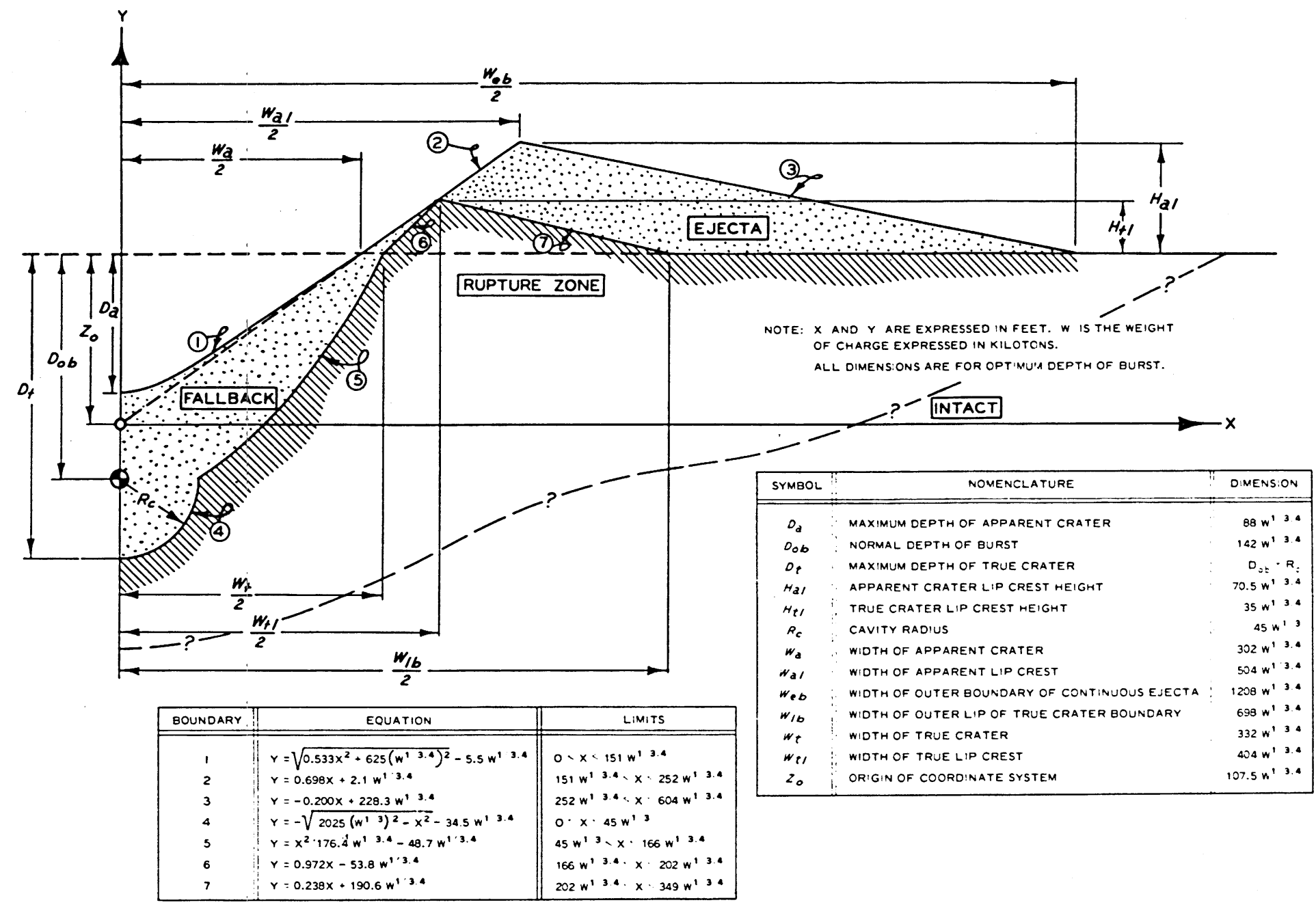

Fig. 41. Scaled row crater dimensions 
NOTE: NUMBERS INDICATE LAYERS

OF MATERIAL REMOVED.

SCALE IN FEET

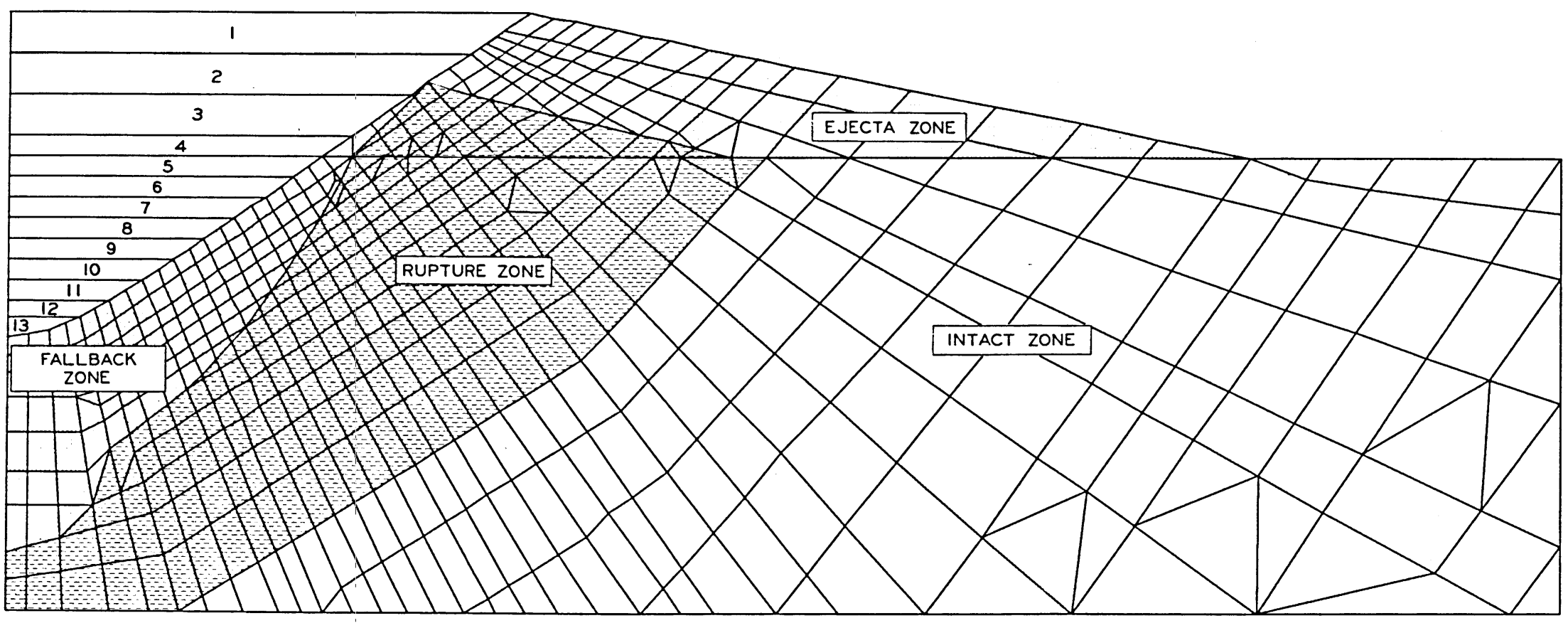

Fig. 42. Finite element grid for crater problem 
in 13 layers as shown in fig. 42. Since this method of removal produces the final crater geometry but does not duplicate the crater formation, the development of displacements indicated by the finite element analyses has no physical meaning. Similarly, the growth of the failed zone is without physical meaning. The stress magnitudes and distribution presented in the following section are those existing after the removal of layer 12 . After layer 12 had been removed, the zone of failed material was continuous from the center line of the crater to the lip of the crater, see for example figs. 43 or 44, such that when an attempt was made to remove layer 13 (see paragraph 33), the stress magnitudes became excessively large throughout the entire problem.

Results

75. Figs. 43 and 44 show contours of the major principal stresses and minor principal stresses, respectively. The stresses were concentrated in the lower part of the fallback zone and caused the increased depth in the failure zone at that location. Fig. 45 shows the contours of the mobilization factor for the crater geometry. The lower boundary of the failure zone corresponds to the 100 percent contour. Again the concentration of stresses in the lower part of the fallback zone is evident.

\section{Factor of Safety}

76. The surface of the fallback material was excavated so as to produce an average slope angle of $35 \mathrm{deg}$ in accordance with the scaling relations shown in fig. 41. If the factor of safety is evaluated on the basis of the infinite slope method, a value of 1.06 is determined. The finite element analysis indicated that the failure zone extends from the center line to the lip of the crater. Near the lip, the failure zone is only one element deep but increases in depth near the bottom of the crater due to large concentration of stresses at that location. The location and extent of the failure surface are quite reasonable, and from an inspection of the stresses, a factor of safety approximately equal to 1.0 is produced. The close agreement in factors of safety from both limit analyses and finite element analyses has been demonstrated previously. 


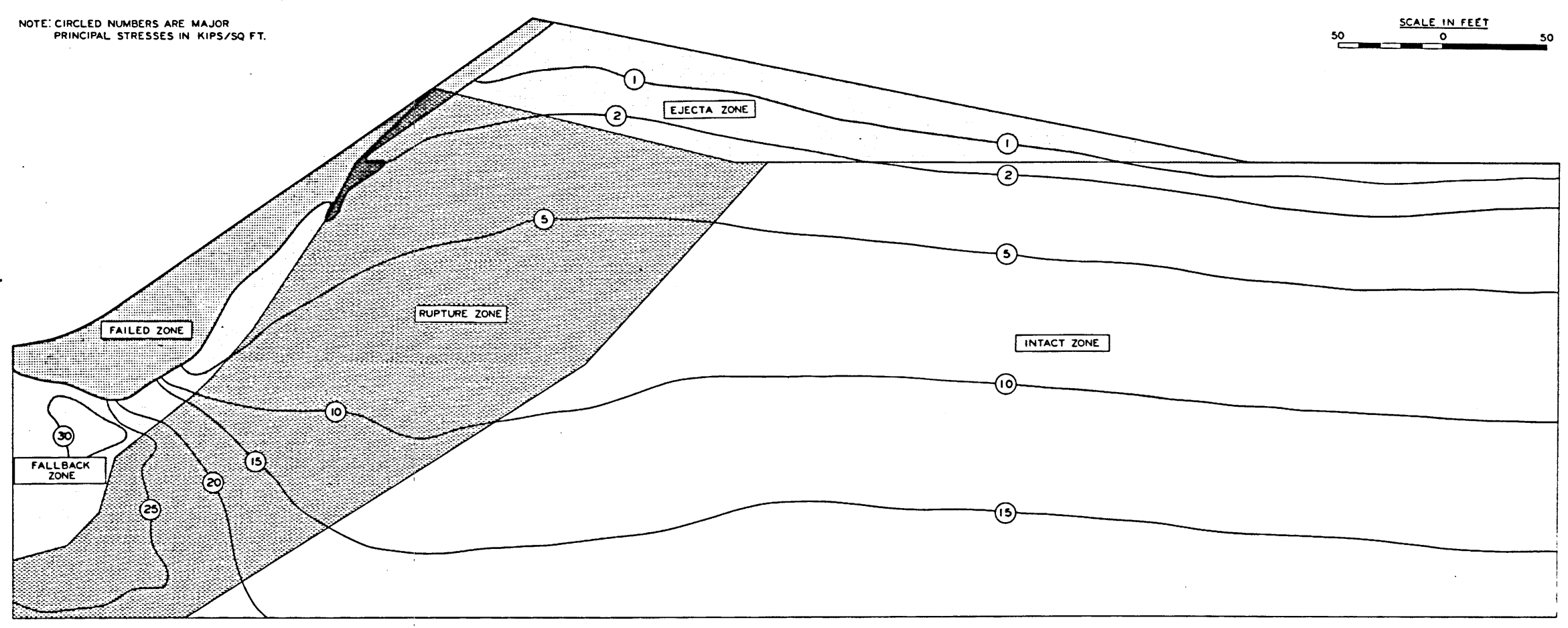

Fig. 43. Contours of major principal stresses 


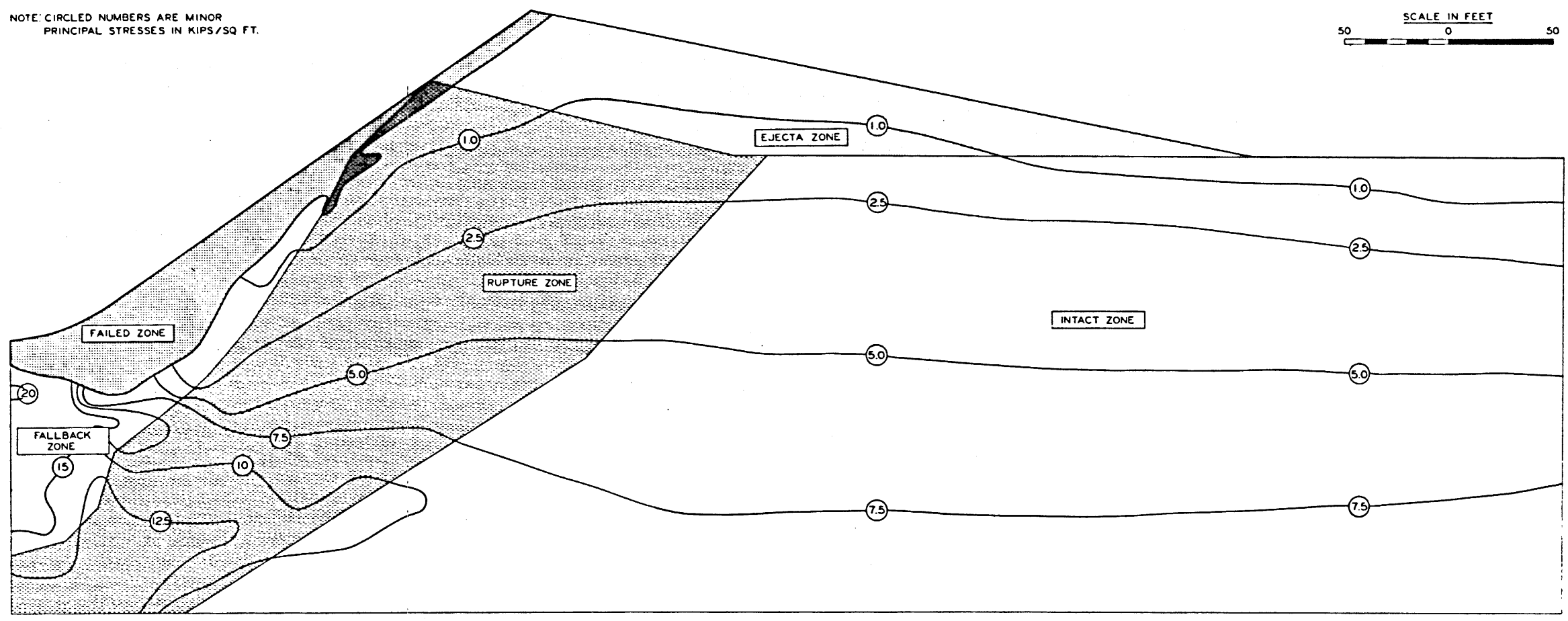

Fig. 44. Contours of minor principal stresses 


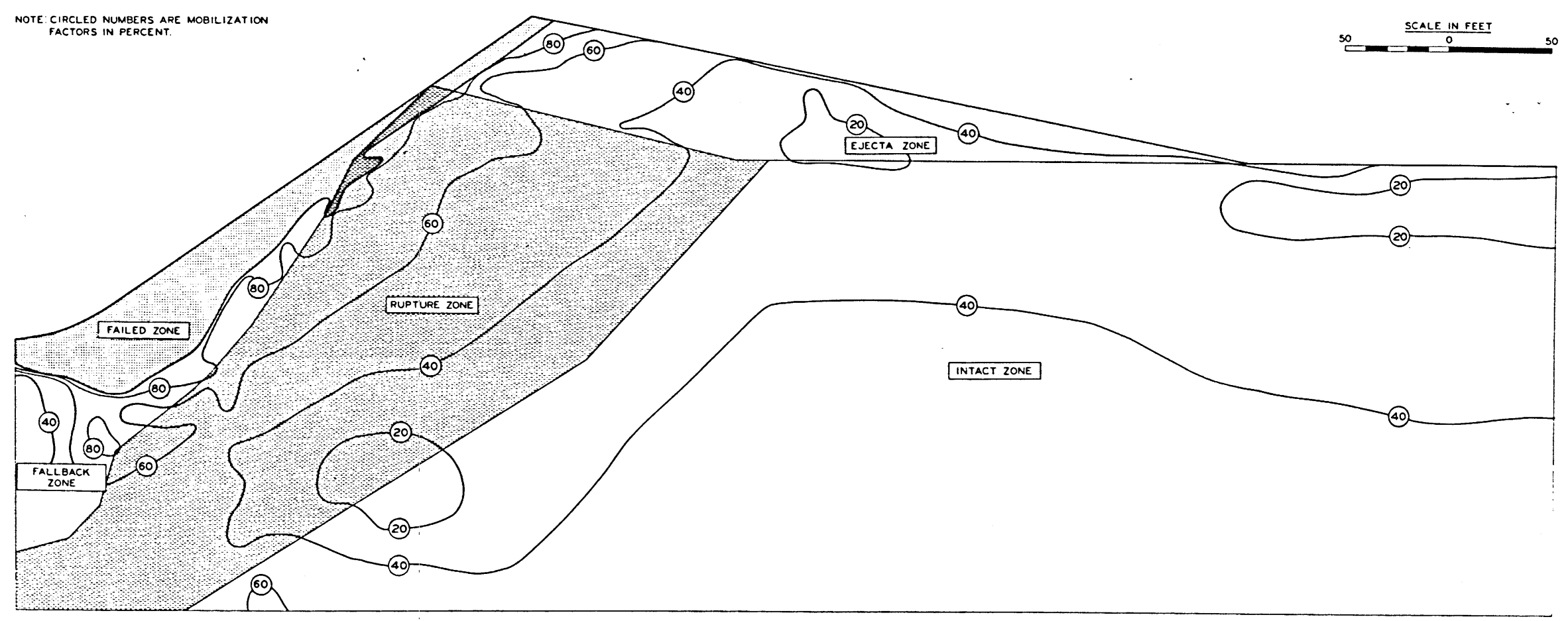

Fig. 45. Contours of mobilization factors 
77. Application of the finite element method to simple slopes indicated that the method can yield close agreement with factors of safety determined from limit analyses. The influence of the initial state of stress upon stress distribution was indicated for excavated slopes. The method indicated close agreement for Otter Brook Dam between measured displacements along the surface and calculated values. The factor of safety was in good agreement with the results from limit analyses. The method was used to predict stress distribution and stress magnitude of a hypothetical row crater utilizing assumed material properties. The results of the analysis are believed to be reasonable.

78. From the application of the code as contained in this report, two directions of research are indicated. First, the method should be applied to as many actual cases as possible to gain confidence and expertise in its use for analysis and design of slopes. Secondly, since the code has been shown to be operative and to yield useful results for crater slopes, the physical properties (i.e., states of stress, stress-strain relationships, and strength relationships) for the various zones surrounding actual craters must be determined. 
1. Kley, R. J. and Lutton, R. J., "A Study of Selected Rock Excavations as Related to Large Nuclear Craters," PNE 5010, Oct 1967, U. S. Army Engineer Nuclear Cratering Group, Livermore, Calif.

2. MacIver, B. N., "The Formation and Initial Stability of Slopes on Cohesionless Materials," PNE 5009, Aug 1967, U. S. Army Engineer Nuclear Cratering Group, Livermore, Calif.

3. Lutton, R. J., "Natural Rubble Slopes and Their Relevance to Crater Fallback Slopes," Technical Report No. 14, Sep 1969, U. S. Army Engineer Nuclear Cratering Group, Livermore, Calif.

4. Banks, D. C. and MacIver, B. N., "Variation in Angle of Internal Friction with Confining Pressure," Miscellaneous Paper S-69-12, Apr 1969, U. S. Army Engineer Waterways Experiment Station, CE, Vicksburg, Miss.

5. Banks, D. C., "Selected Methods for Analyzing the Stability of Crater Slopes," Miscellaneous Paper S-68-8, Jul 1968, U. S. Army Engineer Waterways Experiment Station, CE, Vicksburg, Miss.

6. Turner, M. J. et al., "Stiffness and Deflection Analysis of Complex Structures," Journal of Aeronautical Sciences, Vol 23, No. 9, Sep 1956, pp 805-823.

7. Clough, R. W., "The Stress Distribution of Norfolk Dam," Technical Report Series 100, Issue No. 19, Mar 1962, revised Aug 1962, University of California, Institute of Engineering Research.

8. Wilson, E. L., "Finite Element Analysis of Two-Dimensional Structures," Report No. 63-2, Jun 1963, Structures and Materials Research Division, Department of Civil Engineering, University of California, Berkeley, Calif.

9. Duncan, J. M. and Goodman, R. E., "Finite Element Analyses of Slopes in Jointed Rock," Contract Report S-68-3, Feb 1968, U. S. Army Engineer Waterways Experiment Station, CE, Vicksburg, Miss.; also issued as University of California Report TE-68-1.

10. Dunlop, P., Duncan, J. M., and Seed, H. B., "Finite Element Analyses of Slopes in Soil," Contract Report S-68-6, May 1968, U. S. Army Engineer Waterways Experiment Station, CE, Vicksburg, Miss.; also issued as University of California Report TE-68-3.

11. Gates, R. H., "Inelastic Analysis of Slopes by the Finite Element Method," unpublished Doctor of Philosophy Dissertation, 1968, University of Illinois, Urbana, Ill.

12. Banks, D. C. and Palmerton, J. B., "Application of Finite Element Method in Determining Stability of Crater Slopes; Preliminary Report," Miscellaneous Paper S-68-3, May 1968, U. S. Army Engineer Waterways Experiment Station, CE, Vicksburg, Miss. 
13. Palmerton, J. B., "Application of Finite Element Method to Stability of Cratered Slopes," Progress Report - FY 1968, Jul 1968, U. S. Army Engineer Waterways Experiment Station, CE, Vicksburg, Miss.

14. Zienkiewicz, O. C. and Cheung, Y. K., The Finite Element Method in Structural and Continuum Mechanics, McGraw-Hill, New York, 1967.

15. Desai, C. S. and Abel, J. F., Introduction to the Finite Element in Engineering Analysis, Van Nostrand Reinhold Co., New York (in press).

16. Konaner, R. L., "Hyperbolic Stress-Strain Response: Cohesive Soils," Journal of the Soil Mechanics and Foundation Division, American Society of Civil Engineers, Vol 89, SMI, Feb 1963, pp 115-143.

17. Kondner, R. L. and Zelasko, J. S., "A Hyperbolic Stress-Strain Formulation for Sands," Proceedings of the Second Pan-American Conference on Soil Mechanics and Foundation Engineering, Vol 1, 1963.

18. Kondner, R. I. and Horner, J. M., "Triaxial Compression of a Cohesive Soil with Effective Octahedral Stress Control," Canadian Geotechnical Journal, Vol 2, No. 1, Feb 1965.

19. Janbu, N., "Soil Compressibility as Determined by Oedometer and Triaxial Tests," Proceedings of the European Conference on Soil Mechanics and Foundation Engineering, Vol 1, 1963, pp 19-25.

20. Kulhawy, F. H., Duncan, J. M., and Seed, H. B., "Finite Element Analyses of Stresses and Movements in Embankments During Construction," Contract Report S-69-8, Nov 1969, U. S. Army Engineer Waterways Experiment Station, CE, Vicksburg, Miss.; also issued as University of California Report TE-69-4, Nov 1969.

21. Wright, S. G., "A Study of Slope Stability and the Undrained Shear Strength of Clay Shales," unpublished Doctor of Philosophy Dissertation, 1969, University of California, Berkeley, Calif.

22. Janbu, N., "Application of Composite Slip Surfaces for Stability Analysis," Proceedings of the European Conference on Stability of Earth Slopes, Vol 3, 1955, pp 43-49.

23. Spencer, E., "A Method of Analysis of the Stability of Embankments Assuming Parallel Inter-Slice Forces," Geotechnique, Vol 17, No. 1, Mar 1967.

24. Janbu, N., "Stability Analysis of Slopes with Dimensionless Parameters," Harvard Soil Mechanics Series No. 46, Jan 1954.

25. _. "Discussion of 'Dimensionless Parameters for Homogeneous Earth Slopes' by J. M. Bell." Journal of Soil Mechanics and Foundation Division, American Society of Civil Engineers, Vol 93, No. SM4, Nov 1967.

26. Headquarters, Department of the Army, "Stability of Earth and Rockfill Dams," Engineering Manual, EM 1110-2-1902, 1970, Washington, D. C.

27. Morgenstern, N. R. and Price, V. E., "The Analysis of the Stability of General Slip Surfaces," Geotechnique, Vol 15, No. 1, Mar 1965. 
28. Linell, K. A. and Shea, H. F., "Strength and Deformation Characteristics of Various Glacial Tills in New England," American Society of Civil Engineers Research Conference on Shear Strength of Cohesive Soils, Jun 1960.

29. Fellenius, W., "Erdstatische Berechnungen," Berlin, W. Ernst, 1927.

30. Bishop, A. W., "The Use of the Slip Circle in the Stability Analysis of Slopes," Geotechnique, Vol 5, No. 1, Mar 1955.

31. U. S. Army Engineer Nuclear Cratering Group, Military Engineering with Nuclear Explosives, Report DASA 1669, 1966, Livermore, Calif.

32. Hughes, B. C., et al., "Study of Shape and Slope of Explosion-Produced Craters," Technical Memorandum 65-8, Nov 1965, U. S. Army Engineer Nuclear Cratering Group, Livermore, Calif.

33. Hansen, S. M., et al., "Recommended Explosion-Crater Nomenclature," Geophysics, Vol 29, No. 5, Oct 1964.

34. Fisher, P. R., "Engineering Properties of Craters; Description of Crater Zones and Site Investigation Methods," PNE 5012, Report 1, 1968, U. S. Army Engineer Nuclear Cratering Group, Livermore, Calif. 
APPENDIX A: WES NONLINEAR FINITE ELEMENT COMPUTER PROGRAM

\section{Finite Element Computer Program for Slopes}

1. The program consists of a main program and ten subroutines (INITY, CONSEQ, EXCAV, ADD, STIFF, QUAD, STRESS, TRISTF, BANSOL, and MODIFY). This program is an extensive modification of a program written by E. I. Wilson of the University of California. The modifications were programed by J. B. Palmerton.

\section{Purpose}

2. The program calculates the stresses and displacements resulting from incrementally constructing a cut slope or embankment. A hyperbolic stress-strain relationship is used. Residual stresses may also be considered.

\section{Input Data}

3. IDENTIFICATION CARD: FORMAT (72H).

COLS 1-72 Identifying information to be printed with results

4. OPERATING INFORMATION I: FORMAT (II, I4, 5I5, 3F10.2).

COL I Nonzero value suppresses listing of node and element information

COLS 2-5 Number of nodal points (900 Maximum)

COLS 6-10 Number of elements (800 Maximum)

COLS $11-15$ Number of materials (20 Maximum)

COLS 16-20 Number of pressure cards (150 Maximum)

COLS 2l-25 Leave blank

COLS 26-30 Number of construction steps

COLS 31-40 Minimum $x$-coordinate (left boundary)

COLS 41-50 Maximum $x$-coordinate (right boundary)

COLS 51-60 Minimum y-coordinate (lower boundary)

Note: The left and right boundaries must be vertical. The lower 
boundary must be horizontal. The coordinate system used must be positive $\mathrm{y}$ up and positive $\mathrm{x}$ to right with all points lying in the first quadrant.

5. MATERIAL PROPERTIES I: FORMAT (I5, F5.0, 7F10.0). One card for each material (list consecutively starting with material 1 ). Information for removed element properties must be last card.

COLS 1-5 Material type number

COLS 6-10 For Kondner's full hyperbola leave blank; when using truncated hyperbola, enter percent strain at failure, $\epsilon_{f}$, in percent

COLS 11-20 Density of material

COLS 2l-30 Exponent $n$ in $\left(E_{i}=K \sigma_{3}^{n}\right)$

COLS 31-40 Constant $K$ in $\left(E_{i}=K \sigma_{3}^{n}\right)$

COLS 4l-50 Friction angle $\varnothing$

COLS 51-60 Cohesion $c$ or $\bar{c}$ (enter as negative quantity if

$\bar{c}$.$) If \bar{c}$ is used, the units of cohesion are force per

square length per length of depth from the reference height, $h_{0}$ COLS 61-70 Poisson's ratio (if entered as a negative quantity,

the meaning shall be $k$ ) (see INPUT DECK SETUP)

COLS 71-80 Reference height, $h_{0}$

6. NODAL POINT CARDS: FORMAT (I5, F5.0, 4F10.0). One card for each nodal point unless missing node points are generated. Nodal points must be numbered consecutively starting with 1 .

COLS 1-5 Nodal point number

COLS 6-10 Boundary code

COLS 11-20 x-coordinate

COLS 21-30 y-coordinate

COLS 31-40 Force or displacement in $\mathrm{x}$-direction

COLS 4l-50 Force or displacement in $y$-direction

Meaning of Columns

If Boundary Code is Then COLS 31-40 are Then COLS 41-50 are

0.0

1.0

2.0

3.0

Force

Displacement

Force

Force

Force

Displacement

Displacement

Displacement 
.. 7. If the input cards are nonconsecutive, nodal point information vill be generated between the two points. The $\mathrm{x}$ and $\mathrm{y}$ coordinates are linearly interpolated; the boundary code and thus the forces will automatically be set equal to zero.

Note: Frequently provisions must be made to reserve nodal points and elements in positions to be added later in a construction step. Therefore, for elements and nodal points initially "in-air," a distinct material type characterized by $\gamma=0, \epsilon_{\mathrm{f}}=0, \mathrm{n}=0, \mathrm{~K} \leq 10, \phi=0, \mathrm{c}>0$, $0.0<v<0.50$, and $h_{0}=0$ must be specified. The boundary code for the nodal points "in-air" should be entered as a -1.0 on the left and right boundaries, and entered as a 4.0 elsewhere. Failure to do so will result in erroneous displacements at those points.

8. ELEMENT CARDS: FORMAT (615). One card for each element unless missing elements are generated. Elements must be numbered consecutively starting with 1 .

\section{COLS 1-5 Element number COLS 6-10 Nodal point I COLS 11-15 Nodal point $\mathrm{J}$ COLS 16-20 Nodal point $\mathrm{K}$ COLS 21-25 Nodal point $L$ COLS 26-30 Material type}

9. Nodal points I, J, K, I are the nodal point numbers of the nodes surrounding the element, numbered in a counterclockwise direction. Triangular elements are permissible and are identified by repetition of the last two numbers, i.e., I, J, K, K. Elements will be generated between two nonconsecutive elements. The numbers I, J, K, L are incremented by one for each generated element and the material type is set equal to the type specified by the last card.

10. PRESSURE CARDS: FORMAT (2I5, F10.0). Normal pressures may be prescribed on the boundary when assigning initial stresses. One card is required for each element subjected to a normal pressure.

COIS 1-5 Nodal point I

COLS 6-10 Nodal point $\mathrm{J}$

COLS 11-20 Normal pressure 
11. The boundary element must be on the left as one progresses from I to J. Surface tensile pressures are specified as negative quantities.

12. OPERATING INFORMATION II: The format and description for OPERATING INFORMATION I applies, although it may be desired to change certain values such as number of materials (COLS 11-15).

13. MATERIAL PROPERTIES II: The description for MATERIAL PROPERTIES I applies although certain values may change. In particular, the value of Poisson's ratio (COLS 61-70) must be a positive value between 0.0 and 0.5 .

14. SLOPE CONSTRUCTION CARDS: The remaining cards are used to describe the way in which the slope is to be constructed. One set of the following is needed for each construction step.

15. TYPE OF SLOPE AND OUTPUT INFORMATION CARD: FORMAT (16I5). COL 5 Enter a 1 if excavation (removal); 2 if addition of material

COLS 6-10 Number of iterations for this step

COLS 11-15 Number of times output is desired for this construction step

COLS 16-20 First iteration number for which output is desired COLS 21-25 Second iteration number for which output is desired, continue for other iteration numbers

Note: If no output is desired for this construction step, put a 1 in column 15 and a number greater than the number of iterations (COLS 6-10) in COLS 16-20.

16. FOLLOWING CARDS: FORMAT (16I5).

COLS 1-5 Number of nodal points required to describe new surface after excavation or addition of material (150 Maximum) COLS 6-10 Number of elements removed or added (150 Maximum) COLS 11-15 Material type number. This field has a meaning only if elements are added. For an excavation sequence, it is understood that the last material type previously specified applies to removed elements and the field is left blank

17. NEXT CARDS: FORMAT (16I5). COLS 1-5 Nodal point number of first nodal point along new surface 
COLS 6-10 Nodal point number of second nodal point along new surface, etc., continuing to the total number of nodal points required to describe new surface. Use additional cards as necessary

18. NEXT CARDS: FORMAT (16I5).

COLS 1-5 Element number of the first element to be removed or added

COLS 6-10 Element number of the second element to be removed or added, etc., continuing to the total number of elements to be removed or added in this construction step. Use additional cards as necessary

\section{Input Deck Setup}

19. The input deck may be thought of as two separate decks. The first deck consists of information specified on cards from the IDENTIFICATION CARD through the PRESSURE CARDS and is used to calculate the initial state of stress. The initial state of stress may be calculated in two ways. First, if the initial stress state is required to be $\sigma_{\mathrm{y}}=\gamma \mathrm{y}$, $\sigma_{x}=k \sigma_{y}, \tau_{x y}=0$, then the value of $k$ preceded by a minus sign should be placed in columns 6l-70 of MATERIAL PROPERTIES I. A different value may be used for each material. The second way in which the initial state of stress may be calculated is to simply solve a linear elastic finite element problem by applying whatever forces and displacements that are necessary to achieve the desired initial state of stress. In this case, columns 61-70 of MATERIAL PROPERTIES I have the meaning of Poisson's ratio, a positive value greater than zero and less than 0.50 .

20. The second part of the input deck consists of all cards from OPERATING INFORMATION II to the SLOPE CONSTRUCTION cards. The values given by these cards should be the actual physical properties of the materials. Properties for removed material are commonly given as $\gamma=0.0, \mathrm{n}=0.0$, $K=1.0, \phi=0, c=9 \times 10^{6}$ (or any large value), $v=0.25$. 
21. The information given by OPERATING INFORMATION I and II and MATERIAL PROPERTIES I and II is printed for each finite element problem. A listing of the initial $\sigma_{x}, \sigma_{y}$, and $\tau_{x y}$ stresses is also printed whenever the $k$ option is used. Other information that is printed consists of:

a. Tangent modulus values for each element for each iteration.

b. The incremental displacements of each nodal point for that iteration and the total displacement accumulated through that iteration.

c. The stresses $\sigma_{x}, \sigma_{y}, \tau_{x y}, \sigma_{1}, \sigma_{3}$, and $\sigma_{1}-\sigma_{3}$ following each iteration. Other element information printed is the current mobilization factor, the mobilization factor of the preceding iteration, and the angle from the horizontal to the minor principal plane (direction of major principal stress). The sign convention used is tension positive. 


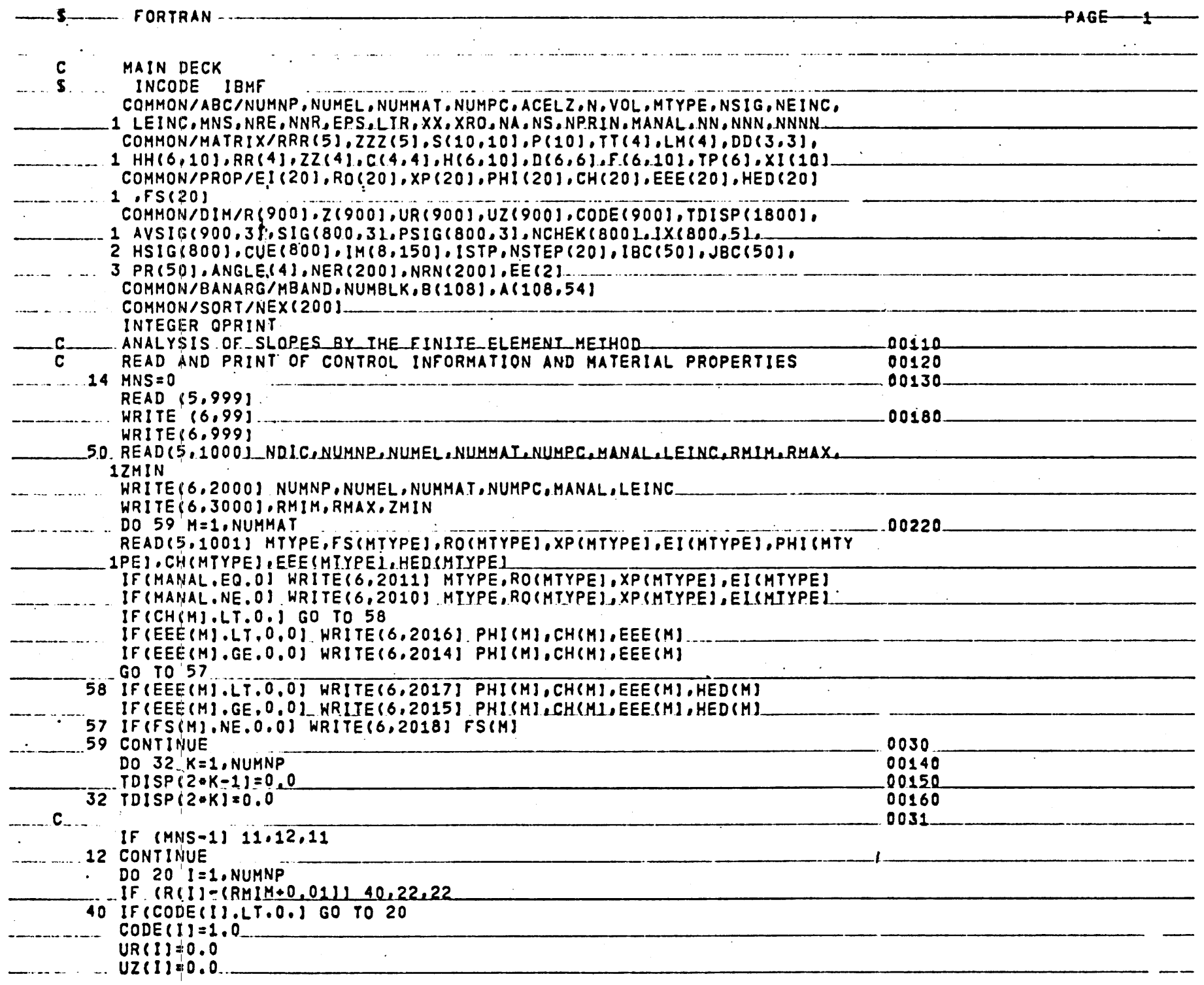




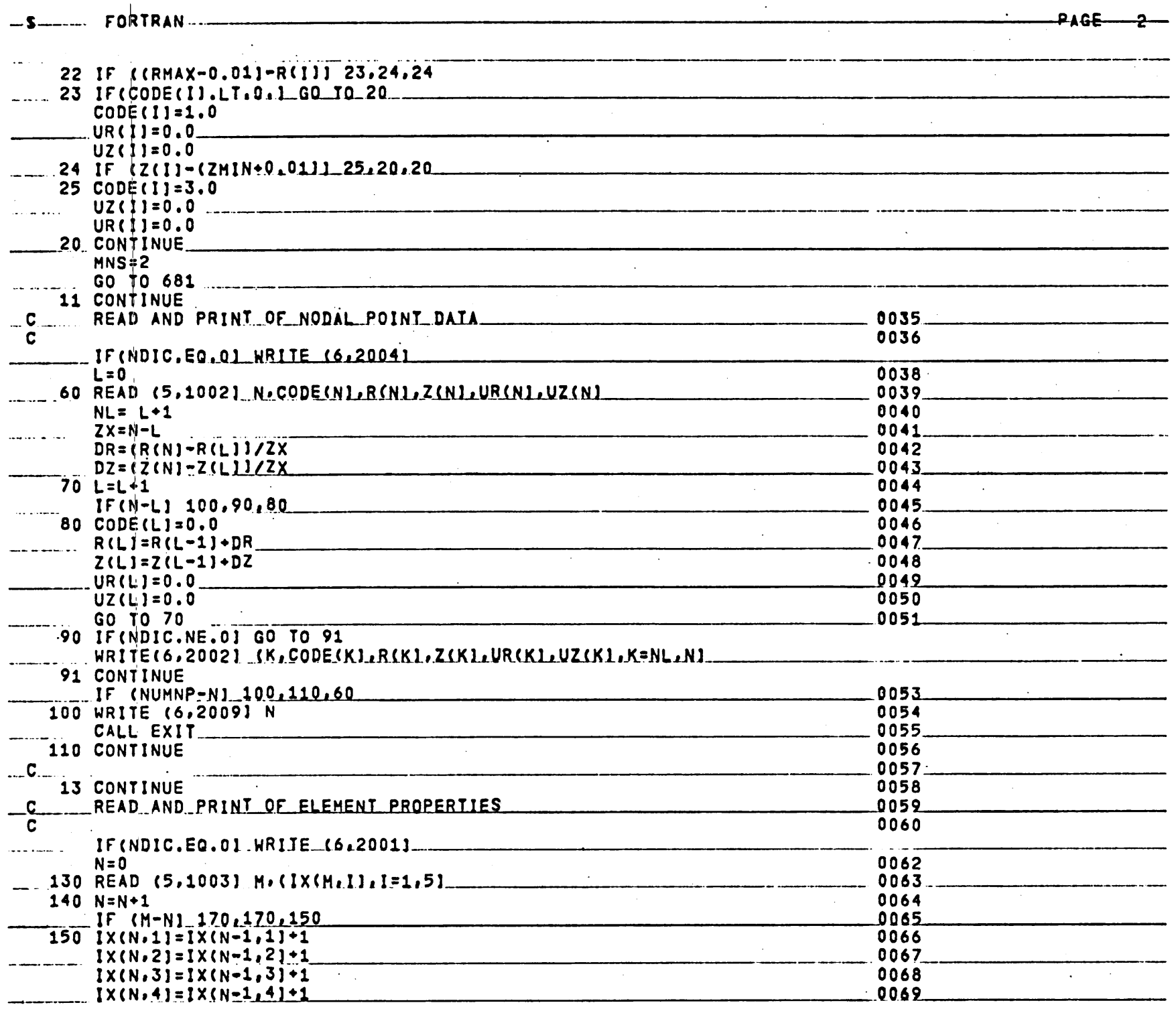




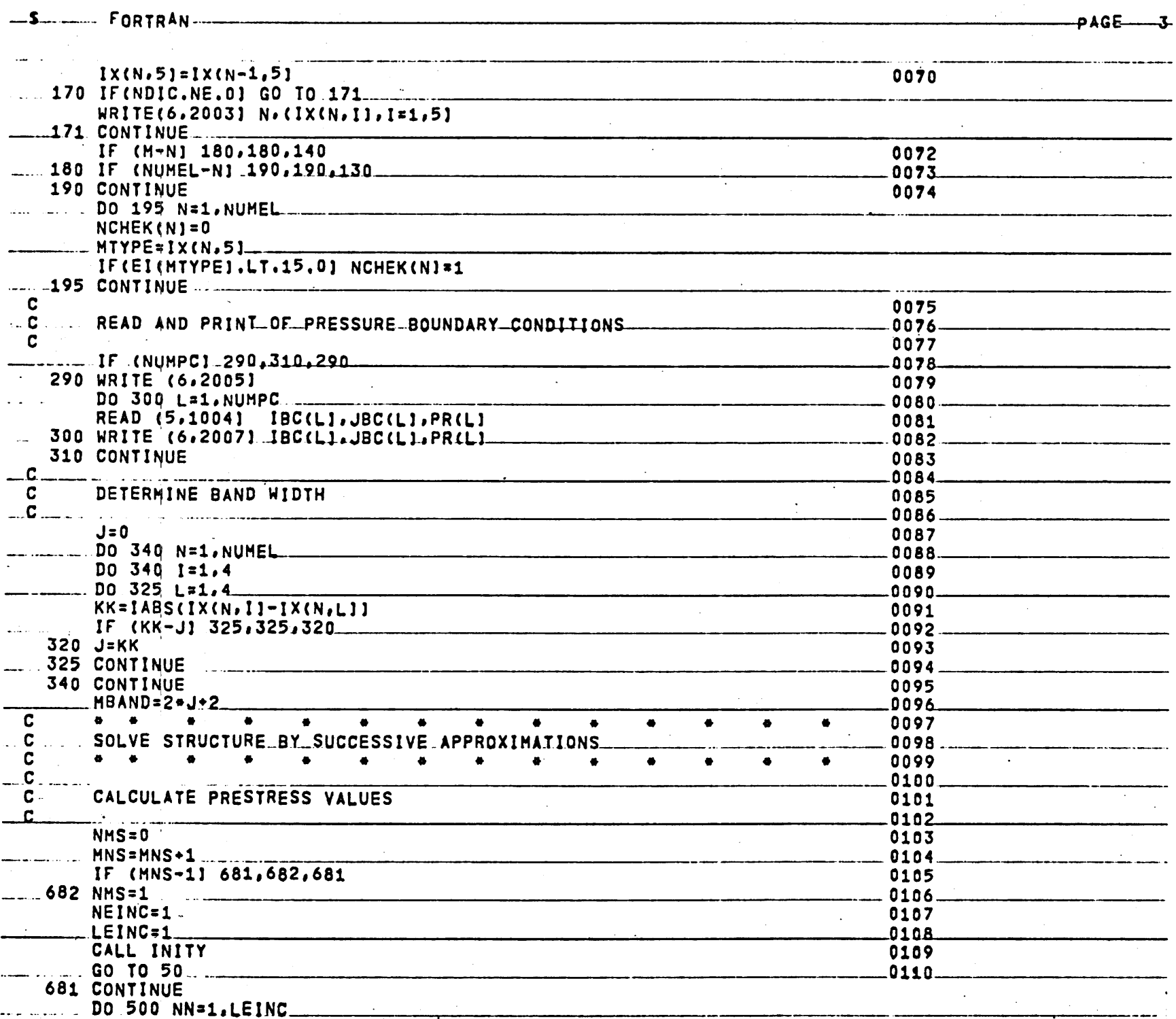




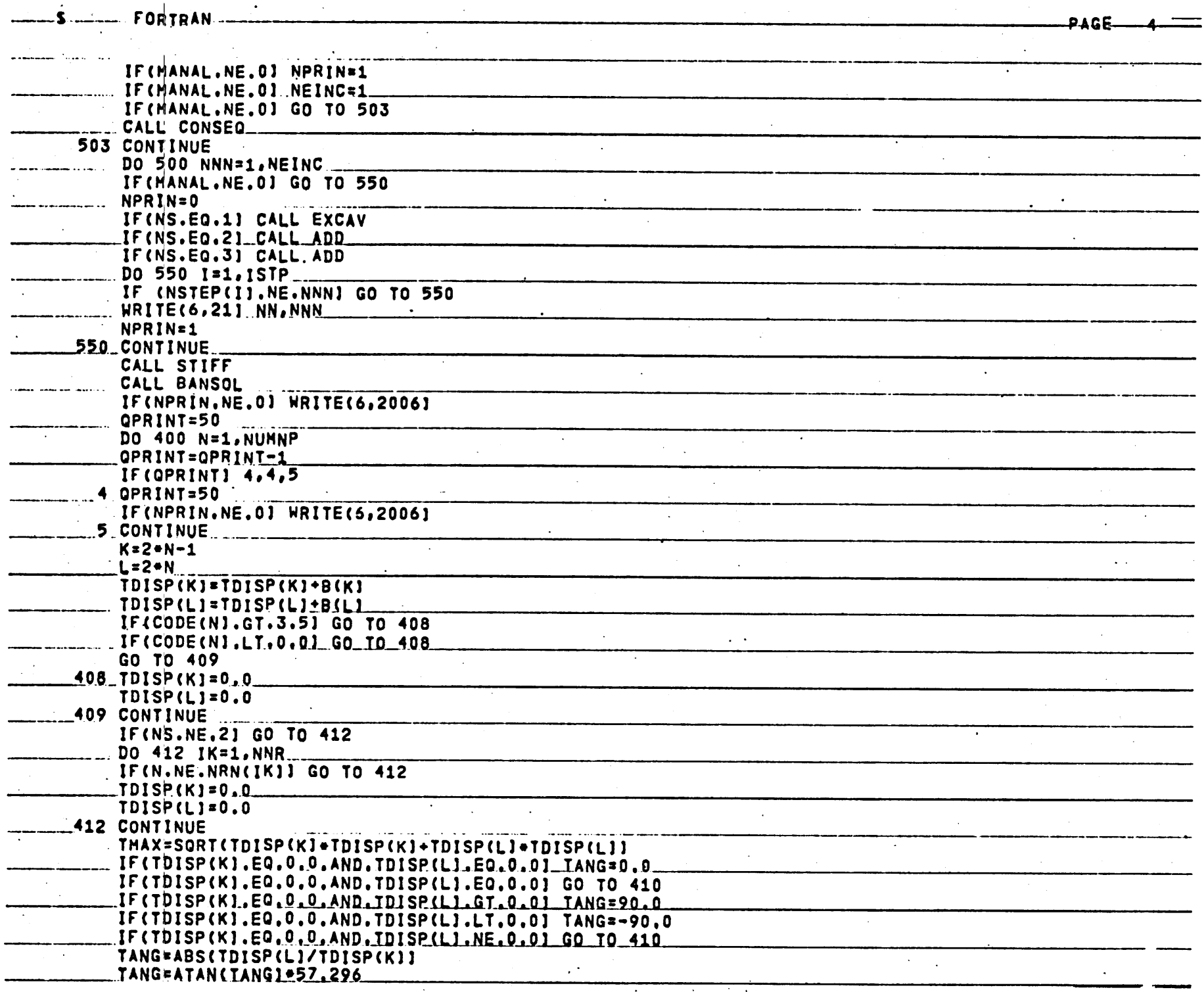




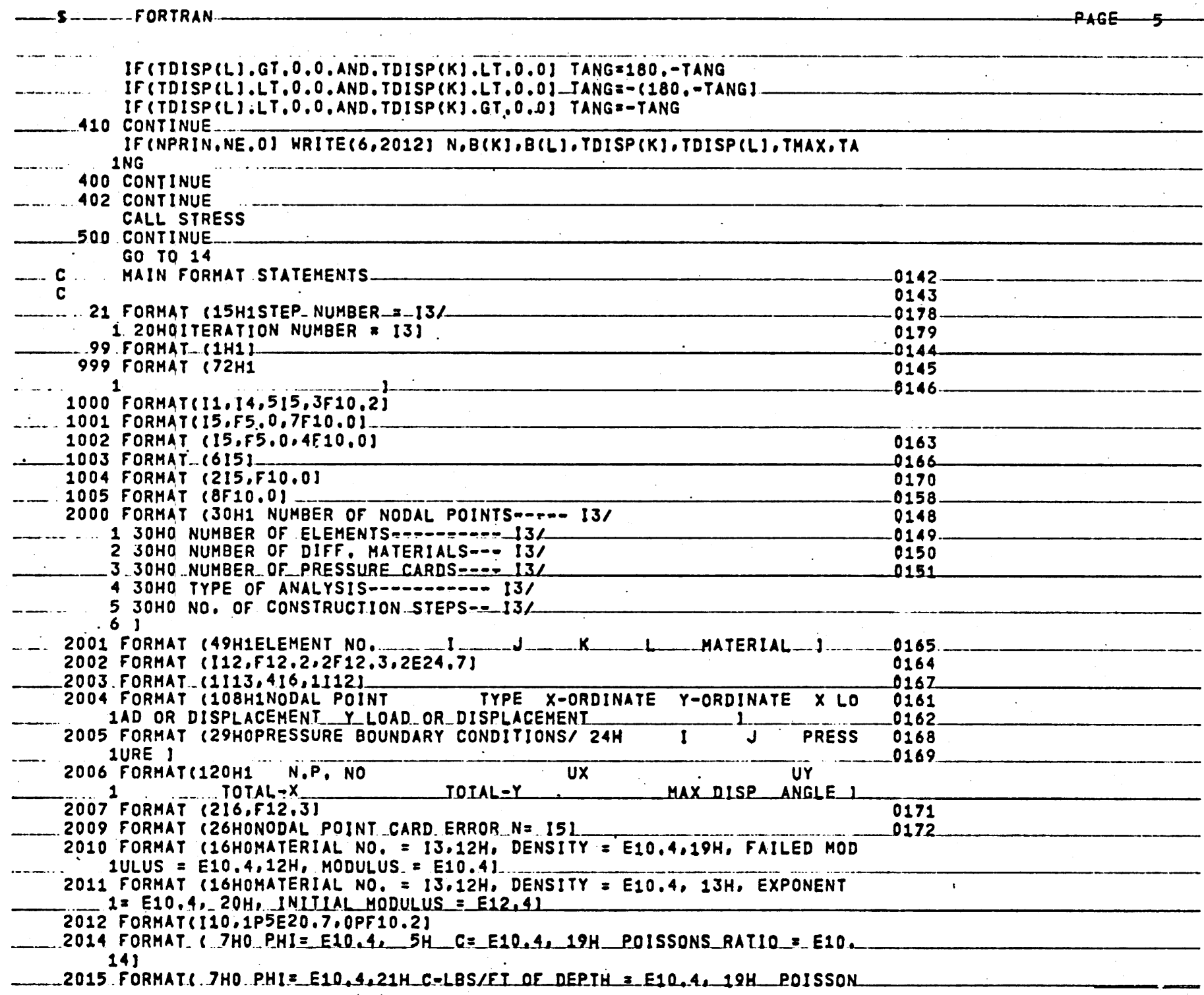


-S... FORTRAN

$P A G E-6$

1S RATIO = E10,4.10HREF. HT, = E10.41

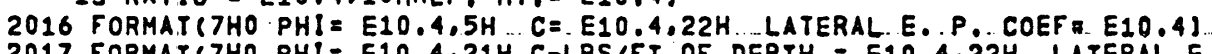

2017 FORMAT 7 7HO PHI = E10.4.21H C-LBS/FT OF DEPTH = E10.4.22H LATERAL E

1. $P$. COEF $=$ E10.4.10HREE. HT. $=E 10.41$

2018 FORMAT (2OHSTRAIN AT FAILURE = F10.2.9HPER CENT J

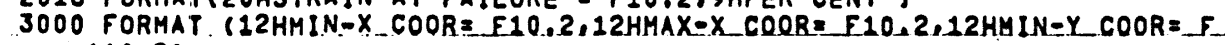

110.21

$-0180$ 


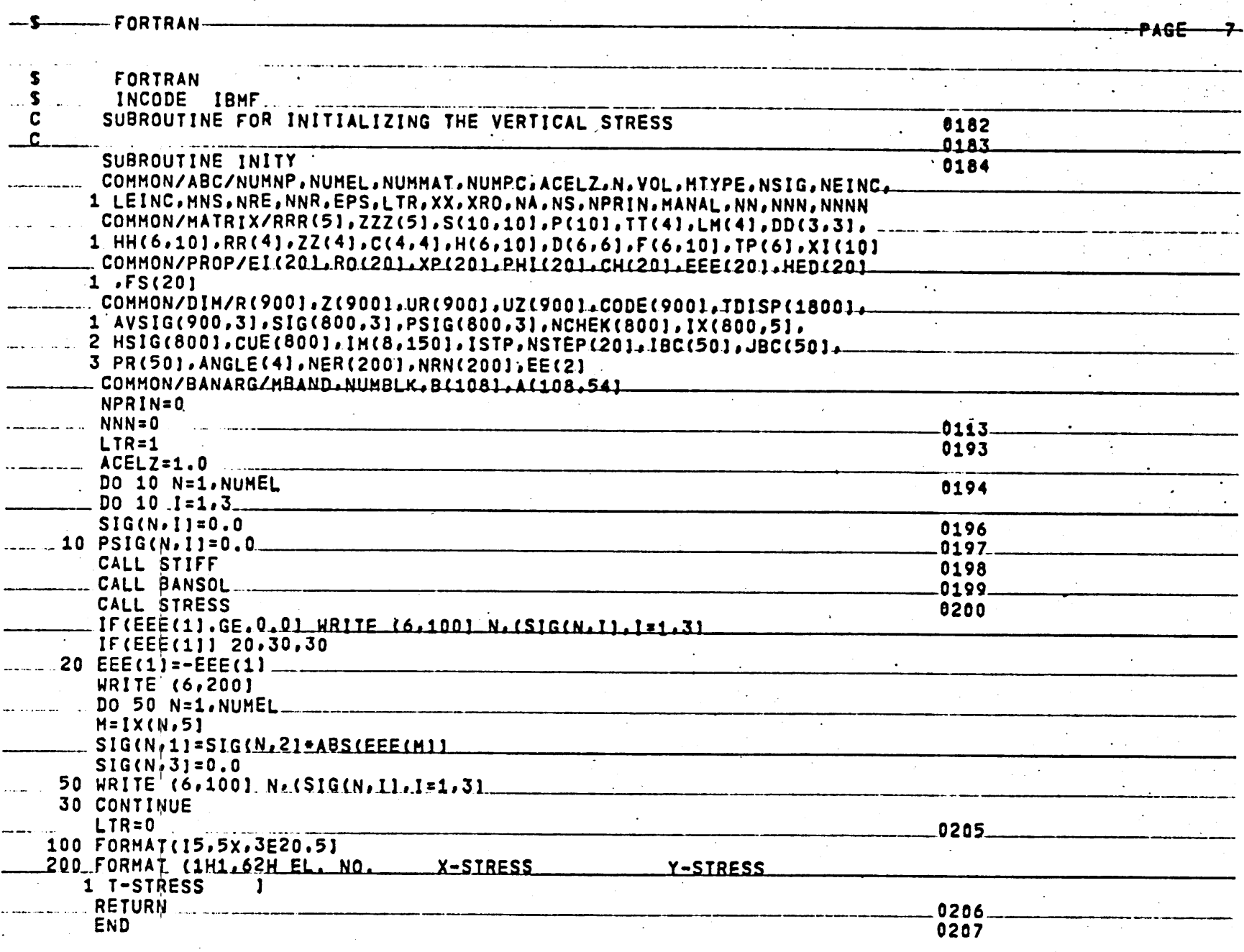




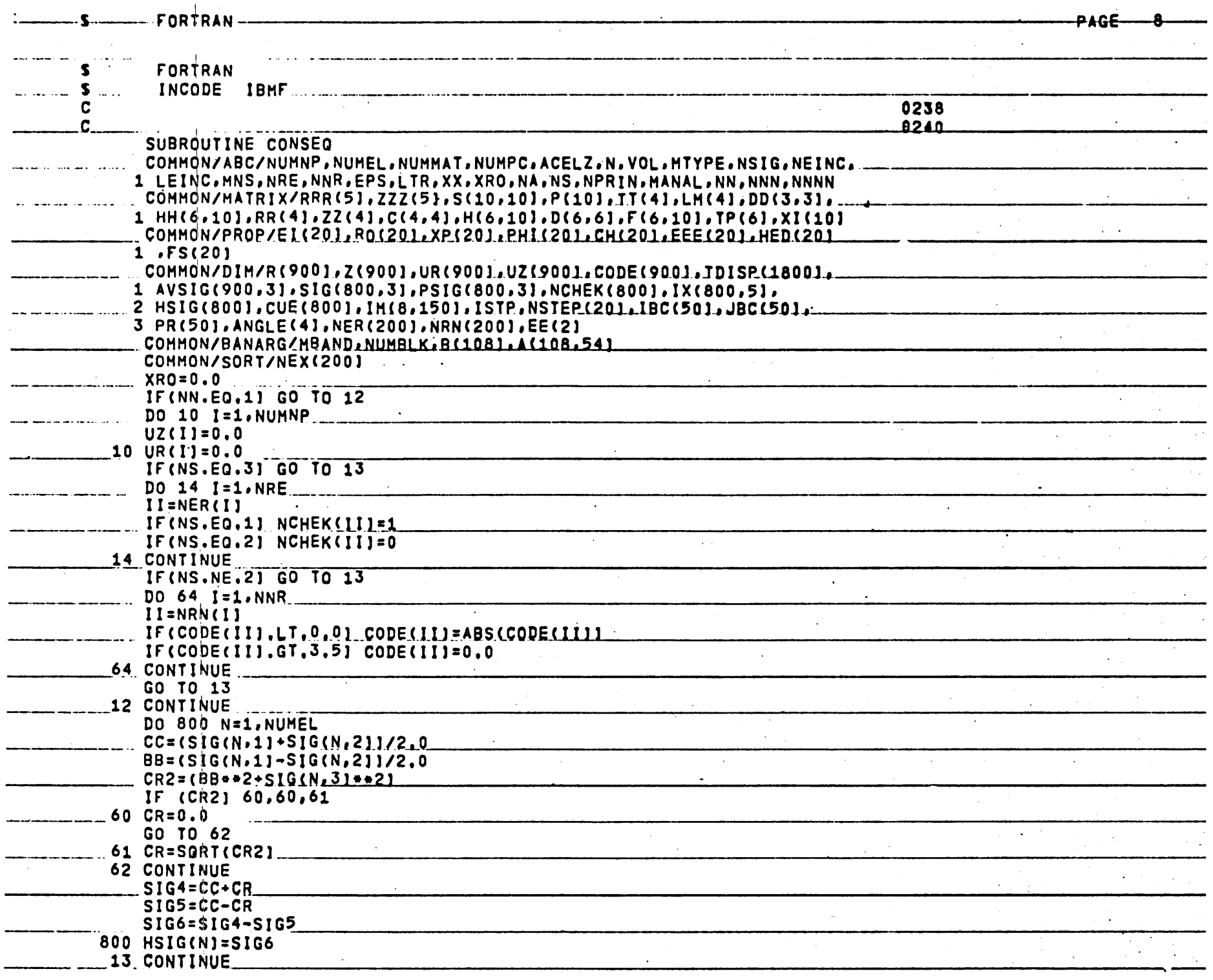




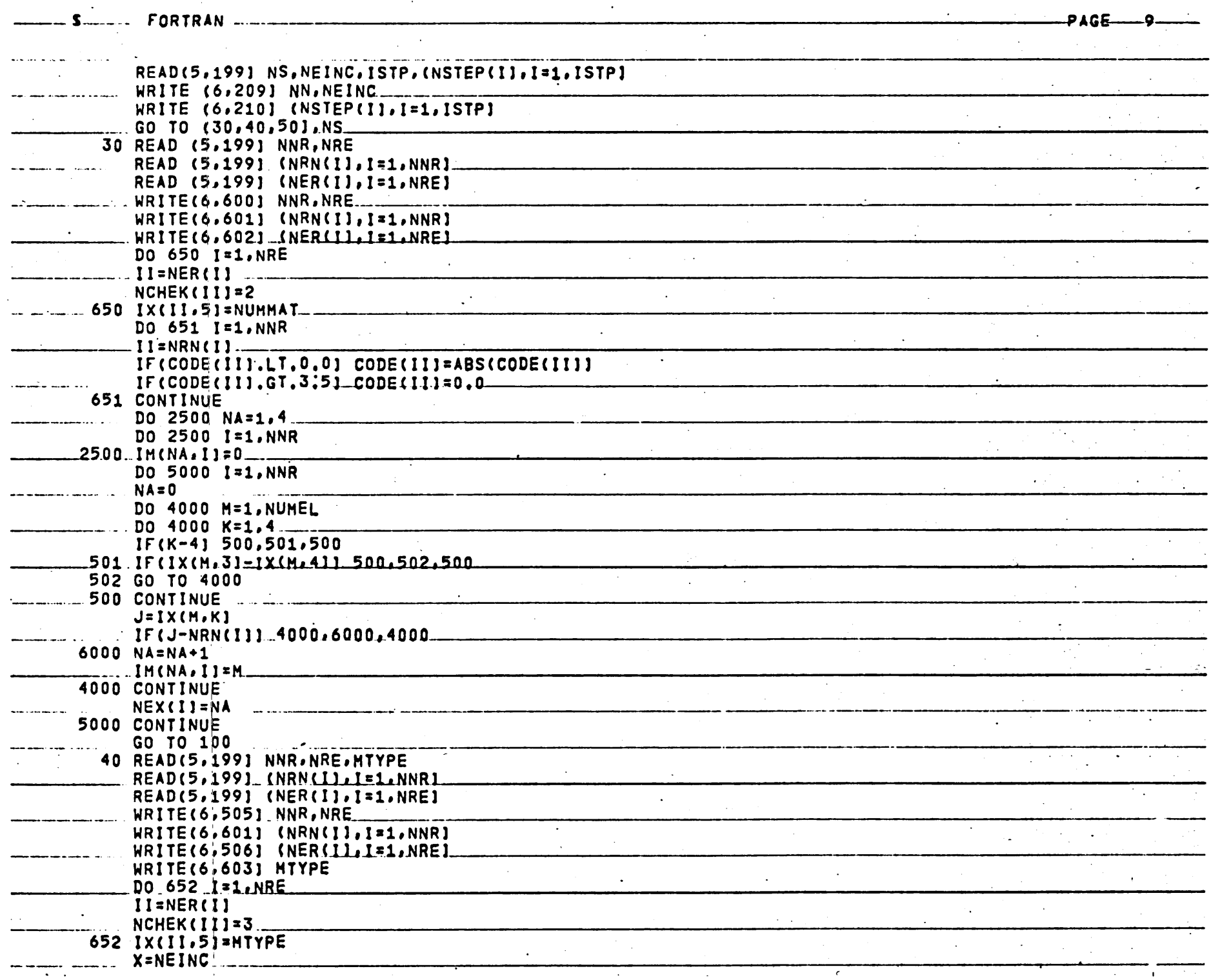


ACELZ $=1 . / X$ $X R O=R O$ (MTYPE

GO TO 100

50. READ $(5.199)$ NNR

WRITE $(6,507)$ NNR

WRITE 6.508

$\triangle C E L Z=0.0$

$x=N E I N C$

$x=1 . / x$

DO 655 . $1=1$. NNR

READ $(5.206)$ N.CODE(N),UR(N),UZ(N)

WRITE $(6,206)$ Ne CODECNI,URCNI,UZ UN

$U R(N)=U R(N) * X$

655 CONTINUE

100 CONTINUE

CONTINUE

RETURN

0314

199 FORMAT(1615)

205 FORMATCI5]

206 FORMAT $(15,55,0,2510,2)$

209 FORMAT 22 HICONSTRUCTION STEP NO. $13,22 \mathrm{H}$ TO BE ACCOMPLISHED IN 13.

111H ITERATIONS

- 210 FORMAT 39 HO OUTPUT TO BE PRINTED FOR ITERATION(SI/1615I

- 505 .FORMAT(41HO THIS SEQUENCE FOR ADDITION OF MATERIAL .13,31HNODES DES

1CRIBE THE NEW SURFACE. I3,19H ELEMENTS ARE ADDED']

506 FORMAT (23HTHE ELEMENTS ADDED. ARE /(12)110))

507 FORMAT (1HO,15,39H BOUNDARY FORCES/DISPLACMENTS SPECIFIEDI

508 FORMAT $30 \mathrm{H}$. NODE CODE X-FORCE

600 FORMAT 32 HOTHIS IS AN EXCAVATION SEQUENCE. I3,46HNODES ARE REQUIRED

1 TO DESCRIBE THE NEW SURFACE, I3,20HELEMENTS ARE REMOVED

601 FORMAT (2OHTHE NODE NUMBERS ARE/(12110)]

602 FORMAT (24HTHE ELEMENTS REMOVED ARE $/(12110)$

603 FORMATI23HMATERIAL TYPE ADDED IS I3] END 
S TORTRAN

S. INCORE IBMF SUBROUTINE EXCAV

SUBROUTINE EXCAV

COMMIN ABC,NUMN, NUMEL NUMMAT I NUMPC, ACELZ, N,YOL, MTYPE, NSIG, NEINC

1 LEINC, MNS, NRE, NNR, EPS, LTR, XX, XRO, NA, NS, NPRIN, MANAL , NN, NNN, NNNN

COMMON/MATRIX/RRR(5),ZZZ(5),S(10,10),P.(10),TT(4),LM(4),DD(3,3)

$1 H H(6,10), R R(4), Z Z(4), C(4,4), H(6,10), D(6,6), F(6,10), T P(6), X)(10)$

CO... COMMON/PROP/EI $(20)$, RO $(20), X P(20), P H I(20), C H(20), E E E(20), H E D(20)$

1 . FS $(20)$

COMMON/DIM/R 900$), Z(900)$ UUR 9001 UZZ1900) CODE 600$)$ TOISP(1800)

1 AVS $\{G(900,3), S[G(800,3)$.PS IG $(800,3)$,NCHEK $(800),[X(800,5)$,

- 2 HSIG(800), CUE $(800)$, IM 8.150$)$. ISTP.NSTEP $201.18 C(50)$. JBC $(50)$.

PR(50),ANGLE(4), NER (200), NRN $(200)$, EE (2)

- COMMON/BANARG/MBAND, NUMBLK, B(108) . Al108.51)

COMMON/SORT/NEX $(200)$

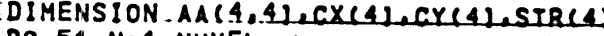

DO $51 \mathrm{~N}=1$. NUMEL

DO $51 \quad l=1.3$

51 PSIG(N,I)=SIG(N,I)

$X=N E I N C$

$x=1 . i x$

IF $S N N$ N NE 11 GO TO 6000

$\triangle C E L Z=0.0$

DO $5000 \quad I=1$.NNR

$N A=N E X(1)$

IF (NA.GT.4) NA $\leq 4$

II = NRN (I)

AVSIG(II.111=0.0

AVSIG $(1] .2)=0.0$

AVSIG $(1], 3]=0.0$

DO 2500 JA $=1, N A$

$M=I M(J A, I)$

$K 1=\lfloor X(M, 1)$

$K 2=\lfloor x(M, 2)$

$K 3=I X(M, 3)$

$K 4=I X(M, 4)$

CX(JA) $=(R(K 1)+R(K 2)+R(K 3)+R(K 4)) / 4,0$

$C Y(J A)=(Z(K 1)+Z(K 2)+Z(K 3)+Z(K 4)) / 4.0$

IF (KJ,NE,K4) GO TO 2500

CX(JA) $=(R(K 1) \pm R(K 2)+R(K 3)) / 3.0$

$C Y(J A)=(Z(K 1)+Z(K 2)+Z(K 3)) / 3,0$

.2500 CONTINUE

IF(NA.NE.2) GO TO 2650

$\ldots \ldots C X(3)=2 . * R(I I)-C X(1)$

$C X(4)=2, * R(I I)-C X(2)$

$C X(4)=2$.
$C Y(3)=2$

$C Y(3)=2 .: Z(1))-C Y(1)$
$C Y(4)=2 .: Z(1)-C Y(2)$

$\operatorname{IM}(3, !)=\operatorname{lM}(2, !)$

$I M(4, I)=I M(1, I)$

$N A=4$ 


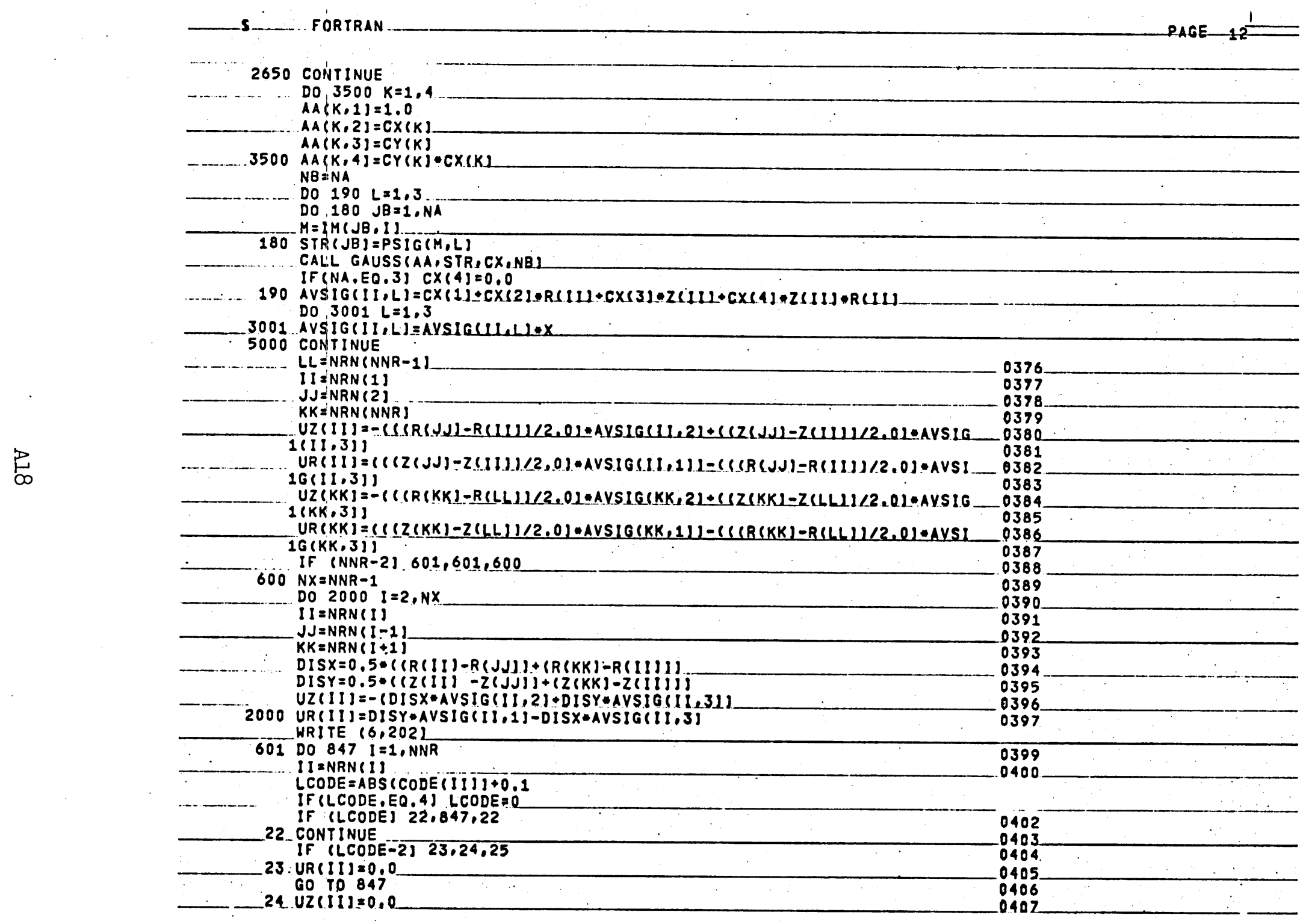




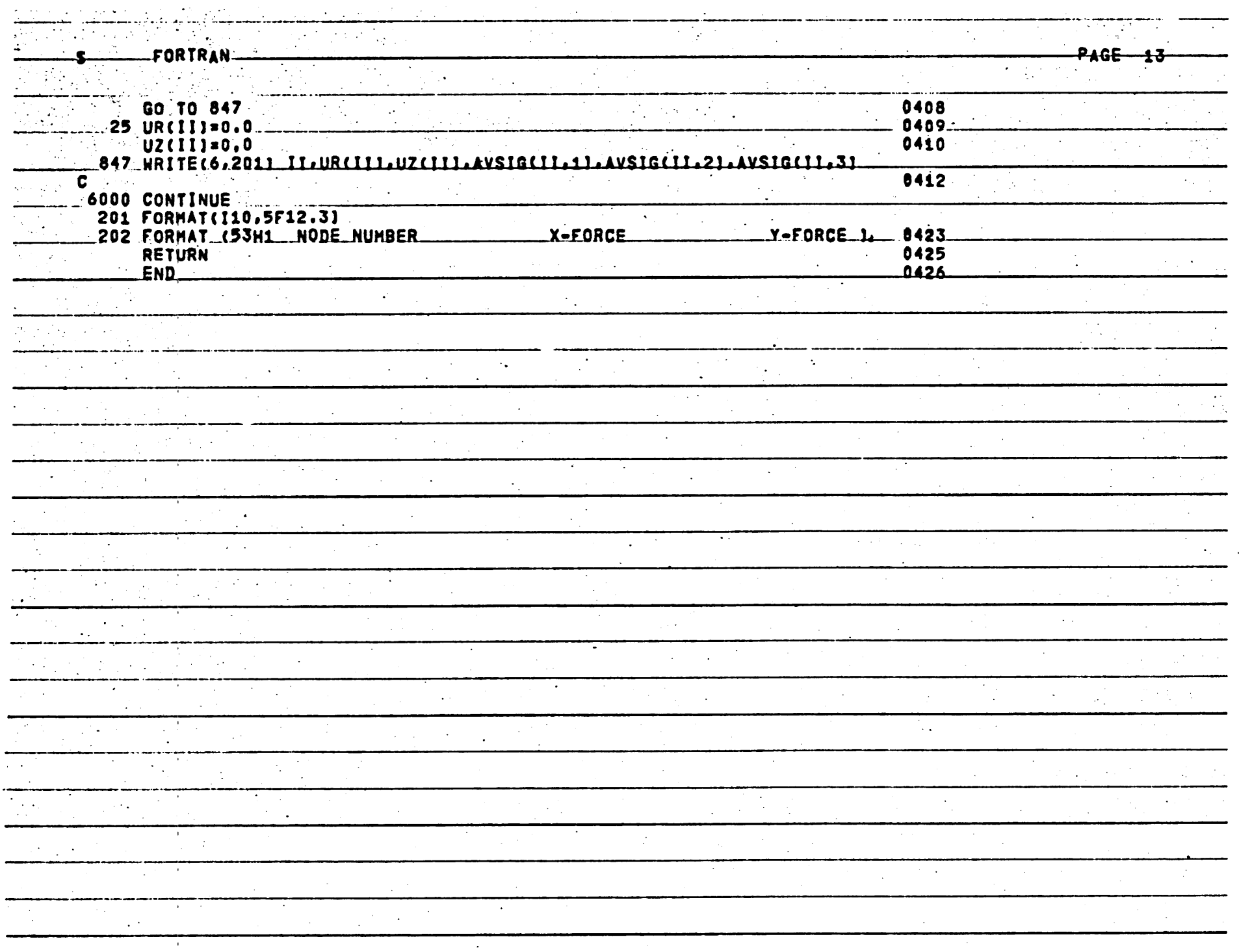


S FORTRAN

S FORTRAN

INCODE IBMF

SUBROUTINE GAUSS $(A, B, X, N B)$

DIMENSION A S R. LleASAYE (4,4), B(4), X(4)

DO $500, I=1.4$
DO $500, J=1.4$

500 ASAVE $(I, J]=A(1, J)$

$N=N B$

KASE $=1$

6. $K=1$,

61. $l=k+1$

IF (KASE) 112.601 .112

$112 L=K$

C.... DO $900 \quad 1 l=I . N$

IF (ABS(A(I),K) )-ABS(A(L,K))] $900,900,901$

$901 . L=I]$

900 CONTINUEE

IF $(L-K) 661,661,1105$

1105 DO $910 \quad J=K, N$

SAVE=A $(K, J)$

- $A\left(K_{0}, J\right)=A(L, J)$

910 A $A(L, J)=S A Y E$

TEMP $=B(K)$
TE

B
$B(K)=B(L)$

$B(L)=$ TEMP

661 IF ( $(K, K, K)), 6,7,6$

7 PRINT 80

80_FORMAT $5 x_{1} 11$ 1H ZERO PIVOT

GO TO 1000

$X M=A(I, K) / A(K, K)$

$A(I, K)=0.0$

$J=K+1$

DO $77 \mathrm{KI}=\mathrm{J}, \mathrm{N}$

$77 A(I, K I)=A(I, K I)-X M-A(K, K I$

$B(l)=B(1)-X M A B(\bar{K})$

IF $(1-N)$ ] $300,301,300$

$300 I=1+1$

GO to 6

301 If $(K-(N-1)) 303,304,303$

30.3 $K=K+1$

Go 1001

$304^{\circ} X(N)=B(N) / A(N . N)$

$l=N-1$

$13 J=1+1$

$S=0.0$

10 $S=S \cdot A(L . J) \cdot x(d)$

If $(J-N)$ 21.16,21

$21 . \mathrm{G}=\mathrm{J}+1$

$1.16 x(1)=(B(1)=51 / 1(1) 1)$ 
s trortran

IF (1-1) 23.22 .23

$23 \cdot 1=1-1$

GO TO 13

22 CONTINUE
1000 CONTINUE

DD 520 S 104.

DO $520 \quad J=1.4$

520. $A(L, J)=A S A V E(L a d)$

RETURN

END 


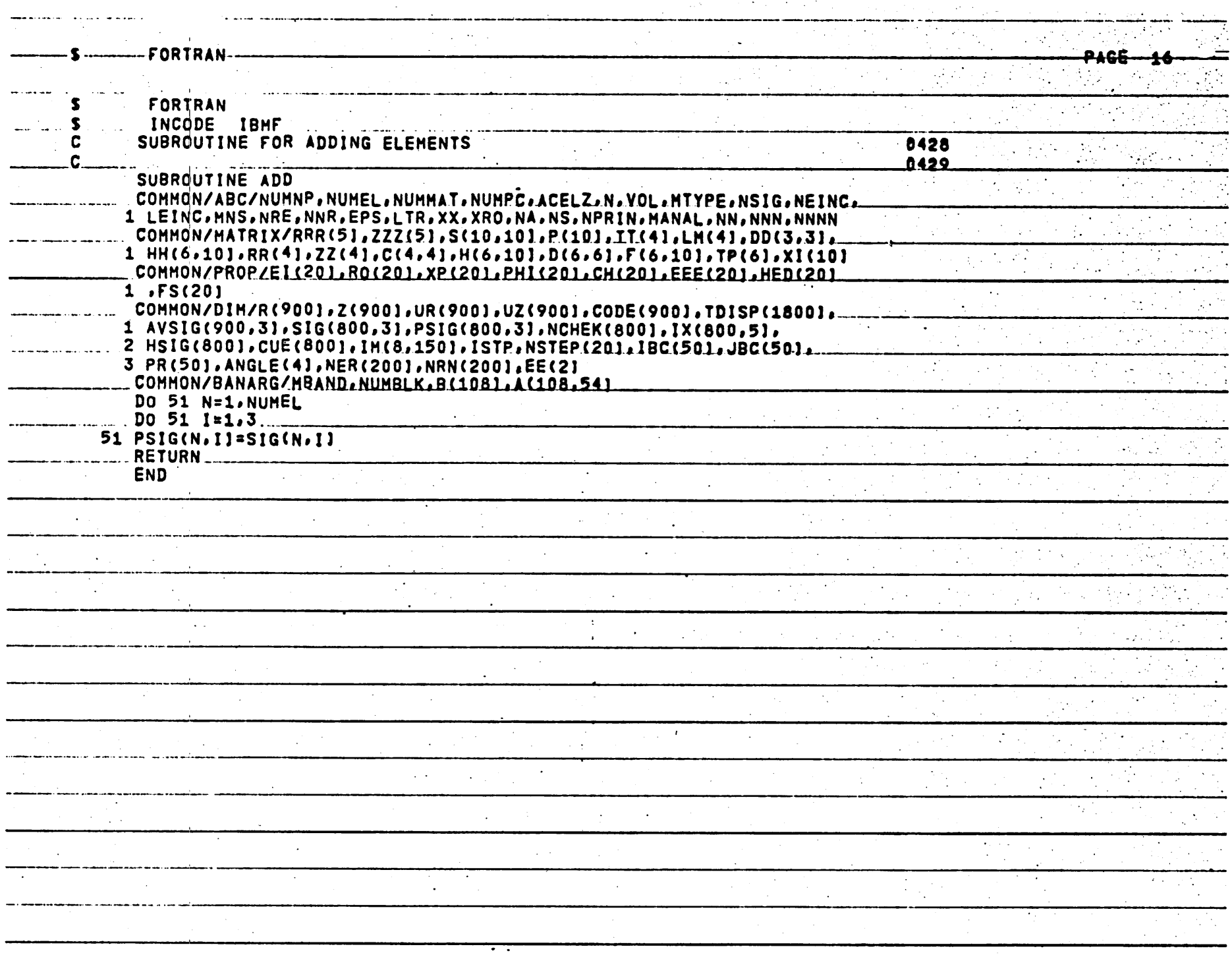




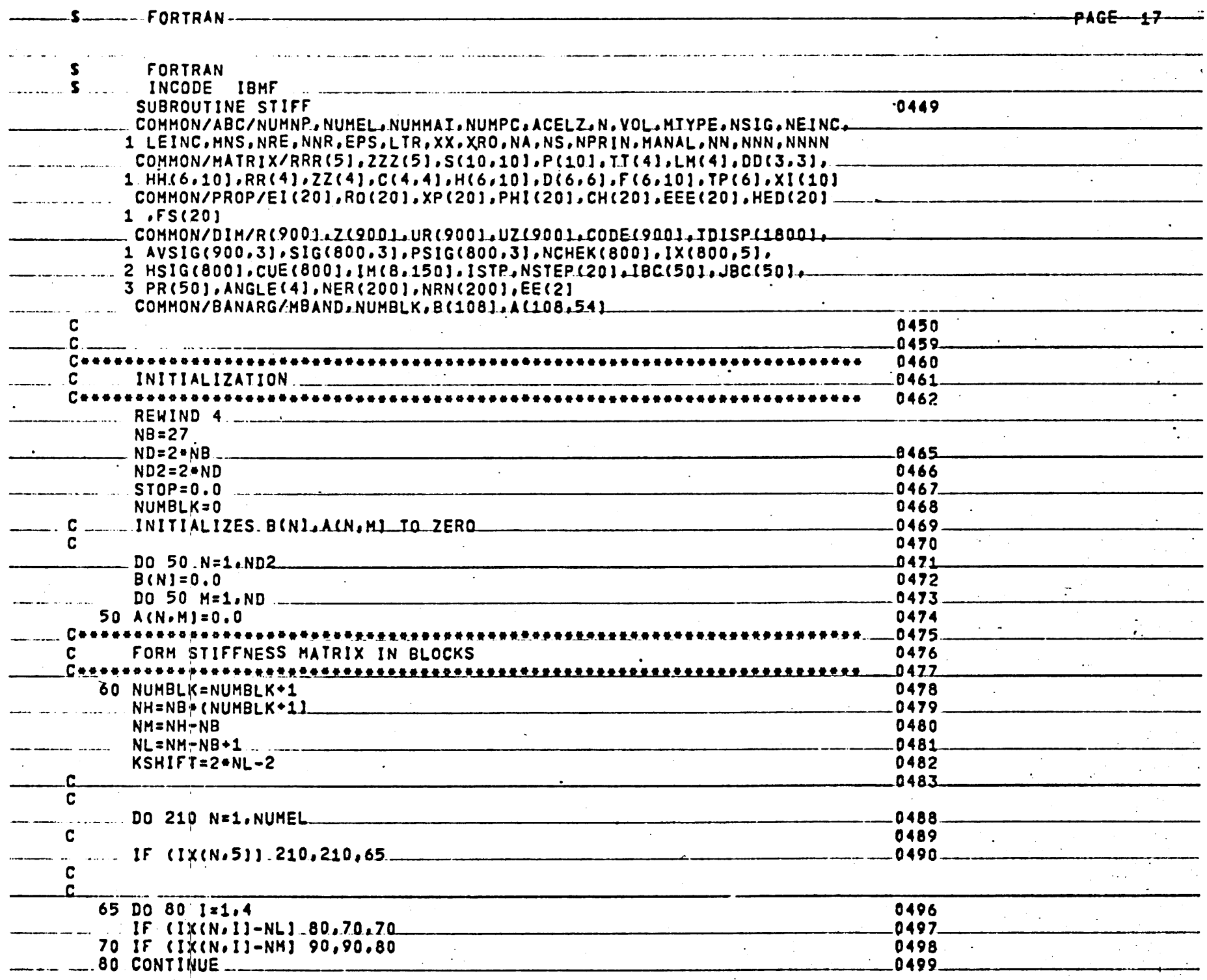


S_... FORTRAN

PAGE 28.

c

GO TO 210

0500

90 NNNN $=0$

0501

CALL QUAD

- $\operatorname{CUE}(N)=E E(1)$

$[X(N, 5]=-1 \times(N, 5)$

c

If IF (VOLI $142,142,144$

STOP $=1.0$

C

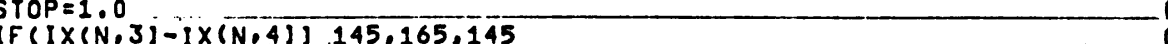

0506

0507

0509

0510

$C C=S(1), 10) / S(10,10)$

$P(1 !)=P(11)-C C \backsim P(10)$

.0514

$150 s(11, J j)=s(11, J j)=C \overline{C * S(10, J J)} 0518$

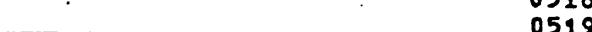

Do $160.11=1.8$ - 0520

$C C=S(11,9) / 5(9,9) \quad 0521$

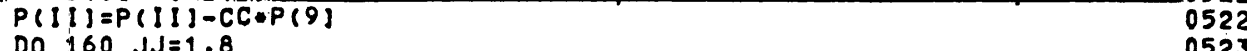

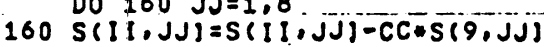

$\mathrm{C}$
$\mathrm{C}$
$\mathrm{C}$

0524

ADD ELEMENT STIFFNESS TO TOTAL STIFFNESS

$L M(1)=2 * 1 \times(\mathrm{N}, 1)=2$

DO $200 \quad I=1.4$

DO $200 \quad K=1,2$

$I I=L M(I]+K-K S H I F T$
$K K=2+I-2+K$

$B(I I)=B(l l)+P(K K)$

DO $200 \quad J=1.4$

$J J=L M(J)+L-I I+I-K S H I F$

$L L=2 \cdot J-2+L$

IF (JJ) $200,200,175$

175 [F (ND-JJ) 180.195 .195

180 WRITE $(6,2004)^{\prime} \mathrm{N}$

STOP $=1.0$

GO TO 210

195 A (II JJ) $=A(1 /$ LJJ $)+S(K K, L L)$

200 CONTINUE

210 CONTINUE

C ADD CONCENTBAIED FORCES HITHIN BLQCK

0531

0532

0533

0534
0535

0536

0537

0538

0539

0540

0541

0542

0542

0543

.0544

0546

0547

0548

0549

0550

0551 


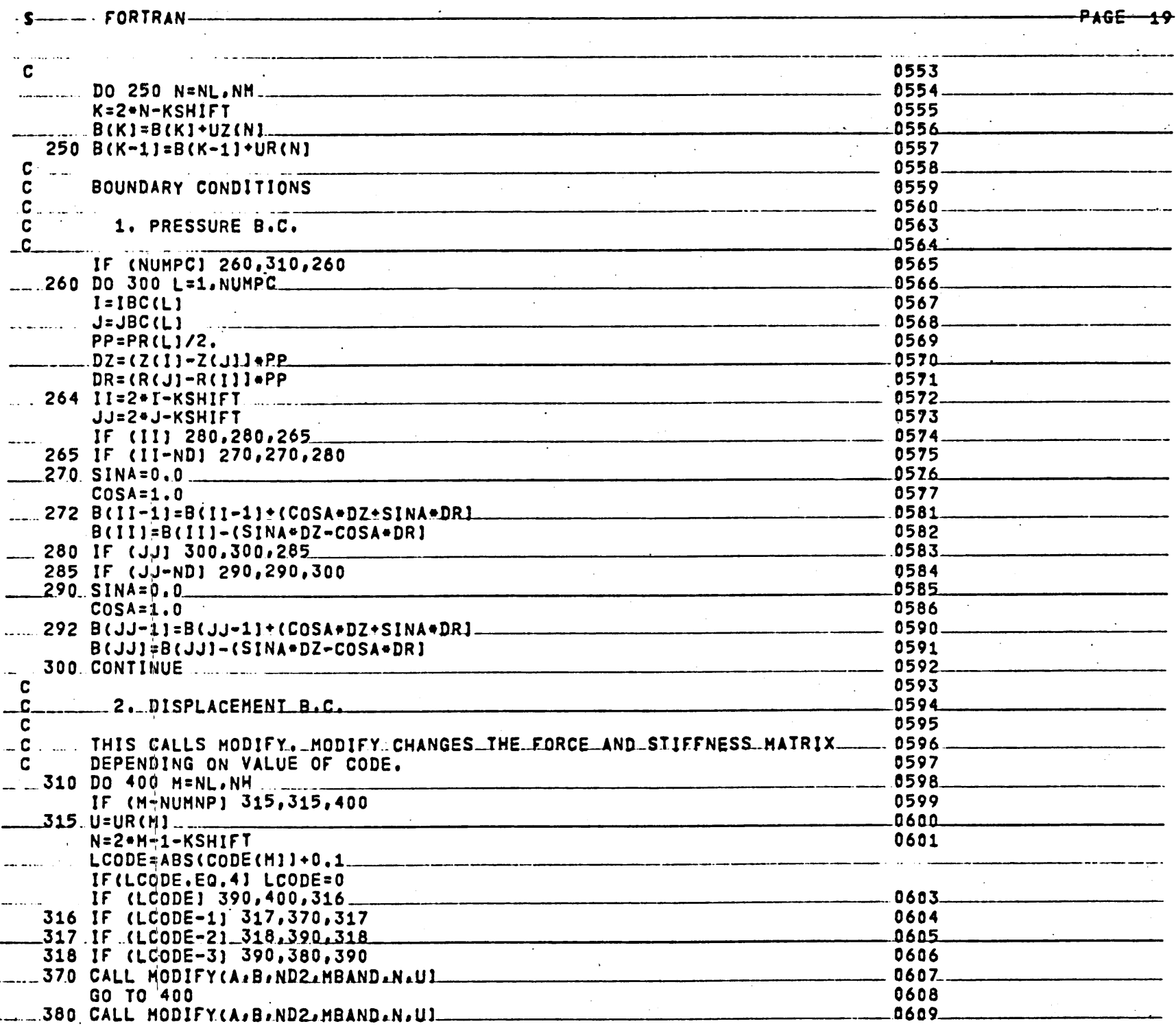




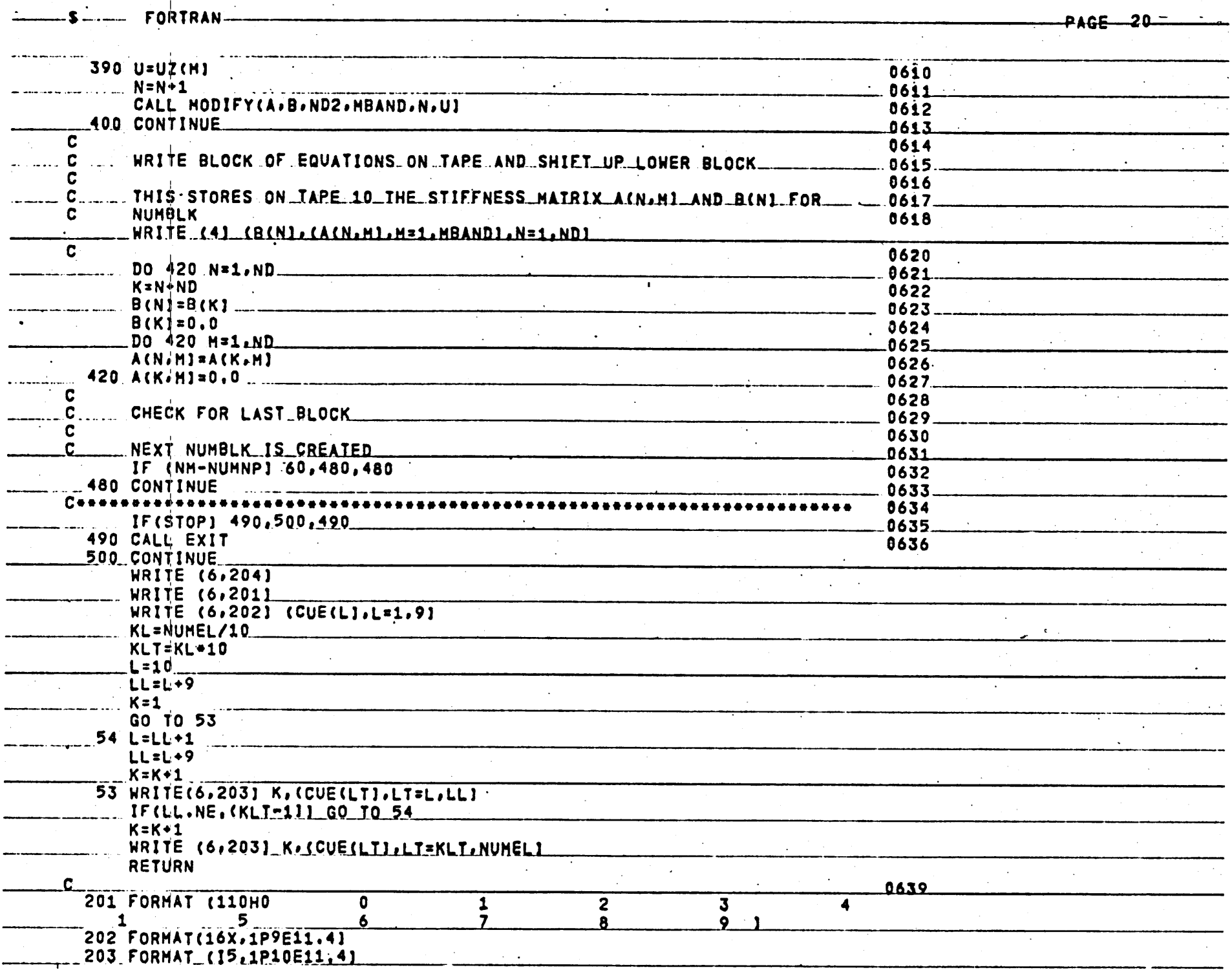




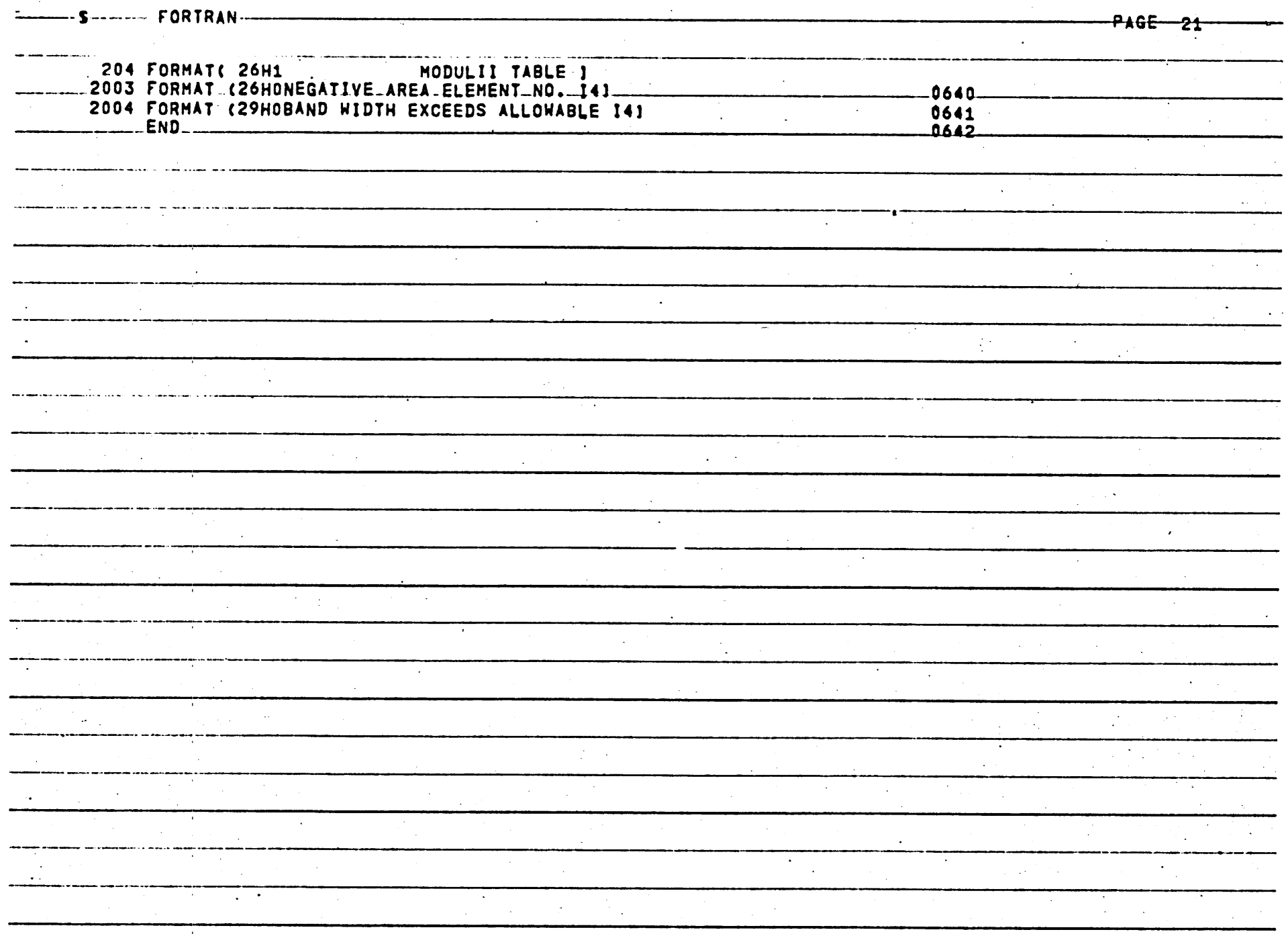




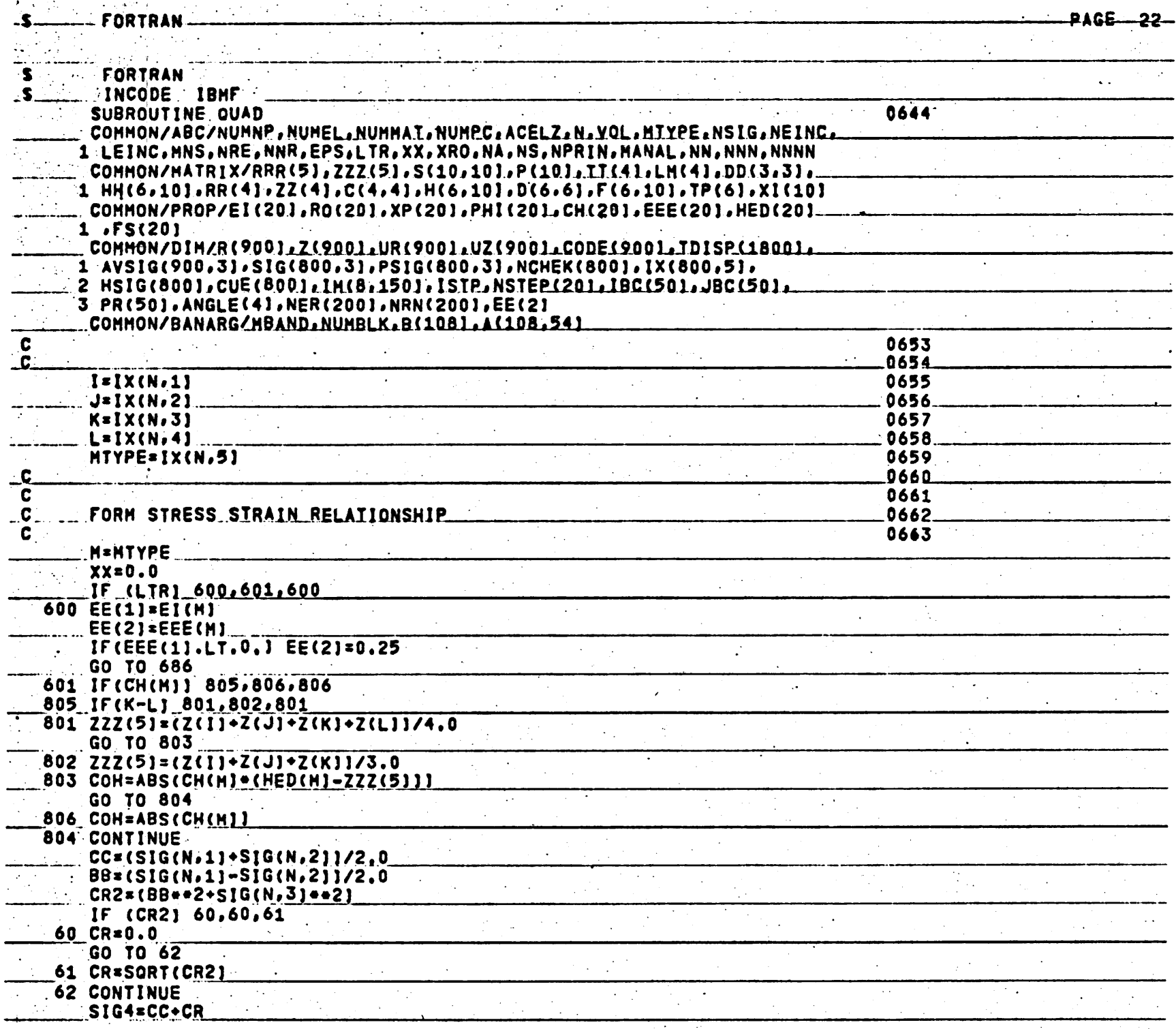




\section{SIG5 $=C C-C R$}

SI $66=5164-5165$

$C C=(P S I G(N, 1)+P S I G(N, 2)) / 2,0$

$B B=\left(P S I G(N, 1)-P S I G(N, 2){ }^{2}\right.$

$\left.C R 2=(B B+\cdots 2+P S) G\left(N_{0} 3\right) * 2\right)$

IF (CR2) 63.63 .64

$63 \mathrm{CR}=0.0$

60 TO 65

64 CR $=$ SORT (CR2)

65. CONTINUE
PSIG4 = CC $\triangle$ CR
PSIG5

PSIGG =PSIGA-PSIGS

PHE = PHI $P M I$

SIGF $=2,0 \cdot C O H \cdot C O S(P H E)+S I N(P H E) *(A B S(S) G 4+S I G 5))$

$X F=S I G F$

IF (FS M).LT.0.001) GO TO 490

IF (SIG4,EO,0,0) COEEI (M)

IF (SIG4.NE, O.0) CQ=E[ (M)•ABS(SIG4) *XP(H)

$X F=(F S(M) \cdot S I G F \cdot C Q \bullet 0.01) /(F S$ (M) $C 0 \bullet 0.01-51 G F)$

.490 CONTINUE

IF SNCHEK SNLER OI GO TO 500

$E E(1)=0.01$ 


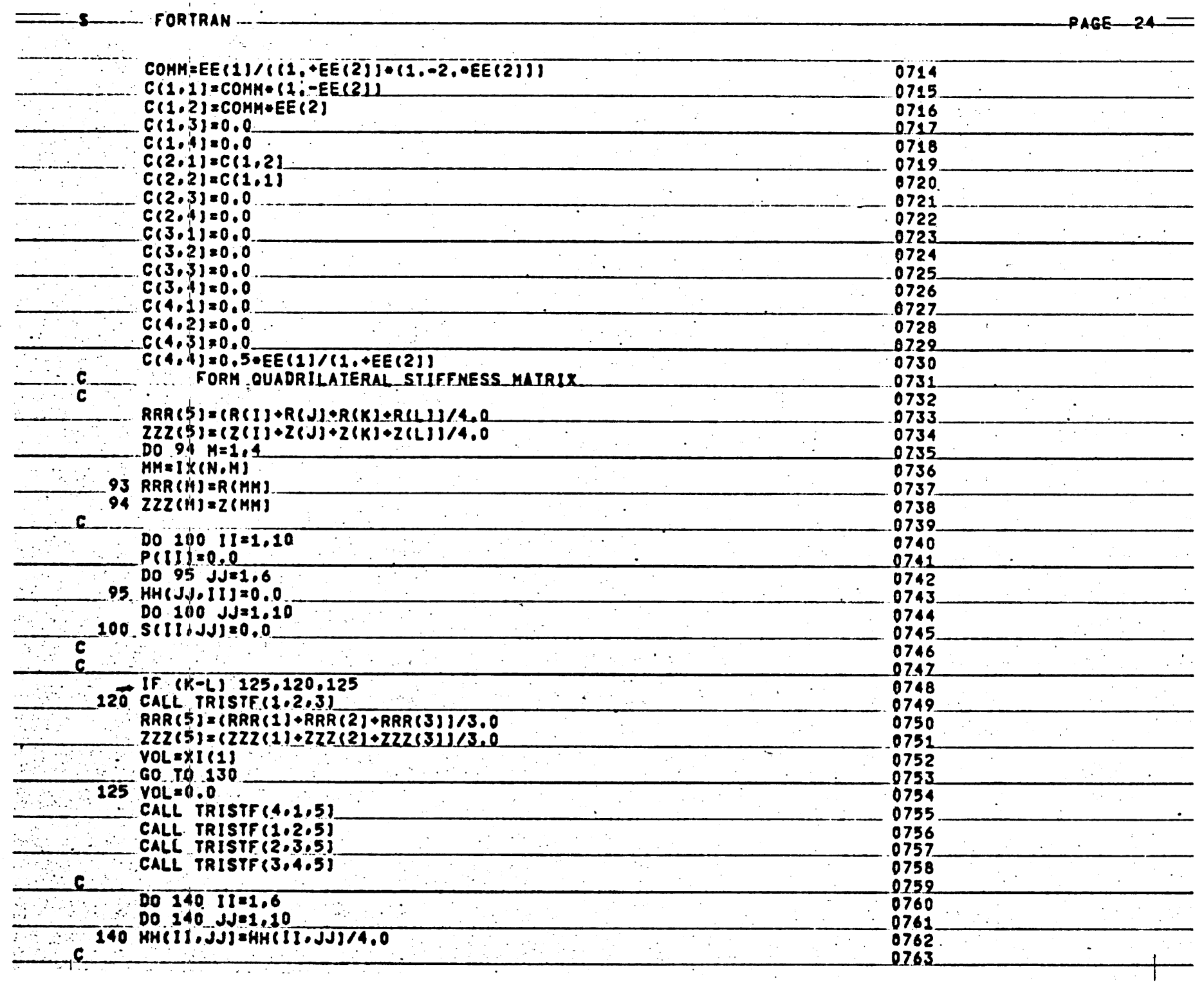




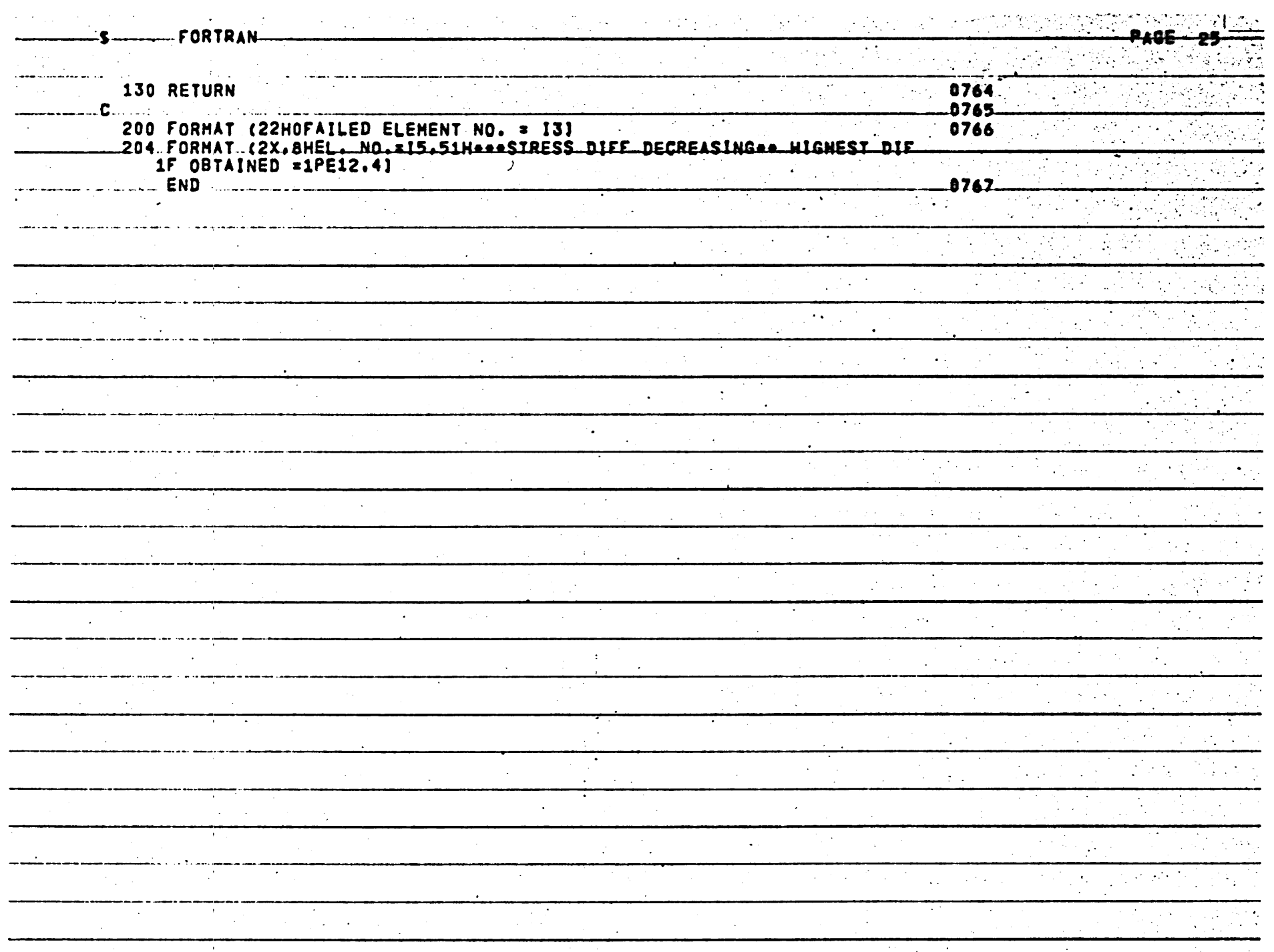




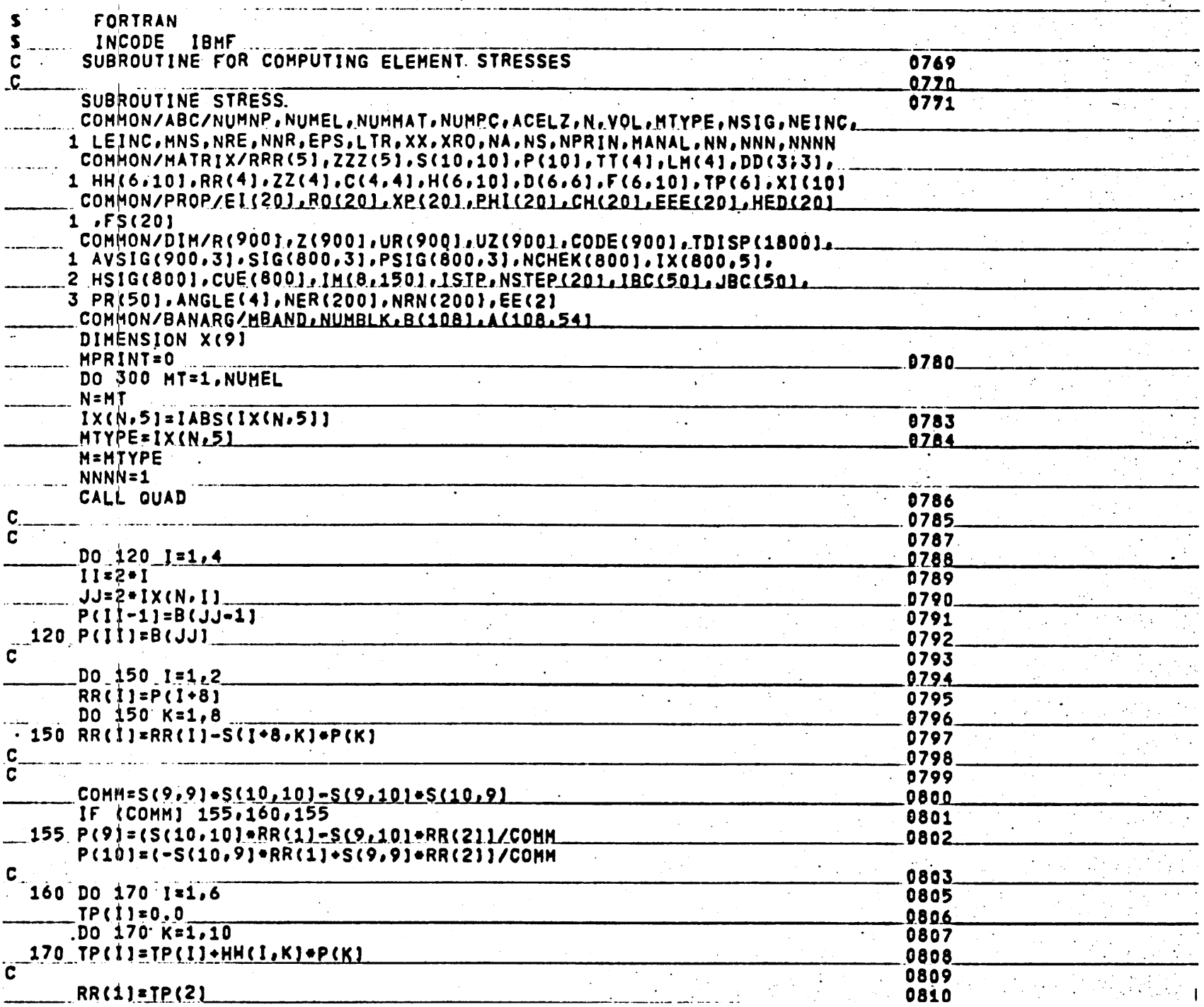




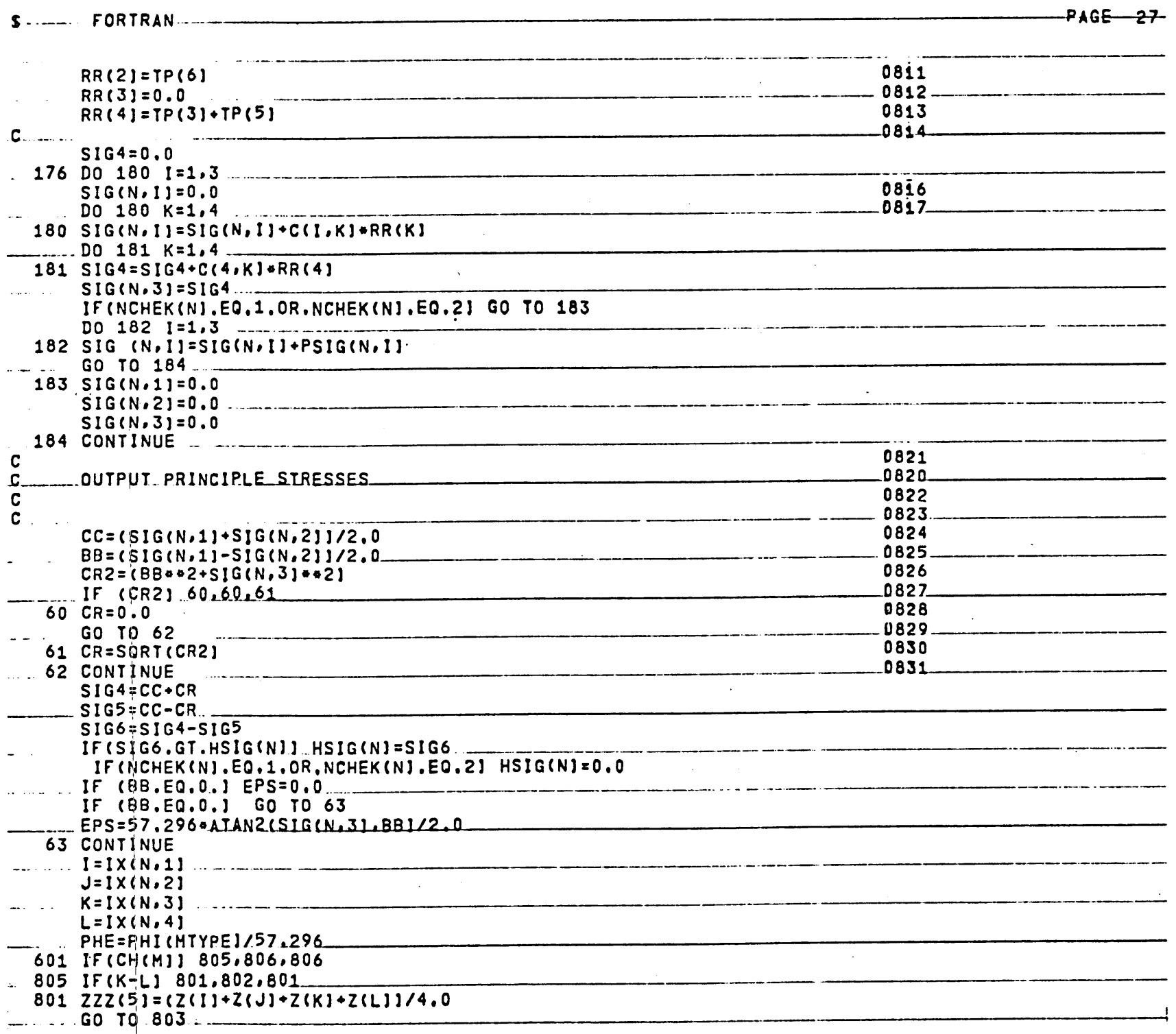




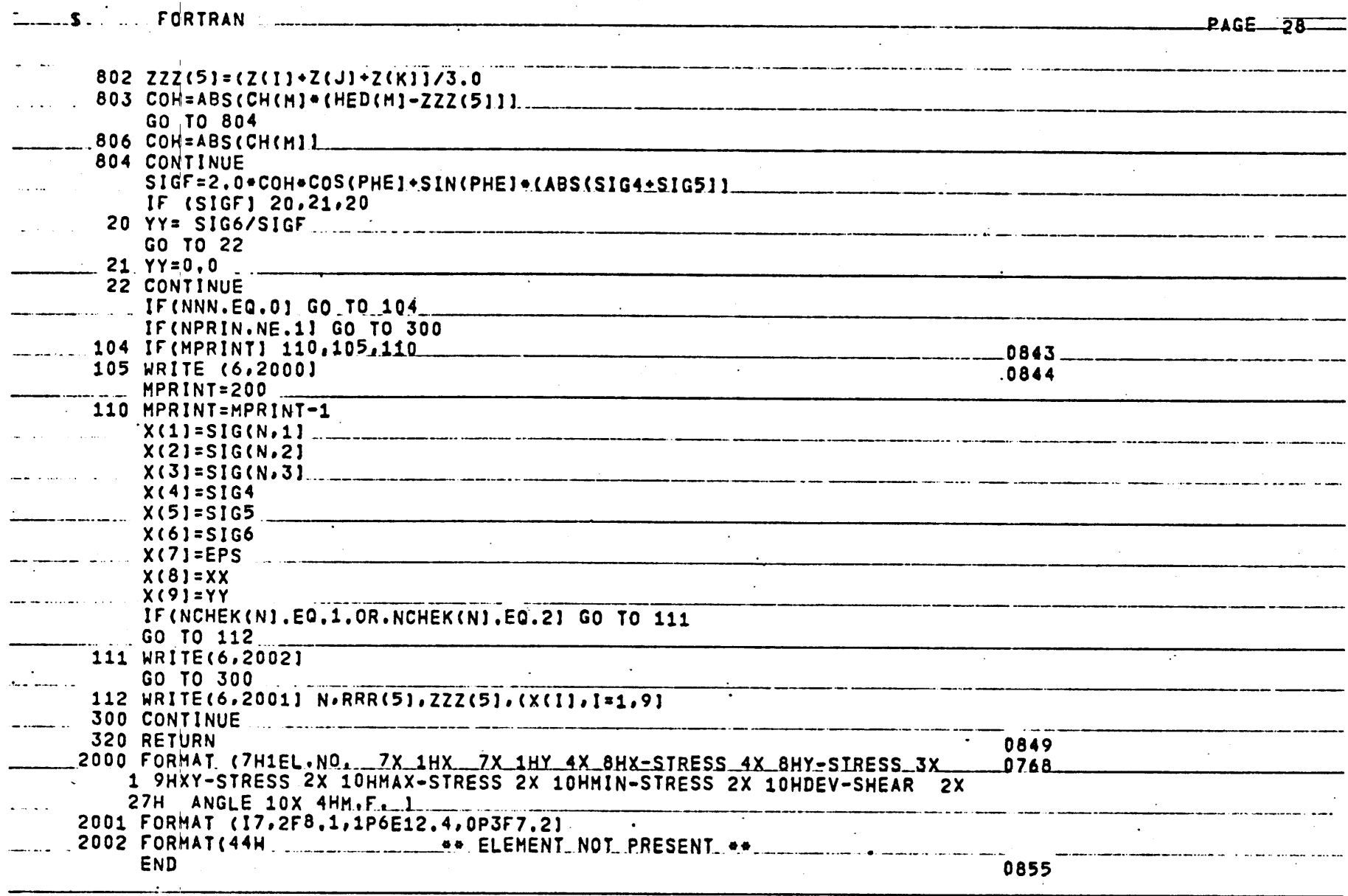




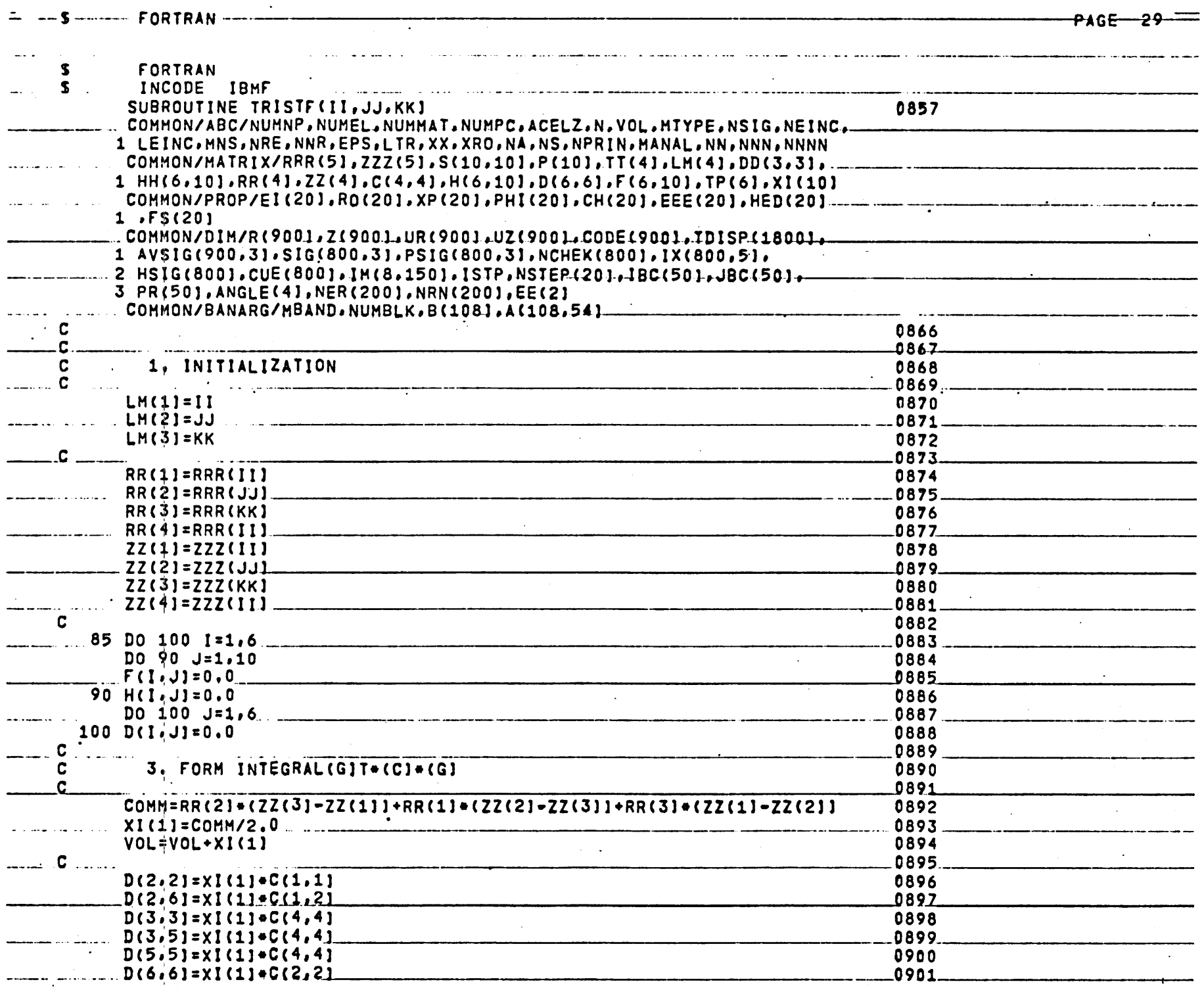


c

108 DO $110 \quad I=1,6$

DO $110 \quad J=1.6$

110. D $(1,1)=D(1, J)$

$c$
$c$
$c$

4. FORM COEFFICIENT-DISPLACEMENT_TRANSFORMATION MATRIX

0902

0903

0904

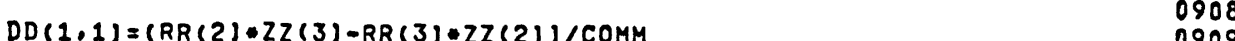
$D D(1,2)=(R R(3) \cdot 2 Z(1)-R R(1) \cdot 2 Z(3)) / C O M M-0910$

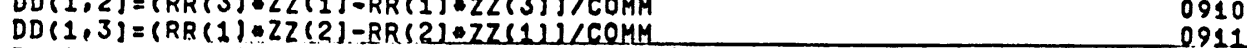
$\begin{array}{ll}D D(1,3)=(R R(1) \cdot 22(2)-R R(2) \cdot Z Z(1)) \angle C O M M & 0.911 \\ D D(2,1)=(2 Z(2)-Z 2(3)) / C O M M & \end{array}$

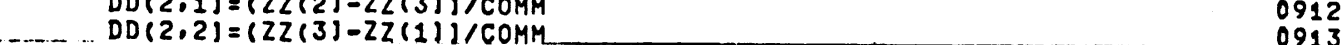
DD 2,3$)=(22(3)-22(1)) / C O M M$ $\begin{array}{ll}D D(2,3)=(2 Z(1)-Z 2(2)) / C O M M & 0914 \\ D D(3,1))=(R R(3)-R R(2)) / C O M M & \end{array}$ $D D(3,1)=(R R(3)-R R(2)] / C O M M$ $\begin{array}{ll}D D(3,2)=(R R(1)-R R(3)) / C O M M & 0916 \\ D D(3,3)=(R R(2)-R R(1)) / C O M M & 0917\end{array}$

DO $120 \quad I=1,3$

$J=2 \cdot L M(1)-1$

$H(1, J)=D D(1,1)$

$H(2, J)=D D(2,1) \cdots 0921$

$\begin{array}{rr}H(2, J)=D D(2,1) & 0922 \\ H(3, J)=D D(3,1) & 0923\end{array}$

$H(5, J+1)=D D(2,1)$

120. $H(6, J+1)=D D(3,1)$

\section{FORM ELEMENT STIFFNESS MATRIX $(H) T \cdot(D) \bullet(H)$}

0926

0927

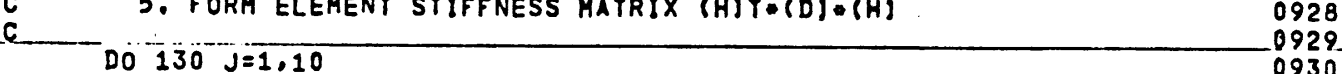

DO $130 \quad j=1,10$

DO $130 K=1,6=$

0931

0932

128 DO $129 \quad I=1.6 \quad 0932$

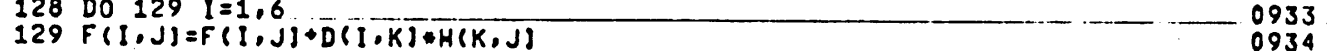
130_CONTINUE

C... DO $140 \quad 1=1,10$

DO $140 \quad K=1,6$

IF (HCK, I) $138,140,138$

0934
0935

0936

0936

138 DO $139 \quad J=1,10$

$139 S(1, J)=S(L, J)+H(K, I) \cdot F(K, J)$

140 CONTINUE

C
C

ACCELERATION LOADS

IF (MNS-1] $5,98,5$

98_COMM $=R O(M T Y P E) \cup X I(1) / 3,0$

DO $169 \quad 1=1.3$

$J=2$ L L $(I)-1$

$169 P(J+1)=P(J+1)-A C E L Z$ COMM

1. 60 TO 400

0938

0939

0940

0941

0942

0943

0943

0946

0947

0940

0950

0931 


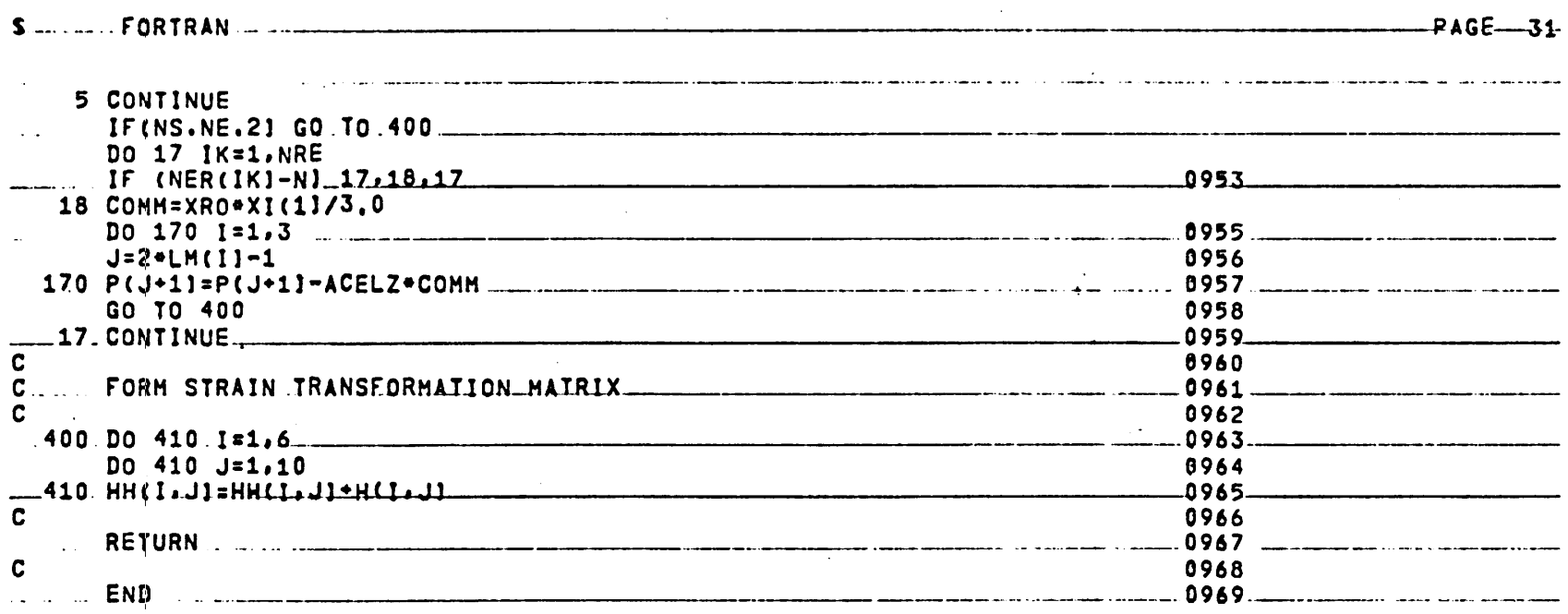




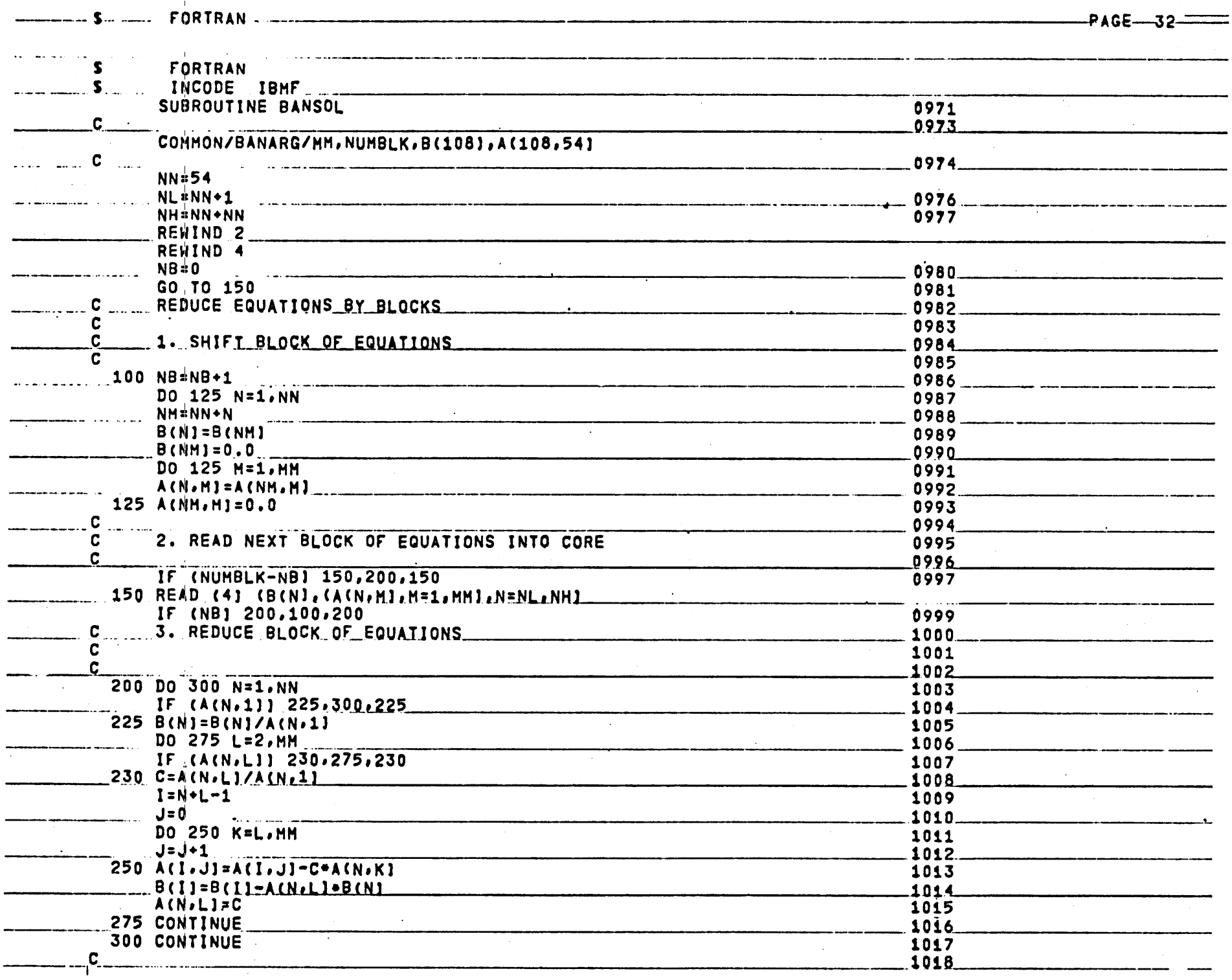




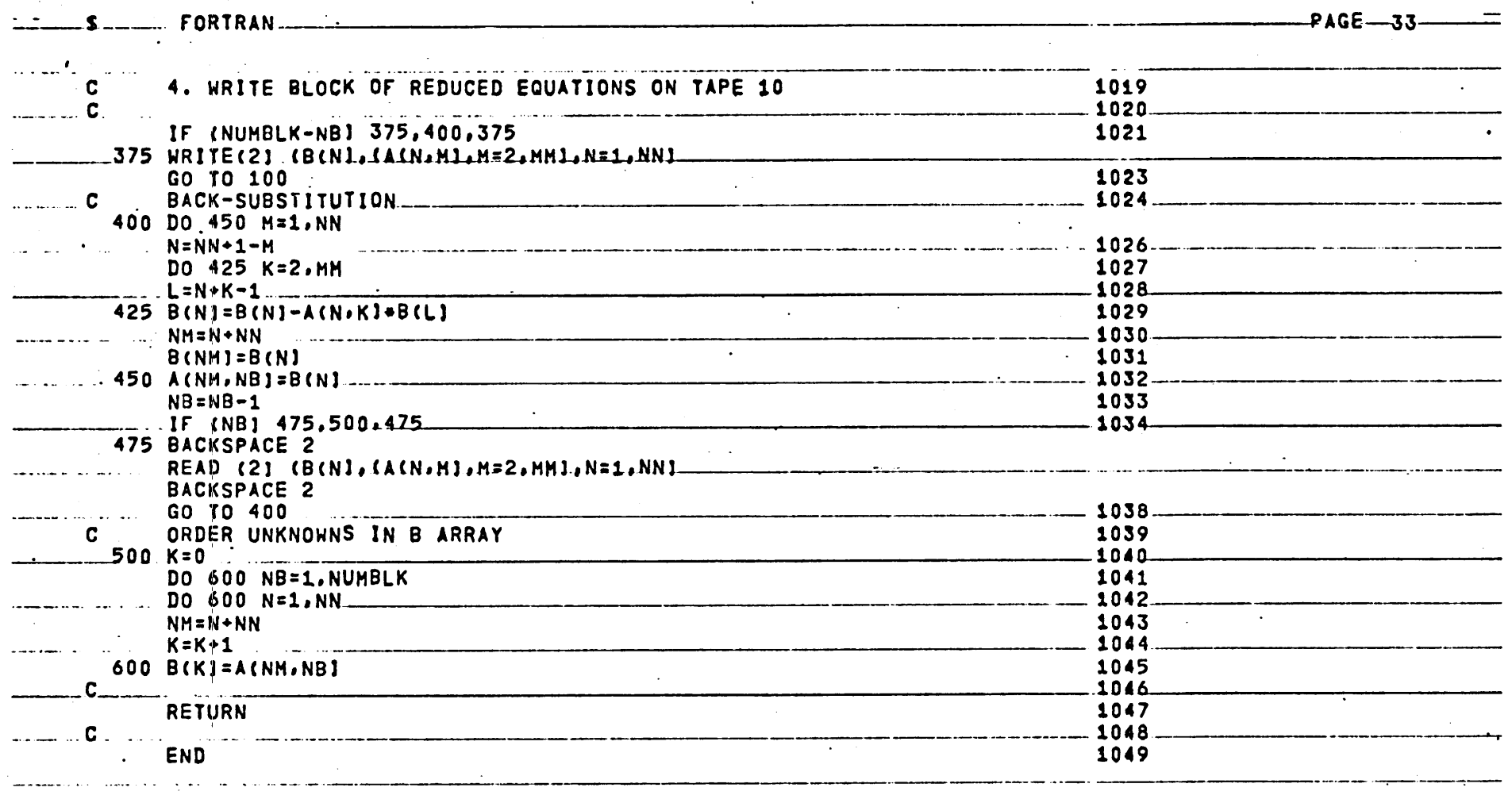


5 FORTRAN

INCODE IBMF

SUBROUTINE MODIFY (A,B,NEQ,MBAND,N.US

DIMENSION A(108,54),B(108)

C DO $250 \quad M=2$.MBAND

$\mathrm{K}=\mathrm{N}-\mathrm{M}+1$

IF $(K) 235.235 .230$

$-230 \quad B(K)=B(K)-A(K, M) \cdot U$

$A(K, M)=0.0$

$235 K=N+M-1$

IF (NEO-K) $250, \overline{240.240}$

240 (K)=B(K)

$A(N, M)=0.0$

$A(N, M)=0.0$
$C O N T I N U E$

CONT INUE
$A(N, 1)=1.0$

$B(N)=U$

RETURN

END

1051

1052

1054

2055

1056 .

1057

1058

1059

1059

1050

1061

1062

1063

1064

1065 


\section{Computer Program for the Stability Analysis of Embankments or Slopes}

1. The program consists of a main program (SR6ZZ) and four subroutines (CIRCLE, LARGES, GAUSSE(A), and RESULT) and was coded by J. B. Palmerton for use on the GE-400 series time-sharing system.

\section{Purpose}

2. This program evaluates the factor of safety of embankments or slopes using stresses obtained from finite element solutions. The factor of safety is obtained by evaluating the mobilized shear stresses and comparing them with the available strengths along circular arcs passed through the embankment or slope.

\section{Sequence of Operation}

3. The main program (SR6ZZ) reads the input data and monitors all operations by calling the following subroutines for each circular arc to be analyzed.

a. CIRCLE divides the failure circle into a specified number of equal segments. The coordinates of the midpoints of the segments, and the angles that the tangents to the midpoints make with the horizontal are calculated.

b. IARGES chooses the four closest element centers to each midpoint.

c. $\operatorname{GAUSSE}(\mathrm{A})$ computes the stresses $\left(\sigma_{x}, \sigma_{y}, \tau_{x y}\right)$ at each midpoint by interpolation from the stresses at the four closest element centers.

d. RESULT computes the normal and shear stresses at each midpoint, then sums the forces acting along the circle and determines the factor of safety. 
4. The data is fed directly into the computer by the operator working from his own terminal within the GE-400 time-sharing system. Prior to running the main program, an open file (SR3I) is established which contains the following information: the number of elements involved, the element numbers, the coordinates of the centers of each element, and the stresses ( $\sigma_{\mathrm{x}}, \sigma_{\mathrm{y}}$, and $\tau_{\mathrm{xy}}$ ) at the element centers. This information is read from the open file by the main program.

5. Once the message RUN is transmitted, two messages will be returned at the teletype asking for information. The first message reads $\mathrm{COH}, \mathrm{PHE}$, XRAD, RADINC, NRAD, NOPT. In response the operator types in the following information: the cohesion of the soil, the friction angle, the length of the radius of the circle to be used for the first trial, the amount by which the radius should be increased in each successive trial, the number of radii to be tried, and the option to be used. The option can be either 0 or 1 . If it is 1 , only the results of the circle having the lowest factor of safety will be printed. If it is 0 , the results for each trial circle are printed.

6. The second message reads XB, YB, XEMIN, XEMAX, NOM, YE, NDIV. The operator then types in the following data: the $\mathrm{x}$-coordinate where the circle intercepts the bottom of the slope, the corresponding y-coordinate, the minimum $x$-coordinate where the trial circle can surface at the top of the slope, the maximum $x$-coordinate where it can surface at the top of the slope, the number of locations where the trial surface may intercept between these two points, the $\mathrm{y}$-coordinate where it intercepts the top of the slope, and the number of segments each circle is to be divided into in each analysis. 
SP. জZ.7.

196\$PPC.

$11 \% 5 M: 3 M$

$1 ? .7 *$

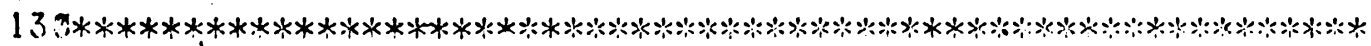

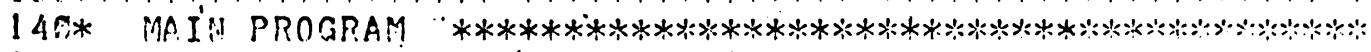

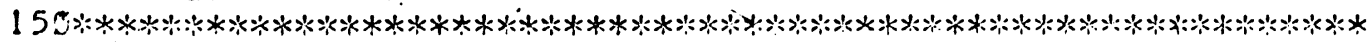

160 ComM0! $\approx(1$ )

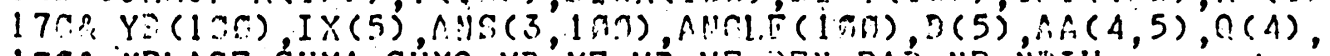

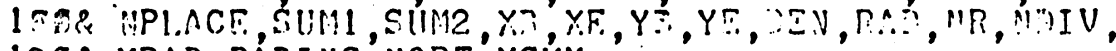

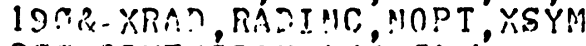

2) TIME!!SION! $A(4,5)$

$21:$ XSYM $=34 \pi$.

$2 ? \pi, M 7:=3$

23." CALL OPENF (1, "SP31")

$24 \pi$ ROS COIIII!UE

25) RE!!IUI: 1

$2590 \%=16 \% \Omega \Omega$

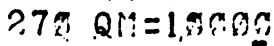

2TH PRIUT, "TITL.F. OF PROBLFM"

2.0 REA? OSं

30 oge forinat (111).

$310 . K 1=K ?=K 3=1$

32. RFAD $(1$,$) NPOINT$

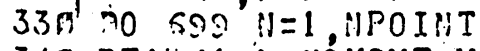

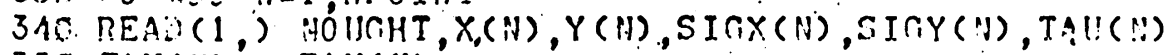

$35 \%$ TAU(M) $=-T A U(M)$

3 Sn 6?S COUTIMUE.

37E PRINT "COH, PHF, XRA?, RATINC, NRAS"

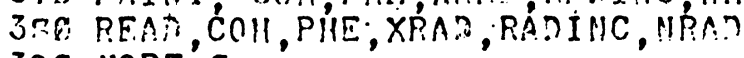

$3 \cap \pi \quad$ NOPT $=0$

4T9: $P A . D=X R A$ I

41 \% PHE $=P H E / 57.206$

125 PRINT, TYPE IN X! ,YR, XFMIN, XFMAX, NOM, YE, MYIV"

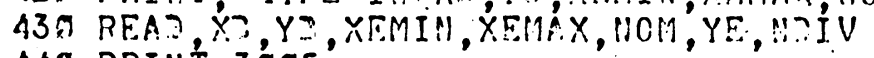

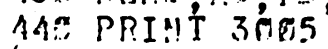

4503 OOS FORIAT C 7 MH

4SERETRENATH

476 PRINT,

FNT POINT

EXIT POINT

RA.TIS

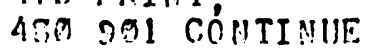
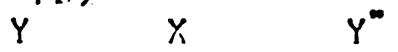

497 nO $22.9 \mathrm{NJ}=1, \mathrm{NOM}$

STC R11011=110M

51: R!IJ $=\| 1 \mathrm{~J}$

52ก XE $=$ XEMIN+(RHJ-1 .)* (X.MAX-XEMIN) /RNOM

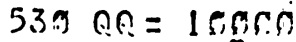

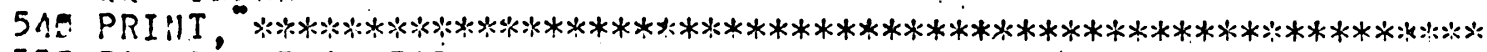

550 I0 $92 \pi$ UR $=1$, MRAD

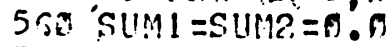

57Ø CALL. CIRCLE.

5 ?ח $\mathrm{QL}=1$.

$59900.49 \pi \quad N=1$, NPLACE 


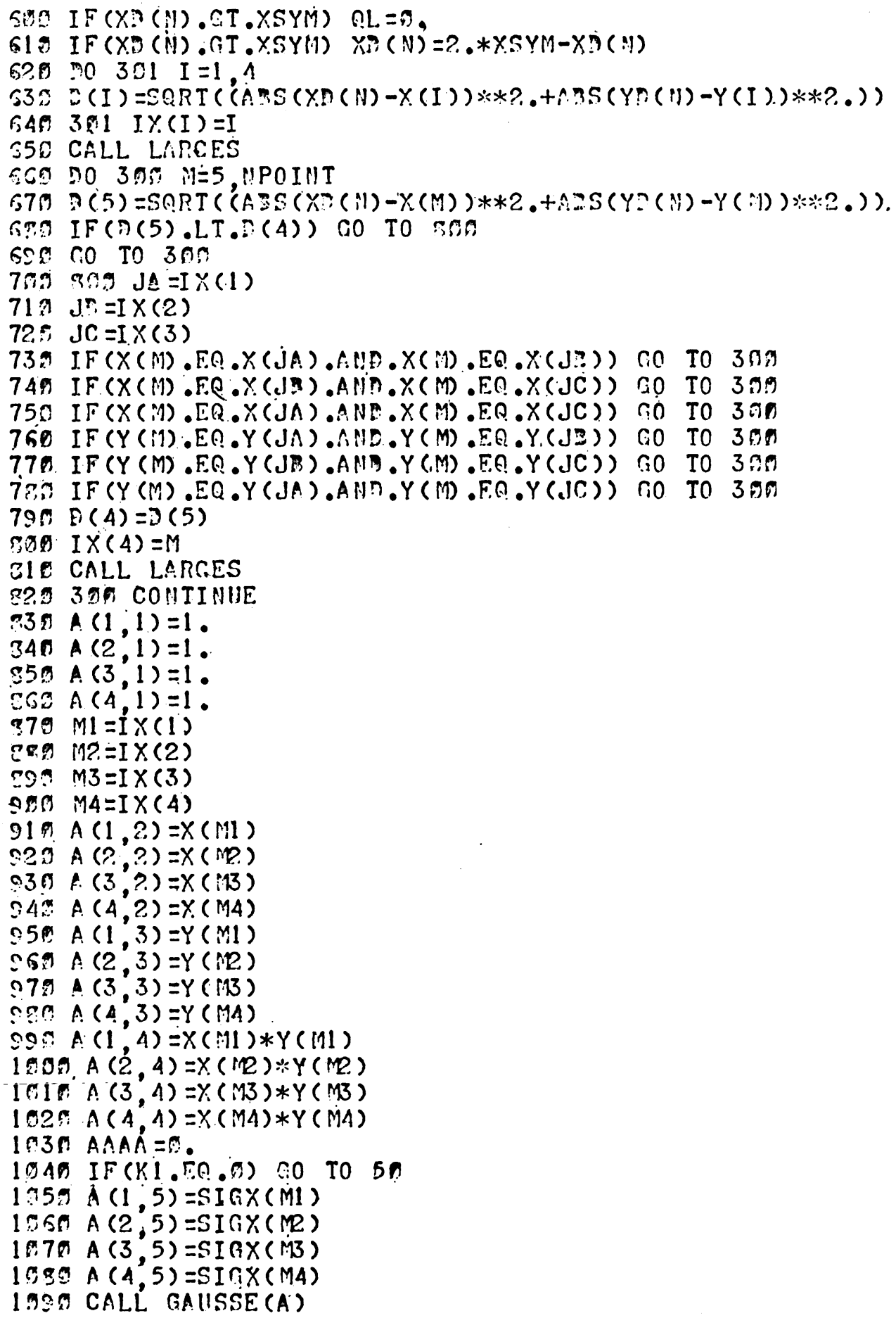


SRSZZ CONTIMUEB

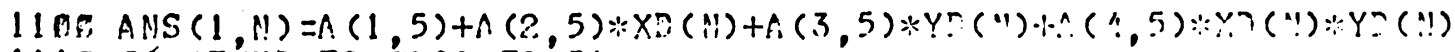

111 \% 5 A IF'(K?.EO.ค) CO TO 51

$112 n \cap(1,5)=S I C Y Y(i 11)$

$113 \cap \wedge(?, 5)=S I G Y(M P)$

$1149 A(3,5)=S I G Y(M 3)$

$115.3 \quad A(4,5)=S I G Y(M 4)$

11 5. CALL GAIISSE. (A)

1179 A!IS $\left.(?, N)=A(1,5)+A(?, 5) * Y^{n}(n !)+f(3,5) * Y\right)(! n)+A(1,5) * \times n(" !) * Y ?(" !)$

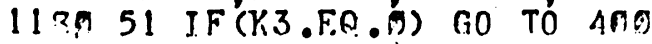

$1192 A(1,5)=$ TAUL $(M i)$

$129 \Omega(2,5)=$ TAll $(R)$

12 In $A(3,5)=\operatorname{TAU}(M 3)$

1?2. $A(4 ; 5)=\operatorname{TAU}(M 4)$

1230 C.RL CAIISSE (A)

$12.4 \%$ ANS $(3, N)=A(1,5)+A(2,5) * X n(!)+A(3,5) * Y 2(! !)+A(1,5) * Y^{n}(! !) * Y^{n}(" !)$

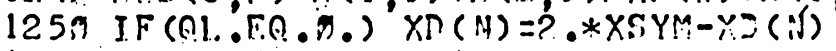

$126 \pi$ IF (QL.E.Q.2. ) nL $=1$.

127\% 43\% CO!TIMUE.

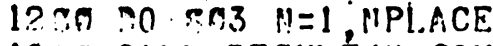

129 CALL RESILT (II, COH, PHF.)

$130 \pi 8 \% 3$ CONTIMUE.

1310 FS $=$ SUM1 $/$ SUIM.

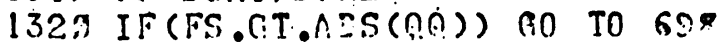

1332 กQ =FS

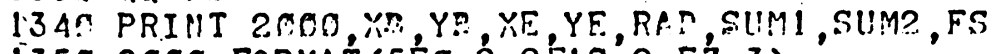

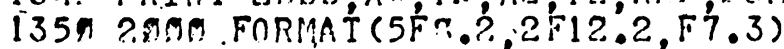

1369 69? IF (FS.CT.AM) ती TO 637

137 Q $\mathrm{Q} ! !=\mathrm{FS}$

13 Cก QRAD =RA

$13 \supseteq 2$ QXXE $=X E$.

$14 M 2$ CO 7 CONTINUE

$141 \%$ O?? COITJMIIE.

1420 \%29 CONTIHUE

1430 KRAE $=$ CRA?

$14 A$ PAD $=$ QPRA?

IA59 IRAE = 1

14 SO XEMIN $=$ O.XE

1.47. XEMAX $=X E M I N+1$.?

1409 NOM=1

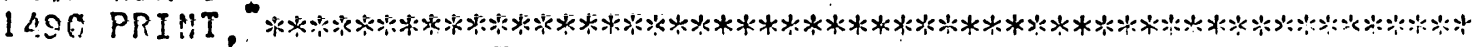

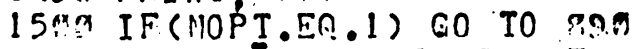

1519 PRINT FOR THE MIN. FS ASOVE, THE FOLLOWIA!G HAS CAICIUAATF"

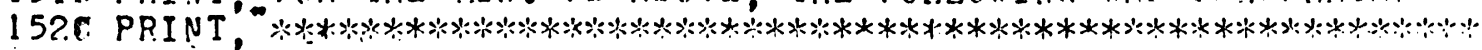

$153 \pi$ PRII!I 4NGI

$154 \%$ PRINT 4FIR.

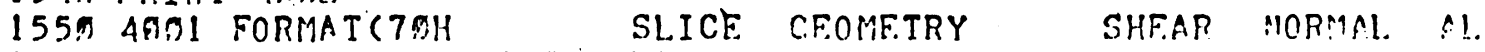

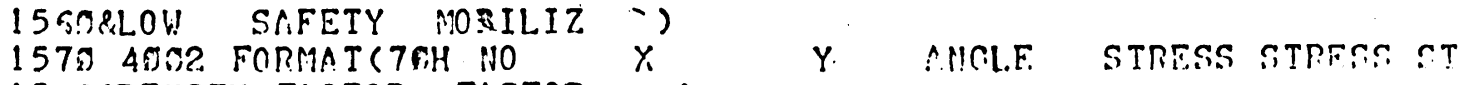

15SPRPE!GTH FACTOR FACTOR )

$159 \pi$ NOPT $=1$ 


\section{SR RZ CONTINUEA}

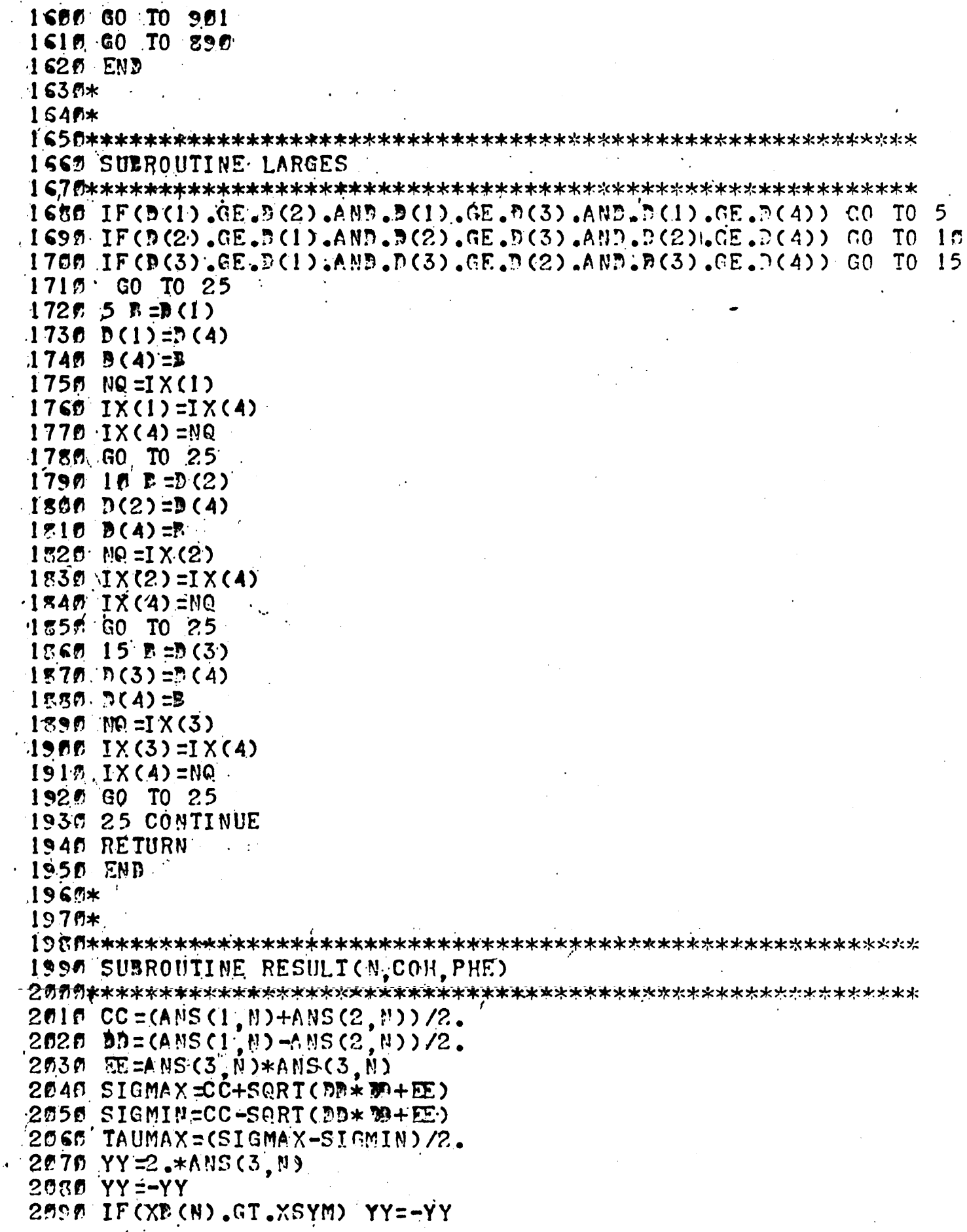


SR GZZ CONIIRUEO

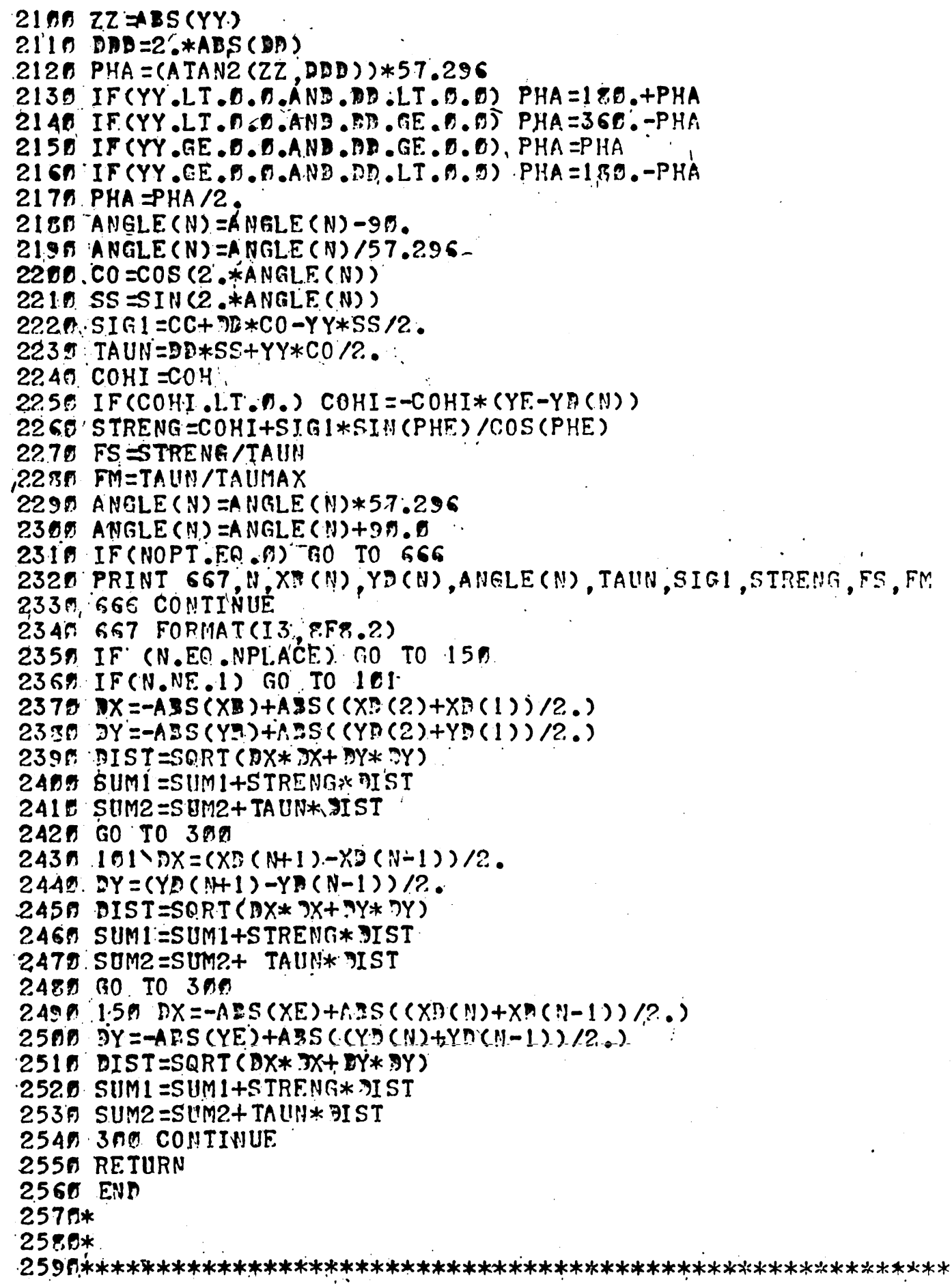




\section{SR EZZ CONTINIJER}

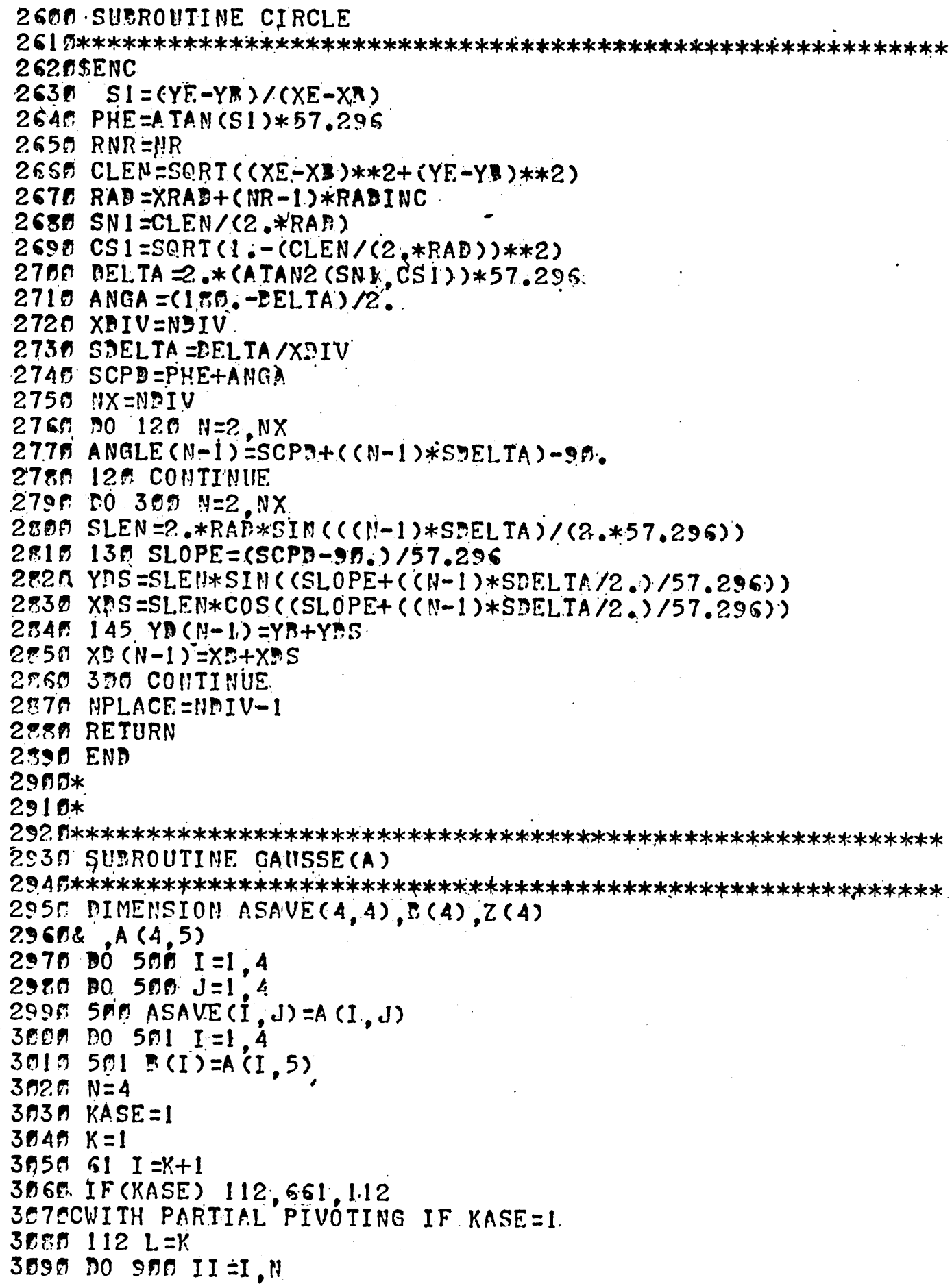


SR RZZ CONTIUIIED

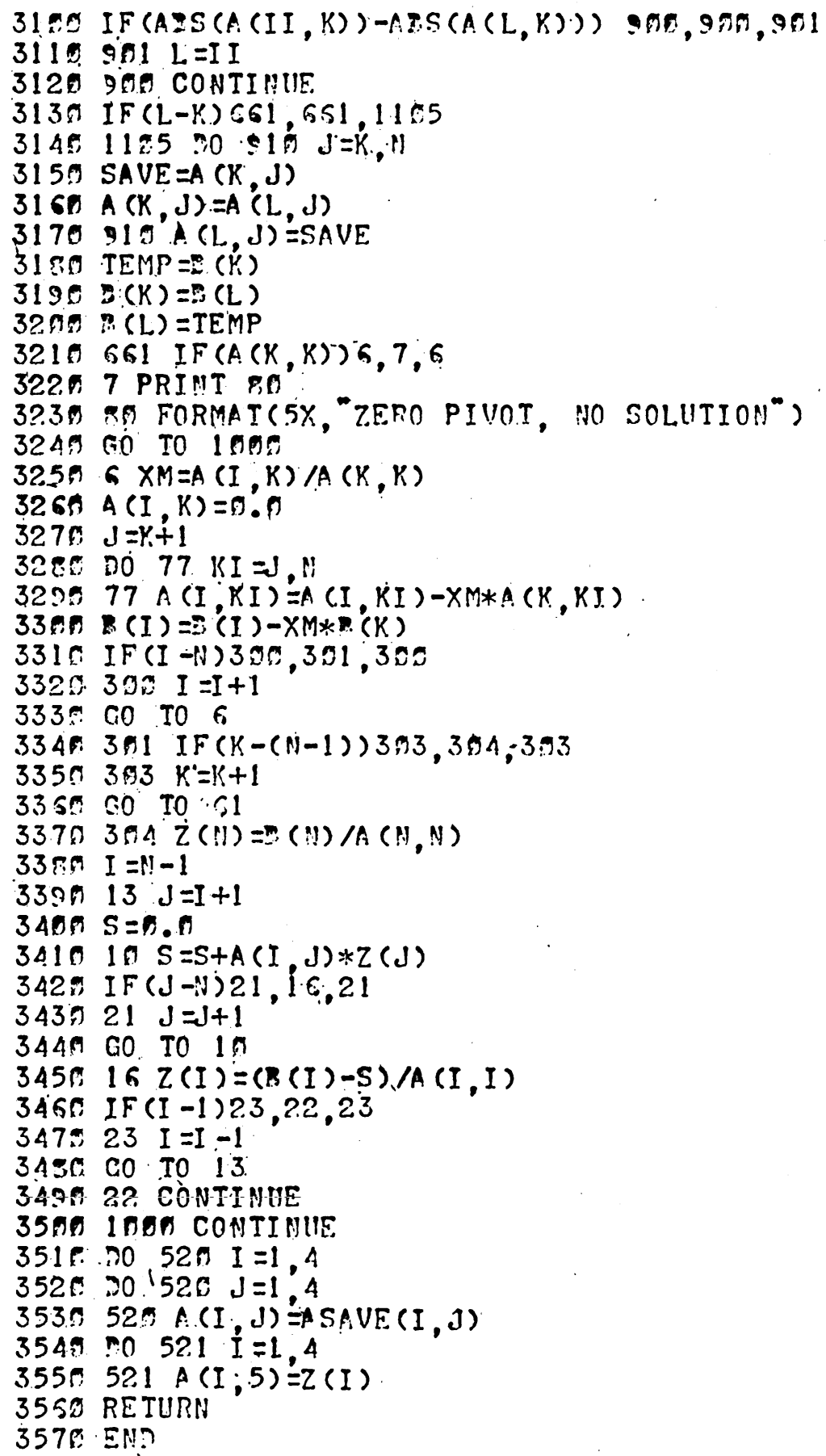


Unclassified

Security Classification

DOCUMENT CONTROL DATA - R \& D .

(Security classification of titlo, body of abatract and indexing annotation must be ontered when the overall report is clasellled) \begin{tabular}{l|l} 
1. ORIGINATING ACTIVITY (Corporale author) & 2E. REPORT SECURITY CLASSIFICATION
\end{tabular}

U. S. Army Engineer Waterways Experiment Station

Vicksburg, Miss. Unclassified

2b. GROUP

3. REPORT TITLE

APPLICATION OF FINITE ELEMENT METHOD IN DETERMINING STABILITY OF CRATER SLOPES

4. DESCRIPTIVE NOTES (TYPe of seport and inclueive datea)

Final report

5. AUTHOR(S) (First name, middlo inillal, last name)

John B. Palmerton

Don C. Banks

\begin{tabular}{|c|c|c|}
\hline $\begin{array}{l}\text { 6. REPORT OATE } \\
\text { January } 1972\end{array}$ & $\begin{array}{l}\text { 70. TOTAL NO. OFPAGES } \\
128\end{array}$ & $\begin{array}{r}\text { 7b. NO. OF REFS } \\
34\end{array}$ \\
\hline $\begin{array}{l}\text { OA. CONTRACT OR GRANT NO. } \\
\text { B. PROJECT NO. }\end{array}$ & $\begin{array}{l}\text { 92. ORIGINATOR'S REPORT NUMB } \\
\text { Miscellaneous Paper }\end{array}$ & $\begin{array}{l}\text { ER(S) } \\
S-72-2\end{array}$ \\
\hline $\begin{array}{l}\text { c. } \\
\text { d. }\end{array}$ & $\begin{array}{l}\text { Ob. OTHER REPORT NO(S) (ANY Oth } \\
\text { thie report) }\end{array}$ & her numbers that may bo aeclened \\
\hline
\end{tabular}

Approved for public release; distribution unlimited.

11. SUPPLEMENTARY NOTES

12. SPONSORING MILITARY ACTIVITY

U. S. Army Engineer Nuclear Cratering Group Livermore, Calif.

\section{ABSTRACT}

The investigations reported herein comprise studies to evaluate applicability of the finite element method to stability analysis of explosively excavated slopes. A finite element program based on nonlinear material properties was developed during this study. The program incorporates a capability to simulate incremental construction of slopes of arbitrary geometry either by excavation or by building up. The stress-strain relationships of materials forming the slope and its foundations are approximated by hyperbolic curves. The hyperbolic curves are asymptotic to the yield strength of the materials as defined by Mohr-Coulomb strength parameters, c (cohesion) and $\varnothing$ (friction angle). Initial states of stress may be incorporated into the analyses. Several examples of simple slopes under various initial states of stress were analyzed. Additional examples were a symmetrical, homogeneous embankment on a rigid foundation and hypothetical row crater excavation slope. Stresses and displacements for the different examples are presented along with a method for determining the factor of safety of $a^{-}$ slope from nonlinear stress analysis. 
Unclassified

Security Classification

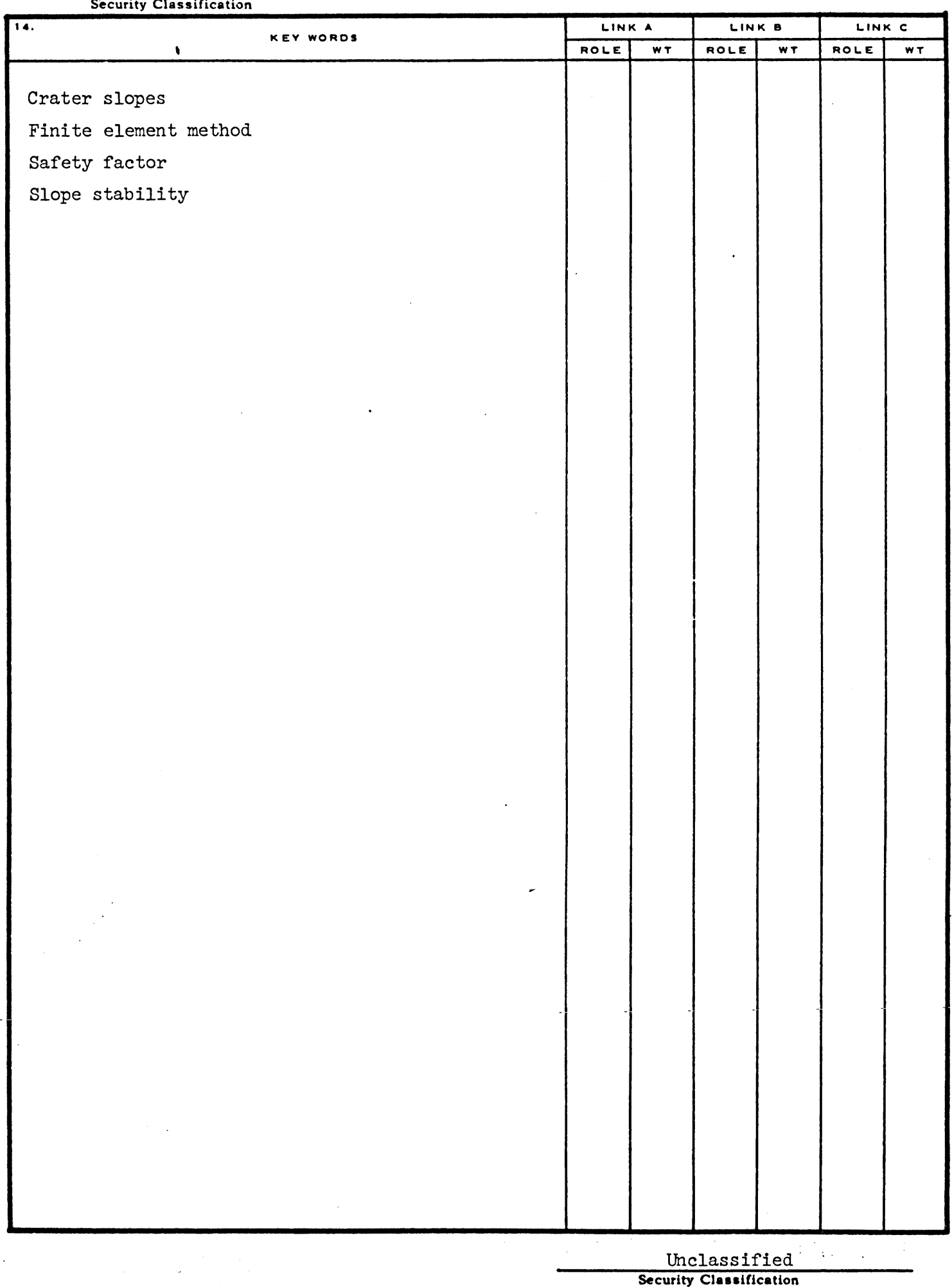

Security Classification 